Aus der Abteilung Kardiologie und Pneumologie

Prof. Dr. med. G. Hasenfuß

Innere Medizin

der Medizinischen Fakultät der Universität Göttingen

\title{
Der positiv inotrope Effekt von Insulin am menschlichen Myokard
}

\author{
INAUGURAL - DISSERTATION \\ zur Erlangung des Doktorgrades \\ der Medizinischen Fakultät der \\ Georg-August-Universität zu Göttingen
}

vorgelegt von

Sebastian Martin Albert Kania geb. Bruns

aus

Bad Harzburg

Göttingen 2015 
Dekan:

I. Berichterstatter:

II. Berichterstatter/in:
Prof. Dr. rer. nat. H.K. Kroemer

Prof. Dr. med. Rolf Wachter

Prof. Dr. Wolfram Hubertus

Zimmermann

III. Berichterstatter/in: $\quad$ PD Dr. Wolfgang Krick

Tag der mündlichen Prüfung: 29.06.2016 


\section{INHALTSVERZEICHNIS}

SEITE

1. EINLEITUNG

1.1 Physiologie der Herzmuskelkontraktion $\quad 5$

\begin{tabular}{ll}
1.2 Regulation der Kontraktionskraft & 7 \\
\hline
\end{tabular}

\begin{tabular}{ll}
1.2 .1 Rolle des Kalziums & 7 \\
\hline
\end{tabular}

1.2.2 Frank-Starling-Mechanismus (FSM)

\begin{tabular}{ll}
$1.2 .3 \mathrm{Kraft}-$ Frequenz-Beziehung & 8 \\
\hline
\end{tabular}

1.3 Definition der Herzinsuffizienz 9

\begin{tabular}{ll}
1.4 Pathophysiologische Veränderungen bei Herzinsuffizienz & 10 \\
\hline
\end{tabular}

\begin{tabular}{ll}
1.4 .1 B-adrenerges System & 10 \\
\hline
\end{tabular}

\begin{tabular}{lr}
1.4 .2 Neurohumorale Aktivierung & 11 \\
\hline 1.4 .3 Wachstumshormene
\end{tabular}

\begin{tabular}{ll}
1.4 .3 Wachstumshormone & 13 \\
\hline 1.4 .4 Hermuskelhypertrophie
\end{tabular}

\begin{tabular}{ll}
1.4 .4 Herzmuskelhypertrophie & 13 \\
\hline 1.4 .5 Kaziumhomorostas
\end{tabular}

\begin{tabular}{ll}
1.4 .5 Kalziumhomöostase & 14 \\
\hline
\end{tabular}

\begin{tabular}{ll}
1.5 Insulin & 15 \\
\hline
\end{tabular}

\begin{tabular}{ll} 
1.5.1 Insulin und Glukosestoffwechsel & 15 \\
\hline
\end{tabular}

\begin{tabular}{ll}
1.5 .2 Insulin und Arterioskleorse & 16 \\
\hline 1.5 .3 Signaltansduktion von
\end{tabular}

\begin{tabular}{ll}
1.5 .3 Signaltransduktion von Insulin & 16 \\
\hline 1.5 .4 Bekannte Wirkungen von Insuln am Myokard
\end{tabular}

\begin{tabular}{ll} 
1.5.4 Bekannte Wirkungen von Insulin am Myokard & 17 \\
\hline
\end{tabular}

\begin{tabular}{ll}
1.6 Fragestellung der Arbeit & 19 \\
\hline
\end{tabular}

\begin{tabular}{lr} 
2. MATERIAL UND METHODEN & 20 \\
\hline
\end{tabular}

\begin{tabular}{lr}
2.1 Untersuchtes Gewebe & 20 \\
\hline
\end{tabular}

\begin{tabular}{ll}
2.2 Transport und Präparation & 21 \\
\hline
\end{tabular}

\begin{tabular}{ll}
2.2 .1 Transport & 21 \\
\hline
\end{tabular}

2.2.2 Präparation 22

\begin{tabular}{ll}
2.2 .3 Tyrode-Lösung 22 \\
\hline
\end{tabular}

2.2.4 Kardioplegie $\quad 22$

2.2.5 Verwendete Substanzen 23

\begin{tabular}{ll}
2.3 Versuchsaufbau & 23 \\
\hline
\end{tabular}

2.3.1 Muskelstreifenanlage $\quad 23$

\begin{tabular}{lr}
2.3 .2 RCC-Anlage & 24 \\
\hline 2.3 .3 Aequorin-Anlage
\end{tabular}

\begin{tabular}{lr}
2.3 .3 Aequorin-Anlage & 25 \\
\hline
\end{tabular}

2.4 Versuchsablauf der Muskelstreifenanlage $\quad 26$

\begin{tabular}{ll}
2.4 .1 Insulin-Einzeldosisexperimente & 27 \\
\hline 2.4 .2 Insulin-Dosis/Wirkungurven
\end{tabular}

\begin{tabular}{ll}
2.4 .2 Insulin-Dosis/Wirkungskurven & 27 \\
\hline
\end{tabular}

2.4.3 Insulinexperimente mit Glukose oder Pyruvat als Energiesubstrat $\quad 27$

\begin{tabular}{ll}
2.4 .4 Insulinexperimente nach Blockade der Glykolyse & 27 \\
\hline
\end{tabular}

2.4 .5 Insulinexperimente in $5 \mathrm{mmol} / 1$ Glukose-Tyrode 28

\begin{tabular}{ll}
2.4 .6 Signaltransduktionsblockade & 28 \\
\hline
\end{tabular}

2.5 Versuchsablauf der RCC-Anlage 28

\begin{tabular}{ll}
2.5 .1 Insulinexperimente nach Blockade des SR & 29 \\
\hline
\end{tabular}

\begin{tabular}{ll}
2.6 Versuchsablauf der Aequorin-Anlage & 30 \\
\hline
\end{tabular}

\begin{tabular}{ll}
2.6 .1 Aequorin & 30 \\
\hline
\end{tabular}

\begin{tabular}{ll}
2.7 Auswertung der Versuche & 31 \\
\hline
\end{tabular} 
2.8 Normierung der Daten 32

2.9 Statistische Auswertung

\begin{tabular}{lr}
3.1 Ergebnisse am humanen Myokard & 33 \\
\hline
\end{tabular}

3.1.1 Wirkung von Insulin auf die isometrische Kraftentwicklung $\quad 33$

\begin{tabular}{ll}
3.1 .2 Konzentrationsabhängiger Effekt von Insulin & 34 \\
\hline
\end{tabular}

\begin{tabular}{ll}
3.1 .3 Insulin-Dosis/Wirkungskurve & 35 \\
\hline $3.1 .4 W i k u n g$
\end{tabular}

3.1.4 Wirkung von Insulin in Abhängigkeit von verschiedenen Energiesubstraten 36

\begin{tabular}{lr}
3.1 .5 Kraftentwicklung in $5 \mathrm{mmol} / \mathrm{l}$ Glukose-Tyrode & 38 \\
\hline $3.1 .6 \mathrm{Kraftentwicklung}$
\end{tabular}

\begin{tabular}{ll}
3.1 .6 Kraftentwicklung nach Hemmung der Glykolyse & 39 \\
\hline
\end{tabular}

3.1.7 Einfluss von Insulin auf die SR-Kalziumbeladung 40

3.1.8 Einfluss von Insulin auf die Kraftentwicklung unabhängig vom $\begin{array}{ll}\text { SR-Kalziumgehalt } & 42\end{array}$

3.1.9 Wirkung von Insulin auf intrazelluläre Kalziumtransienten $\quad 43$

3.1.10 Untersuchung potentieller Signaltransduktionswege $\quad 45$

\begin{tabular}{ll}
3.2 Ergebnisse am Kaninchenmyokard & 47 \\
\hline
\end{tabular}

\begin{tabular}{lr}
3.2 .1 Insulin-Einzeldosisexperimente & 47 \\
\hline 3.2 .2 Insulin-Dosis/Winungur
\end{tabular}

\begin{tabular}{ll}
3.2 .2 Insulin-Dosis/Wirkungskurve & 49 \\
\hline 3.2 .3 Einfluss
\end{tabular}

\begin{tabular}{ll}
3.2 .3 Einfluss von Insulin auf die SR-Kalziumbeladung & 50 \\
\hline
\end{tabular}

\begin{tabular}{lr} 
4. DISKUSSION & 52 \\
\hline
\end{tabular}

4.1 Direkte funktionelle Effekte von Insulin am humanen Myokard $\quad 53$

4.2 Signaltransduktionswege von Insulin im humanen Myokard 54

4.3 Der Einfluss von Insulin auf die intrazelluläre Kalziumhomöostase $\quad 55$

4.3.1 Der Einfluss von Rapid Cooling Contractures auf den SR-Kalziumgehalt des Myokards

\begin{tabular}{lr} 
4.3.2 Aequorin & 58 \\
\hline
\end{tabular}

\begin{tabular}{lr}
4.4 Pyruvat & 60 \\
\hline
\end{tabular}

\begin{tabular}{lr}
\hline 4.5 Limitationen der Arbeit & 62 \\
\hline
\end{tabular}

5.ZUSAMMENFASSUNG

6. LITERATURVERZEICHNIS $\quad 64$ 


\section{EINLEITUNG}

\subsection{Physiologie der Herzmuskelkontraktion}

$\mathrm{Zu}$ jeder Kontraktion der Herzmuskelzelle wird ein elektrisches Signal, das von den Schrittmacherzentren des Herzens über Leitungsbahnen und Nervenfasern die Zelle erreicht, in eine mechanische Bewegung umgesetzt. Dieser Vorgang wird daher als elektromechanische Kopplung bezeichnet.

Das die Zellmembran erreichende Aktionspotential (AP) wird in einem ersten Schritt durch die Aktivierung von $\mathrm{Na}^{+}$-Kanälen aufrechterhalten und über die Zelloberfläche weitergeleitet. Aufgrund der räumlichen Lagebeziehungen in der Zelle ist keine schnelle Kopplung des kontraktilen Systems über die Diffusion von $\mathrm{Ca}^{2+}$-Ionen von der äußeren Membran zum Sarkomer $\mathrm{zu}$ erreichen. Bei allen größeren Muskelfasern lassen sich daher Membraneinstülpungen (T-Tubuli) nachweisen, die vom Sarkolemm rechtwinklig im Bereich der Z-Membranen (Huxley und Hanson 1954) weit in das Zellinnere reichen und damit eine enge räumliche und zeitliche Kopplung zwischen Extrazellulärraum und Sarkoplasmatischem Retikulum (SR), dem Kalziumspeicher der Zelle, ermöglichen (Wibo und Godfraind 1991). In den T-Tubuli werden spannungsabhängige (long lasting) L-Typ $\mathrm{Ca}^{2+}$-Kanäle aktiviert, die einen ins Zellinnere gerichteten $\mathrm{Ca}^{2+}$-Strom erzeugen (Nilius et al. 1985, Bean 1989).

Die Freisetzung von $\mathrm{Ca}^{2+}{ }_{-}$-Ionen aus dem SR erfolgt über die Ryanodinrezeptoren (RyR). Anders als im Skelettmuskel, wo die RyR-Aktivierung direkt durch den L-Typ-Ca ${ }^{2+}$-Kanal getriggert wird, erfolgt dies in der Herzmuskelzelle durch die Bindung des von extrazellulär einströmenden Kalziums an den RyR. Hierdurch aktiviert, erfolgt eine Kalziumfreisetzung aus dem SR in Form eines $\mathrm{Ca}^{2+}$-Sparks. Erreichen diese $\mathrm{Ca}^{2+}$-Sparks in Bezug auf Quantität und zeitliche Dynamik einen Schwellenwert (Callewaert 1992), dann breitet sich die Öffnung der Ryanodinrezeptoren über das gesamte $\mathrm{SR}$ aus und bewirkt eine massive Kalziumausschüttung in das Zytosol (Fabiato 1983). Erst durch diesen Mechanismus wird ausreichend Kalzium freigesetzt, um eine Kontraktion auszulösen (Niggli und Lederer 1990). Dies wird als Kalzium-induzierte Kalzium-Freisetzung (CICR) bezeichnet und ist spezifisch für die Herzmuskelzelle (Näbauer et al. 1989). Erst die Erhöhung der zytosolischen Kalziumkonzentration ermöglicht den dritten Schritt der elektromechanischen Kopplung.

Für die Muskelverkürzung ist eine große Anzahl in Reihe geschalteter Sarkomere im Muskel notwendig. Ein Sarkomer besteht aus den dünnen Aktin- und dickeren Myosinfilamenten, 
wobei die Myosinfilamente zentral im Sarkomer liegen und im Verhältnis 2:1 von den Aktinfilamenten umgeben sind. Beide Filamente sind durch so genannte Querbrücken, die Myosinköpfchen, welche über den Myosinhals am Myosinfilament fixiert sind, verbunden (Huxley 1974, Rayment et al. 1993). Die Aktinfilamente sind wiederum im rechten Winkel an den abschließenden Z-Scheiben befestigt. Dies ergibt unter dem Mikroskop das typische Bild der Querstreifung.

Die Verkürzung der Sarkomere erfolgt durch das Gleiten beider Filamente übereinander, ohne dass sie sich selbst verkürzen. Dies wird als Gleitmodell der Muskelkontraktion (sliding filaments) bezeichnet und erstmals von Huxley und Hanson 1954 formuliert.

Im Ruhezustand blockiert Tropomyosin die Myosin-Bindungsstelle am Aktinfilament. Troponin C, das durch die steigende zytosolische Kalziumkonzentration aktiviert wird, verursacht im Komplex mit Tropomyosin eine Konformationsänderung des Proteins, so dass die Myosinbindungsstellen am Aktinfilament freigegeben werden.

Die Myosinköpfchen sind mit Bindungsstellen für Aktin und ATP sowie eine MyosinATPase ausgestattet.

Die Hydrolyse von ATP zu ADP+ $\mathrm{P}_{\mathrm{i}}$ bewirkt eine Rückstellung des Myosinkopfes in seine rechtwinklige Ausgangslage (Eisenberg und Greene 1980, Brenner und Eisenberg 1987) und bildet die Grundlage für eine Bindung mit dem Aktinfilament.

Die durch die feste Bindung an Aktin und Freisetzung des hydrolytisch entstandenen $\mathrm{P}_{\mathrm{i}}$ verursachte Bewegung des Myosinkopfes um $45^{\circ}$ wird auf das Aktin übertragen und führt zu einer Verschiebung des Aktins gegenüber dem Myosin und $\mathrm{zu}$ einer Verkürzung des Sarkomers.

Im letzten Schritt des Zyklus wird ADP vom Myosinkopf freigesetzt. Das Myosinköpfchen wird durch erneute Bindung eines Moleküles ATP vom Aktin gelöst.

Um die Relaxation der Muskelzelle einzuleiten, muss die zytosolische Kalziumkonzentration wieder auf diastolische Werte gesenkt werden. Dies erfolgt zu einem Großteil über die SR$\mathrm{Ca}^{2+}$-ATPase (SERCA), die das ins Zytosol freigesetze Kalzium zurück in das Sarkoplasmatische Retikulum pumpt (Bers 2000). Ein weiters Drittel wird über den $\mathrm{Na}^{+} / \mathrm{Ca}^{2+}$ Austauscher (NCX), der sich in den T-Tubuli befindet, aus der Zelle eliminiert. Dabei wird ein $\mathrm{Ca}^{2+}$-Ion im Austausch gegen drei $\mathrm{Na}^{+}$-Ionen nach extrazellulär verschoben (Bridge et al. 1990), was als forward mode bezeichnet wird (Shigekawa und Iwamoto 2001). Das restliche Kalzium wird über die sarkolemmale Kalziumpumpe sowie die Mitochondrien aus dem Zytosol entfernt. Die relativen Anteile der intrazellulären Kalziumelimination betragen von 
SERCA zu NCX zu sarkolemmaler $\mathrm{Ca}^{2+}$-ATPase zu mitochondrialer Kalziumaufnahme 71:27:1:1 (Bers 2000).

\subsection{Regulation der Kontraktionskraft}

\subsubsection{Rolle des Kalziums}

Den zentralen Schritt der Kraftgeneration stellt die Bindung des Kalziums an Troponin C dar, was die Interaktion von Aktin mit Myosin ermöglicht. Dies stellt den zentralen Punkt des Exzitations-Kontraktions-Mechanismus dar.

Betrachtet man die Möglichkeiten zur Beeinflussung der Kraftgeneration durch Kalzium, so lässt sich eine Einteilung in drei Gruppen vornehmen.

Gruppe eins umfasst Veränderungen der Amplitude der nach intrazellulär gerichteteten Kalziumtransienten und deren zeitliche Kinetik und repräsentiert den upstream, da dieser Mechanismus der Bindung an Troponin C vorgelagert ist. Die Erhöhung der nach intrazellulär gerichteten Kalziumtransienten kann zum einen über den transsarkolemmalen Einstrom durch den spannungsabhängigen L-Typ-Ca ${ }^{2+}-$ Kanal erfolgen. Zum anderen können veränderte extra- und intrazelluläre $\mathrm{Na}^{+}-$und $\mathrm{Ca}^{2+}$-Konzentration einen geringen, nach intrazellulär gerichteten $\mathrm{Ca}^{2+}$-Transport über den NXC im so genannten reverse mode auslösen und so die zytosolische Kalziumkonzentration erhöhen (Kohomoto et al. 1994, Weber et al. 2003, Dipla et al. 1999). Der Kalziumeinstrom löst eine Kalziumfreisetzung aus dem sarkoplasmatischen Retikulum (Carafoli 1985, Bers et al. 1993, Bers 2000) über den RyR (Ryanodinrezeptor) aus. Dieser wird durch eine Vielzahl von Regulatorproteinen gesteuert. So ist bekannt, dass FKBP12.6 durch Bindung an den RyR den Kanal stabilisiert und funktionell mit umgebenden RyR verlinkt, so dass ein geringerer diastolischer $\mathrm{Ca}^{2+}$-Leak und eine koordiniertere Öffnung mehrerer Kanäle (coupled gating) während des Aktionspotentiales resultieren und damit eine verbesserte Kalziumfreisetzung aus dem SR ermöglicht wird (Brillantes et al. 1994, Marx et al. 2001, Prestle et al. 2001). Es sind multiple weitere Interaktionen von Regulatorproteinen bekannt (Maier und Bers 2002, Seidler et al. 2003). Die genaue Anzahl, deren Funktion und Interaktion untereinander ist aber bis heute Gegenstand der Forschung.

Des Weiteren regulieren intrazelluläre Puffer die Kalziumkonzentration im Zytosol. Hierbei kommt neben den Mitochondrien dem Troponin $\mathrm{C}$ das größte Gewicht zu. Wie oben beschrieben, führt eine Bindung des Kalziums an Troponin C zu einer Kontraktion, welche erst nach Elimination des Kalziums aus dem Zytosol beendet wird. Hochselektive mitochondriale $\mathrm{Ca}^{2+}$-Kanäle können direkt entlang des Konzentrationsgefälles, ohne ATP- 
Hydrolyse, das Kalzium aus dem Zytosol in die Mitochondrien überführen (Kirichok et al. 2004).

Gruppe zwei umfasst Änderungen der Bindungsaffinität des Kalziums zum Troponin C und wird als central beschrieben. Sie beruht auf dem Grad der Troponin I - Phophorylierung oder der direkten Änderung des Querbrücken-Kraft-Zeit Integrals (Peña und Wolska 2004). Gesteuert wird die Troponin I-Phophorylierung über die Aktivierung der sarkolemmalen Adenylatzyklase und eine Erhöhung der cAMP- Konzentration in den Myozyten, was letztlich zu einer Verminderung der inhibitorischen Wirkung des Troponin I auf den Troponinkomplex führt (Winegrad 1984, Kentish et al. 2001).

Die letzte Gruppe, auch als downstream bezeichnet, beschreibt Interaktionen der Myofilamente auf Basis vorgegebener Troponin-Kalziumbindungen (Blinks und Endoh 1986, Endoh 1998) und deren Effekt.

\subsubsection{Frank-Starling-Mechanismus (FSM)}

1895 konnte durch Frank und im Jahr 1914 auch durch Patterson und Starling gezeigt werden, dass eine Myokarddehnung während der Diastole die systolische Kontraktilität erhöht. Den eigentlichen Nachweis des Zusammenhangs zwischen Muskeldehnung und myokardialer Kontraktilität konnte erst 1966 durch Gordon, Huxley und Julian erbracht werden (Gordon et al. 1966 a, Gordon et al. 1966 b). Diese Untersuchung ergab, dass für die Erhöhung der systolischen Kraft eine bessere Überlappung der Myofilamente verantwortlich ist. Gleichzeitig steigert Vordehnung die $\mathrm{Ca}^{2+}$-Empfindlichkeit der Myofilamente. Daraus ergibt sich bei identischer Kalziumkonzentration, dass die Kraftentwicklung nach Erhöhung der Sarkomerlänge größer ist (Allen und Kentish 1985).

\subsubsection{Kraft-Frequenzbeziehung}

Die Steigerung der Kontraktionskraft des Herzens durch höhere Frequenzen konnte erstmals 1871 von Bowditch experimentell am Froschherzen beschrieben werden und ist bisher durch eine Vielzahl an Untersuchungen sowohl an verschiedenen Tierspezies als auch am Menschen bestätigt worden (Buckley et al. 1972, Koch-Weser 1963, Mulieri et al. 1992, Pieske et al. 1995).

Die Kontraktionskraftzunahme beruht auf einem zweiphasigen Verlauf, bei dem jede Phase durch eine Zunahme der intrazellulären Kalziumtransienten charakterisiert ist (Allen und Blinks 1978, Lee 1987, Pieske et al. 1995).

Die Gründe und die Kinetik der Kontraktionskraftzunahme unterscheiden sich bei beiden Phasen. 
In der ersten Phase, die aus wenigen Kontraktionen besteht, erfolgt eine stärkere Beladung des SR mit $\mathrm{Ca}^{2+}$-Ionen. Diese kann erfolgen, da bei steigender Frequenz sowohl die Offenwahrscheinlichkeit als auch die Öffnungsdauer der sarkolemmalen $\mathrm{Ca}^{2+}$-Kanäle und damit der Kalziumeinstrom zunehmen (Piot et al. 1996). Zudem zeigt sich ein erhöhter $\mathrm{Ca}^{2+}-$ Ionen-Einstrom über den L-Typ- $\mathrm{Ca}^{2+}$-Kanal.

Der Mechanismus der zweiten Phase beruht auf einer anderen Grundlage, die langsamer ist und im Minutenbereich wirkt. Die Basis hierfür ist ein Anstieg des intrazellulären Natriums in der Folge der vermehrten $\mathrm{Ca}^{2+}$-Extrusion über den NCX mit konsekutiver Verschiebung von Natrium nach intrazellulär. Hierdurch wird die Aktivität des NCX in die Richtung des reverse mode verschoben, so dass auch über diesen Kanal zusätzlich Kalzium für die Kontraktion zur Verfügung steht (Despa et al. 2002).

Am Kaninchenmyokard scheint die Kraftzunahme bei langsamen Stimulationsfrequenzen $(<0,5 \mathrm{~Hz})$ mehr über die Dauer und weniger über die Höhe des Kalziumtransienten zu wirken, während bei einer mittleren Stimulationsfrequenz $(0.5-2.0 \mathrm{~Hz})$ die Amplitude des Transienten mit der Kraftzunahme korreliert und bei hohen Frequenzen $(>2,5 \mathrm{~Hz})$ wiederum nicht mehr nachweisbar ist (Endoh 2004).

Untersuchungen an insuffizienten Herzen zeigten sowohl unter experimentellen Bedingungen (Davies et al. 1995, Feldmann et al. 1988 b, Mulieri et al. 1992, Pieske et al. 1992, Schwinger et al. 1993) als auch unter In-vivo-Bedingungen (Feldmann et al. 1988 a, Hasenfuss et al. 1994 a), dass die Kraft-Frequenz-Beziehung aufgehoben oder sogar umgekehrt ist.

Ursächlich hierfür könnten einerseits die Abnahme der intrazellulären Kalziumtransienten (Pieske et al. 1995), anderseits die reduzierte SR-Kalzium-Aufnahmekapazität (Hasenfuss et al. 1994 b) sein, als auch die reduzierte bzw. aufgehobene Möglichkeit die Offenwahrscheinlichkeit des $\mathrm{Ca}^{2+}$-Kanals (Piot et al. 1996) zu erhöhen.

\subsection{Definition der Herzinsuffizienz}

Die klinische Diagnose Herzinsuffizienz beschreibt einen Symptomkomplex, der durch das Unvermögen des Herzens gekennzeichnet ist, bei ausreichend venösem Angebot ein adäquates Herzminutenvolumen in Ruhe (Ruheinsuffizienz) und bei Belastung (Belastungsinsuffizienz) aufrechtzuerhalten. Ursächlich für eine Herzinsuffizienz kann der segmentale Verlust von Myozyten durch Myokardinfarkte (ischämische Kardiomyopathie, ICM), anhaltende Druck- und Volumenbelastung bei Hypertonie und Klappenvitien, Füllungsbehinderung des Ventrikels infolge von Rhythmusstörungen oder Relaxationsstörungen (diastolische Dysfunktion) sein. Außerdem können diffuse 
Zellschädigungen infolge von metabolischen und toxischen Einflüssen (z.B. dilatative Kardiomyopathie, DCM) zu einer manifesten Herzinsuffizienz führen. Als Ursache der DCM werden neben familiärer Disposition, Autoimmunerkrankungen (Maisch et al. 1983, Anderson et al. 1984, Schulze et al. 1989, Limas et al. 1990), alkoholtoxische Einflüsse (Munziger 1887, Diamond 1989, Urbano-Marquez et al. 1989, Regan 1990), virale Infektionen (Cambridge et al. 1979, Bowles et al. 1989) und Nebenwirkungen von Medikamenten (Henderson und Frei 1980) diskutiert.

Klinisches Korrelat der Herzinsuffizienz sind ein reduziertes Herzminutenvolumen, eine verringerte Ejektionsfraktion und ein kompensatorisch erhöhter peripherer Gefäßwiderstand. Dementsprechend vielfältig äußern sich die Symptome der Herzinsuffizienz, die sich in allen Teilen des Herz-Kreislaufsystems und dessen übergeordneten humoralen Regelsystem manifestieren können.

\subsection{Pathophysiologische Veränderungen bei Herzinsuffizienz}

Das klinische Syndrom der Herzinsuffizienz wird als eine chronisch progressive Erkrankung betrachtet. Nach einer initialen Schädigung des Myokards kommt es zu einem Kontraktilitätsverlust und einer Abnahme des Herzzeitvolumens. Zur Sicherung einer ausreichenden Herzkreislauffunktion verfügt der Organismus über eine Vielzahl von Kompensationsmechanismen, auf die im Folgenden kurz eingegangen werden soll.

Das Zusammenwirken dieser Kompensationsmechanismen dient der Aufrechterhaltung einer ausreichenden Organperfusion sowie eines entsprechenden Herzzeitvolumens.

Hält dieser Zustand der aktivierten Systeme über längere Zeit an, ohne dass die initial schädigende Ursache beseitigt wird, entwickelt sich der ursprünglich schützende Mechanismus zu einem Circulus vitiosus. Die Herzinsuffizienz dekompensiert.

\subsubsection{B-adrenerges System}

Bekannt ist, dass bei Patienten mit einer chronischen Herzinsuffizienz eine erhöhte Sympathikusaktivität nachzuweisen ist (Cohn et al. 1984). Katecholamine wirken dabei positiv auf die Kraftentwicklung (inotrop), die Schlagfrequenz (chronotrop) und die Relaxationszeit (lusitrop) (Lohse et al. 2003). Auch das Phänomen der Frequenzinotropie (siehe 1.2.3.) wird $B$-adrenerg vermittelt.

Herzinsuffiziente Patienten zeigen eine gesteigerte Ausscheidung von Katecholaminmetaboliten im Urin, welche auf eine zwei- bis dreifache Erhöhung der Noradrenalinspiegel im Vergleich zur Norm zurückzuführen ist (Thomas und Marks 1978). 
Die Höhe der Plasmakonzentrationen zeigt dabei eine Korrelation zum Schweregrad und der Prognose der Erkrankung (Francis et al. 1990).

Begründet ist die Erhöhung der Plasmaspiegel einerseits durch eine gesteigerte neuronale Freisetzung mit verminderter Wiederaufnahme von Noradrenalin an peripheren Nervenendigungen (Esler et al. 1997). Zusätzlich weisen Untersuchungen darauf hin, dass das Herz selbst wesentlich zur Katecholaminfreisetzung beiträgt. So findet man im Koronarsinusblut bei insuffizienten Herzen höhere Katecholaminkonzentrationen als im peripher arteriellen Blut (Rose et al. 1985). Einhergehend damit zeigen terminal insuffiziente Myokardproben einen geringeren Katecholamingehalt als Myokardproben aus gesunden Herzen (Chidsey et al. 1966, Daly und Sole 1990).

Durch eine andauernde katecholaminerge Stimulation erfolgt eine Desensibilisierung der myokardialen $\beta$-Adrenozeptoren sowie eine Abnahme der $\beta$-Rezeptorendichte (Bristow et al. 1982, Böhm et al. 1988, Brodde 1991), wie es vor allem am insuffizienten Myokard nachweisbar ist.

Analog konnten Untersuchungen an insuffizienten Herzen zeigen, dass die Frequenzinotropie aufgehoben oder sogar umgekehrt ist (siehe 1.2.3).

Ursächlich hierfür ist unter anderem die gestörte Kalziumhomöostase (siehe 1.4.5)

\subsubsection{Neurohumorale Aktivierung}

Ein weiterer Kompensationsmechanismus bei Herzinsuffizienz besteht in der Beeinflussung des Renin-Angiotensin-Aldosteron-Systems (RAAS).

Bei dem RAAS handelt es sich um ein Hormonsystem, das abhängig von der Lokalisation der entsprechenden Angiotensin-Rezeptoren (AT) eine Vielzahl von Effekten auf den Organismus hat. Man unterscheidet in dieser Rezeptorklasse die $\mathrm{AT}_{1^{-}}$(Murphy et al. 1991) und $\mathrm{AT}_{2}$-Rezeptoren (Mukoyama et al. 1993), wobei bei Nagern noch zwischen $\mathrm{AT}_{1 \mathrm{a}-}$ und $\mathrm{AT}_{1 \mathrm{~b}}$-Rezeptoren unterschieden wird (Elton et al. 1992). Der $\mathrm{AT}_{2}$-Rezeptor führt zu einer Aktivierung von Tyrosin- und Serin/Threonin-Proteinphosphatasen (Ichiki et al. 1995), die beiden G-Protein-gekoppelten $\mathrm{AT}_{1}$-Rezeptoren hingegen bewirken über eine intrazelluläre Kalziumfreisetzung sowie eine Aktivierung der Phospholipase C (Marrero et al. 1994) eine Vasokonstriktion (Kanaide et al. 2003) und Zellhypertrophie (Sadoshima und Izumo 1993).

Durch einen Blutdruckabfall an der Niere (wie z.B. bei Herzinsuffizienz) und vermehrter Badrenerger Stimulation wird am juxtaglomerulären Apparat vermehrt Renin ausgeschüttet. Dieses wandelt das in der Leber gebildete Angiotensinogen zu Angiotensin I um, das wiederum durch das angiotensin converting enzym (ACE) zu Angiotensin II (AT II) 
umgebaut wird. AT II bewirkt eine Aldosteron-Ausschüttung aus der Nebennierenrinde und eine zusätzliche Vasokonstriktion über $\mathrm{AT}_{1}$-Rezeptoren.

Aldosteron führt zu vermehrter $\mathrm{Na}^{+}$-Retention und $\mathrm{K}^{+}$-Ausscheidung. Die Natriumretention bewirkt eine Volumenzunahme im Organismus mit dem Ziel der Blutdruckerhöhung, welche ihr pathologisches Korrelat in der Entstehung von Ödemen findet.

Ein weiterer Punkt der neurohumoralen Aktivierung ist die Erhöhung der Plasma-EndothelinSpiegel $\left(\mathrm{ET}_{1}\right)$ um den Faktor zwei bis drei bei herzinsuffizienten Patienten (McMurray et al. 1992, Cody et al. 1992). Diese korrelieren mit der Angiotensin II-Konzentration, der Höhe des pulmonalarteriellen Drucks, der NYHA-Klasse sowie der linksventrikulären Ejektionsfraktion. Demzufolge haben Patienten mit erhöhten EndothelinPlasmakonzentrationen eine schlechtere Prognose gegenüber anderen Patienten (Pousset et al. 1997, Hulsmann et al. 1998).

Ursächlich für die Veränderung des Endothelins-Spiegels kommen eine Aktivierung des RAAS, Hypoxie, Ischämie und die Freisetzung von Zytokinen in Frage (Hu et al. 1998, Hieda und Gomez-Sanchez 1990, Tonnessen et al. 1993). Die Endothelin-Effekte werden über entsprechende Rezeptoren der Subklassen A, B und C vermittelt und führen bei bestehender eingeschränkter Pumpfunktion des Herzens zu einer peripheren (Cowburn et al. 1999) und renalen Vasokonstriktion mit Natriumretention (Rabelink et al. 1994).

Die natürlichen Gegenspieler des RAAS und der adrenergen Stimulation bei chronischer Herzinsuffizienz sind das atriale natriuretische Peptid (ANP) und das brain natriuretic peptide (BNP). Die Hauptwirkung besteht in einer Vasodilatation sowie einer erhöhten Natriurese und Diurese (Wilkins et al. 1997). Weitere Effekte sind eine verminderte NatriumReabsorbtion, eine Verminderung der renalen Renin- und Angiotensin II-Freisetzung sowie eine Hemmung des Antidiuretischen Hormons (Jensen et al. 1998).

Die Bildung des ANP erfolgt überwiegend in den kardialen Vorhöfen und ist abhängig von dem intraatrialen Volumen. Die Signalübermittlung erfolgt bei den meisten ANP-Wirkungen über den ANP-Rezeptor mittels Aktivierung der Guanylat-Zyklase und Bildung von zyklischem GMP. Die Bedeutung des ANP für die Wasser- und Natriumregulation bei Herzinsuffizienz ist trotz der pathophysiologischen Zusammenhänge nicht eindeutig geklärt (De Nicola et al. 1997).

Verglichen mit der Rolle des ANP kommt dem BNP in der Diagnostik ein viel höherer Stellenwert zu (de Lemos et al. 2003). Das als erstes im Schweinegehirn nachgewiesene BNP wird als Antwort auf steigende Füllungsdrücke im menschlichen Ventrikel gebildet und sezerniert und führt über den BNP-Rezeptor zur Vasodilatation und Diurese mit vermehrter 
Natriumausscheidung (Mair et al. 2001). Hohe BNP-Spiegel finden sich bei eingeschränkter linksventrikulärer Funktion und sind als guter prognostischer Indikator bei Herzinsuffizienz (Tsutamoto et al. 1997) und akutem Koronarsyndrom (de Lemos et al. 2001) etabliert (Herrmann-Lingen et al. 2003).

\subsubsection{Wachstumshormone}

Das dem Insulin strukturell nahe verwandte Peptidhormon IGF-1 (insulin like growth factor 1) wird regional, unter anderem in Herzmuskelzellen (Ren et al. 1999), unter dem Einfluss des GH (growth hormone) synthetisiert. Die funktionellen Effekte von IGF-1 zeigen sich in einer positiven Inotropie des Herzens, der $\mathrm{PI}_{3}-$ Kinase-vermittelt ist und von einem parallelen Anstieg der intrazellulären Kalziumtransienten sowie einer Erhöhung der SRKalziumbeladung begleitet wird. Ein Teil der positiven Inotropie wird auch durch den L-Typ$\mathrm{Ca}^{2+}$-Kanal, den $\mathrm{NCX}$, den $\mathrm{Na}^{+} / \mathrm{H}^{+}$-Austauscher und via Proteinkinase $\mathrm{C}$ (PKC) vermittelt (von Lewinski et al. 2003).

\subsubsection{Herzmuskelhypertrophie}

Druck- und Volumenbelastungen des Herzens führen kurzfristig über den Frank-StarlingMechanismus (siehe 1.2.2) zu einer verbesserten Kontraktionskraft des Herzen. Hält diese Belastung jedoch dauerhaft an, wie z.B. bei Klappenstenosen und -insuffizienzen, Septumdefekten oder einer arteriellen Hypertonie, kommt es zu einer Hypertrophie der Herzmuskulatur. Dies dient der Aufrechterhaltung einer konstanten Wandspannung nach dem Gesetz von Laplace.

Bereits 1983 konnte Simpson zeigen, dass ein Auslöser der Hypertrophie die dauerhafte Stimulation von $\alpha_{1}$-Rezeptoren durch Norepinephrin darstellt. Aber auch eine dauerhafte Stimulation G-Protein-gekoppelter Rezeptoren (Molkentin und Dorn 2001) wie der ETRezeptor für Endothelin (Ito et al. 1991), AT -Rezeptor für Angiotensin II (Sadoshima und Izumo 1993, Yamazaki et al. 1995) und B-Rezeptoren (Engelhardt et al. 1999) münden in erhöhter Fibroblastenproliferation und gesteigerter Kollagensynthese.

Die im Rahmen der gestörten Kalzium-Homöostase (siehe 1.4.5) global erhöhte Kalziumkonzentration führt zusätzlich zur Aktivierung der $\mathrm{Ca}^{2+} /$ Calmodulin-abhängigen Proteinphosphatase 2b, genannt Calcineurin, die über die Aktivierung von NFAT die Genexpression von z.B. $\beta$-Myosin-Schwerkette, ANP und BNP vermittelt, wie sie für Zellhypertrophie und -remodelling typisch sind (Molkentin et al. 1998). Ähnlich wirkt sich die Kalzium-vermittelte Aktivierung der $\mathrm{Ca}^{2+} / \mathrm{Calmodulin-abhänigigen} \mathrm{Proteinkinase} \mathrm{II}$ 
(CaMKII) aus, die über den Transkriptionsfaktor MEF2 eine Herzmuskelhypertrophie induziert (Zhang et al. 2002, Zhang et al. 2003).

Die Herzmuskelhypetrophie stellt einen sehr wichtigen prognostischen Parameter der Herzinsuffizienz dar (Levy et al. 1990), da durch die anhaltend erhöhten Wandspannungen der diastoliche koronare Blutfluss abnimmt und das Herz so ischämisch geschädigt wird (Hittinger et al. 1995). So folgen auf Zellebene dem anfänglich adaptiven Zustand der Zellhypertrophie bei Fortbestehen der herzmuskelbelastenden Situation vermehrte Zellapoptose (Dorn 2009, Erickson et al. 2008) und -nekrose (Kung et al. 2011) und damit die Herzinsuffizienz. Als Auslöser hierfür wird eine erhöhte Kalziumkonzentration in Mitochondrien (Nakagawa et al. 2005) diskutiert.

\subsubsection{Kalziumhomöostase}

Die myokardiale kontraktile Dysfunktion ist der Endzustand einer Reihe pathophysiologischer Prozesse, in deren Mittelpunkt die gestörte Kalziumhömostase der Zelle steht.

Gwathmey konnte 1987 erstmals mit Hilfe des Biolumineszenzfarbstoffs Aequorin zeigen, dass in insuffizienten Herzmuskelstreifen erhöhte zytosolische Kalziumkonzentrationen vorliegen. Die Erhöhung des Kalziums bezieht sich dabei nicht nur auf die Dauer der Aktionspotentiale, sondern umfasst ebenfalls die gesamte Diastole (Beuckelmann et al. 1992). Wird in diesem Zustand ein Aktionspotential ausgelöst, steigt der Kalziumtransient auf ein im Vergleich zum normalen Niveau geringeres Maximum, so dass die Amplitude des Kalziumtransienten insgesamt geringer ausfällt als am gesunden Herzen. Zeitgleich zeigt sich eine verringerte Wiederaufnahme des Kalziums in das SR (Schmidt U et al. 1998), was eine reduzierte Kraftentwicklung der Zelle (Pieske et al. 1995) sowie eine verlangsamte Relaxationszeit mit erhöhter diastolischer Muskelspannung (Harding et al. 1992) nach sich zieht.

Der veränderten Kalziumhomöostase liegen Veränderungen verschiedener Pumpen und Kanäle zu Grunde, die am CICR beteiligt sind. So findet sich in der insuffizienten Herzmuskelzelle eine verringerte Expression der SERCA2a (Meyer et al. 1995), so dass die Kalzium-Wiederaufnahme in das SR deutlich verringert wird. Zudem wird Phospholamban (PLB) vermehrt exprimiert (Meyer et al. 1995), das in dephosphorylliertem Zustand die SERCA hemmt. Durch die so erhöhte PLB:SERCA-Ratio und eine chronische Hypophosphoryllierung des PLB (Linck et al. 1996, Movsesian et al. 1994) kommt dessen inhibitorischer Effekt mehr zum Tragen. 
Zeitgleich findet sich eine erhöhte Expression des NCX (Studer et al. 1994), so dass in Zusammenschau dieser Expressionsmuster ein Netto-Shift des Kalziums in den Extrazellularraum (bei weiterhin erhöhten diastolischen Kalziumkonzentrationen) und eine Depletion des SR (Pieske et al. 1999) zu beobachten ist. Zusätzlich lässt sich in insuffizienten Herzzellen ein erhöhter $\mathrm{Na}^{+}$-Einstrom feststellen (Pieske et al. 2002, Valdivia et al. 2005), der den reverse mode des $\mathrm{NCX}$ und damit einen $\mathrm{Ca}^{2+}$-Einstrom in die Zelle begünstigt (Kohomoto et al. 1994).

Doch auch wenn die Amplitude der Kalziumtransienten aus dem SR verringert ist, zeigt sich eine vermehrte Frequenz der $\mathrm{Ca}^{2+}$-Sparks (Maier et al. 2003). Dies ist durch die vergrößerte Offenwahrscheinlichkeit der RyR zu erklären (Yano et al. 2000). Durch die Wirkung der Proteinkinase A (PKA) und Dissoziation der Proteinphosphatasen 1 und 2A vom Kanal (Reiken et al. 2003) ist der RyR hyperphosphoryliert, was eine Abspaltung der stabilisierenden Moleküle Calstabin2 (Wehrens et al. 2004) und FKBP12.6 (Marx et al. 2000) nach sich zieht und damit in einem diastolischen Kalziumverlust mündet.

Die veränderte Kalziumhomöostase zeichnet sich also durch eine fortlaufend erhöhte Kalziumkonzentration des Zytosols mit Kalziumdepletion des SR aus (Lindner et al.1998), was sich zum einen in einer verringerten Kontraktionskraft, zum anderen in Hypertrophie und Apoptose/Nekrose (siehe 1.4.4) zeigt, aber auch eine gesteigertes Risiko für Arrhythmien (Wehrens et al. 2003, Lehnart et al. 2005) mit sich bringt. Interessanterweise scheint die veränderte Kalziumhomöostase unabhängig vom Auslöser eine gemeinsame Endstrecke der Herzinsuffizienz darzustellen. Sie konnte sowohl in insuffizienten Herzzellen aufgrund von Hypertension (Gomez et al. 1997) als auch in Folge einer Ischämie (Gomez et al. 2001) oder dilatativer Kardiomyopathie (Beuckelmann und Erdmann 1992) nachgewiesen werden.

\subsection{Insulin}

\subsubsection{Insulin und Glukosestoffwechsel}

Insulin wird in den B-Zellen des Pankreas gebildet und sezerniert. Die Vorstufe des Insulinmoleküls, Proinsulin, besteht aus der A-Kette (21 Aminosäuren), der B-Kette (30 Aminosäuren) und dem so genannten connective peptide, dem C-Peptid (31 Aminosäuren). Unter der Bildung von Disulfidbrücken wird das Molekül so gefaltet, dass A- und B-Kette sich parallel aneinander lagern. Im Anschluss wird durch Abspaltung des nicht notwendigen C-Peptids Insulin gebildet (Philippe 1991). 
Die Sekretion von Insulin aus den Langerhansschen Zellen des Pankreas unterliegt einem direkten Regulationsmechanismus durch den Blutzuckerspiegel. Durch hohe Blutzuckerspiegel wird Insulin aus den B-Zellen sezerniert (Goodison et al. 1992).

Eine Beeinflussung der Insulinsekretion erfolgt auch durch das autonome Nervensystem. Durch Neurotransmitter wie Epinephrin und Acetylcholin werden die intravasalen Insulinspiegel erhöht. Ein negativer Regulationsmechanismus auf die Insulin-Genexpression erfolgt direkt durch Insulin selbst (Koranyi et al. 1992).

\subsubsection{Insulin und Arteriosklerose}

Insulin scheint jedoch auch außerhalb des Glukosestoffwechsels eine Rolle zu spielen. So wird postuliert, dass es, vermittelt über mitogene Effekte durch Bindung an den IGF-1Rezeptor (1.4.3), zur Krebsentstehung beiträgt (Noto et al. 2013, Yang und Yee 2012). Auch in der Genese der Alzheimer-Erkrankung wird der Einfluss von Insulin diskutiert (Sebastião et al. 2014).

Ein erhöhter Insulin-Plasmaspiegel zählt aber auch zu einem der Faktoren, die zu einer endothelialen Dysfunktion (Arcaro et al. 2002) und im weiteren Verlauf zu einer Artheriosklerose führen.

So bewirkt die Hyperinsulinämie eine Abnahme der eNOS (endotheliale StickstoffmonoxidSynthetase) mit konsekutiver Reduktion des Stickstoffmonoxid (NO). Hierdurch entfällt die Endothel schützende Wirkung des NO in Form von Vasodilatation, Entzündungshemmung und die Unterdrückung von Endothelzellproliferation und -migration (Hsueh und Quiñones 2003) und es kommt zu einer chronischen Inflammation. Dadurch wird eine Adhäsion von Monozyten und Makrophagen vermittelt (Cybulsky und Gimbrone 1991), die in die Zellwand einwandern und durch die Sekretion und Produktion von Zytokinen die Entzündungsreaktion weiter unterhalten und verstärken (Knorr et al. 2014). Durch Aufnahme von Lipoproteinen werden sie zu Schaumzellen umgewandelt, ein arteriosklerotischer Plaque entsteht (Libby 2002).

\subsubsection{Signaltransduktion von Insulin}

Der Insulin-Rezeptor ist ein tetrameres Protein, welches aus zwei extrazellulären $\alpha$ Untereinheiten und zwei transmenbranen ß-Untereinheiten besteht. Die Untereinheiten funktionieren wie allosterische Enzyme (Ottensmeyer et al. 2000, Bertrand et al. 2008). Der Rezeptor gehört zu der Rezeptorenfamilie, der auch der IGF-1-Rezeptor und der Insulin Rezeptor-related receptor angehören (Patti und Kahn 1998), wobei zwischen InsulinRezeptor und IGF-1-Rezeptor Strukturähnlichkeiten bestehen, die Kreuzreaktionen und 
überlappende funktionelle Effekte zwischen den beiden Rezeptoren und deren Liganden erklären (Nakae et al. 2001, Siddle et al. 2001).

Die Bindung von Insulin an den $\alpha$-Untereinheiten des Insulin-Rezeptors führt zu einer Konformationsänderung und Annäherung der ß-Untereinheiten aneinander, die sich nun gegenseitig phosphorylieren, was als trans-Autophosphorylierung bezeichnet wird. (Patti und Kahn 1998). Hierdurch können die Proteine der Insulinrezeptor-Substrat-Familie und Shc (Src-Homology-Collagen)-Proteine, die als Adaptor-Proteine fungieren, gebunden werden, die wiederum die Bindung und Phosphorylierung von weiteren Kinasen ermöglichen (White 1998, Pessin und Saltiel 2000). In der weiteren downstream-Kaskade kommt es zur Aktivierung von zwei wesentlichen Transduktionswegen, der Phosphatidylinositol ${ }_{3}$-Kinase $\left(\mathrm{PI}_{3}\right.$-Kinase) und der mitogen-aktivierten Proteinkinase (MAPK). Es wird vermutet, dass der Transduktionsweg der $\mathrm{PI}_{3}$-Kinase den wesentlichen Teil der Signaltransduktion übernimmt (Muniyappa et al. 2007, Thirone et al. 2006).

Die $\mathrm{PI}_{3}$-Kinase ist eine heterodimeres Protein mit einer p110 katalytischen- und einer p85 regulatorischen Untereinheit, von der mindestens acht Isoformen bekannt sind. Die aktivierte $\mathrm{PI}_{3}$-Kinase vermittelt vor allem die Glukoseaufnahme in die Zelle, sowie die Glykogen- und Lipidsynthese (Saltiel und Kahn 2001).

Über den MAPK-abhängigen Weg werden vor allem Wachstums- und Differenzierungsprozesse vermittelt (Avruch 1998).

\subsubsection{Bekannte Wirkungen von Insulin am Myokard}

Wie bereits im Kapitel 1.5.2 beschrieben, hat der Glukosestoffwechsel eine zentrale Rolle in der Entwicklung der Arteriosklerose und der Inflammation. Die Effekte von Insulin am menschlichen Myokard sind noch nicht vollständig untersucht. An verschiedenen Spezies konnten jedoch bereits Insulineffekte nachgeweisen werden. So ist bekannt, dass die Signaltrasduktion am Insulin/IGF-Rezeptor bei Fruchtfliegen (Drosophila melanogaster) eine zentrale Rolle in der Regulation der Lebensdauer zeigt. Die Reduktion der Insulin/IGFSignaltransduktion reduzierte die Inzidenz von Herzinsuffizienz (Wessells et al. 2004). Eine weitere Untersuchung zeigte, dass $\beta_{3}$-Adrenozeptoren am Myokard einen negativ intotropen Effekt vermitteln. So zeigten diabetische Ratten eine Hochregulation der $\beta_{3}$-Adrenozeptoren durch Erhöhung mRNA-Level. Nach Behandlung mit Insulin verbesserte sich die Kontraktilität (Kayki-Multu et al. 2014).

Am Schweineherzen konnte eine Sepsis-induzierte Myokarddepression durch Insulininfusionen verringert werden. Eine antiinflammatorische Wirkung wurde nicht 
beobachtet, so dass der Effekt der positiv inotropen Wirkung zugeschrieben wurde (Levenbrown et al. 2013).

Es ist lange bekannt, dass Infusionen mit Glukose, Insulin und Kalium in vivo die myokardiale Kontraktilität im akuten Myokardinfarkt verbessern (Sodi-Pallares et al. 1962). Aktuelle Daten zeigen, dass nach Aortenklappenersatz-Operation die Inzidenz von einem niedrigen Herzzeitvolumen durch eine perioperative Insulin-, Glukose- und Kaliuminfusionen verringert werden kann (Howell et al. 2011).

An Erdhörnchen wurden sowohl transiente $(20 \mathrm{~min})$ positiv inotrope, ausbleibende als auch negativ inotrope Effekte von Insulin beschrieben. Diese waren dosisabhängig und führten bei hohen Insulindosen zu einer negativen Inotropie. Zudem wurde eine saisonale Abhängigkeit des Effektes beschrieben, welcher Einfluss auf das intrazelluläre $\mathrm{Ca}^{2+}$-handling hat (Nakipova et al. 2012). Des Weiteren sind funktionelle Effekte zwischen Kontrollgruppen und diabetischen Spezies in verschiedenen Modellen beschrieben worden: Lamm (Downing und Lee 1979), Ratten (Kolter et al. 1997) und Menschen (Jagasia et al. 2001) mit Reduktion der Insulin-vermittelten Inotropie in den diabetischen Tieren.

Aussagen zu positiver Inotropie-Entwicklung durch Insulin (Vetter et al. 1988, Sasso et al. 2000) stehen Untersuchungen gegenüber, die diesen Effekt nicht zeigen konnten (Airaksinen et al. 1985, Markovitz et al. 1985).

Patienten nach Herztransplantation infolge von chronischer Herzinsuffizienz leiden häufig an Diabetes mellitus oder Insulinresistenz (Swan et al. 1997, Anker und Al-Nasser 2000). Letztere korreliert wiederum mit der Inzidenz von chronischer Herzinsuffizienz (Paolisso et al. 1991, Swan et al. 1997) und dem Übergang von Hypertrophie zu Dilatation (Friehs et al. 1999).

Zusammenfassend kann gesagt werden, dass von Insulin bekannt ist, dass es sowohl SerumGlukosespiegel als auch Proteinsynthese und Wachstum beeinflusst. Funktionelle Effekte von Insulin sind bereits in vielen Modellen getestet worden und ergaben zum Teil uneinheitliche Daten. Bis heute liegen keine Daten zu den funktionellen Effekten von Insulin an humanen Muskelstreifenpräparaten vor. 


\subsection{Fragestellung der Arbeit}

Aufgrund der uneinheitlichen Datenlage in der Literatur zur Wirkung von Insulin am menschlichen Myokard und dessen Signaltransduktion befasst sich diese Arbeit mit den folgenden Fragestellungen:

- Hat Insulin funktionelle Effekte am insuffizienten menschlichen Myokard?

- Können diese Effekte zu Vergleichszwecken auch am Kaninchenmyokard gezeigt werden?

- Sind Insulin-Effekte am Myokard substratspezifisch bzw. konzentrationsabhängig?

- Welchen Einfluss hat Insulin auf die Kalziumhomöostase eines Mehrzellpräparates?

- Welche subzellulären Mechanismen vermitteln den funktionellen Effekt von Insulin? 


\section{MATERial Und MeThoden}

\subsection{Untersuchtes Gewebe}

Das menschliche Myokard wurde von der Abteilung Herzchirurgie des Herz- und Diabeteszentrums Nordrhein-Westfalen in Bad Oeynhausen und von der Abteilung Herz- und Thoraxchirurgie des Universitätsklinikums Göttingen zur Verfügung gestellt.

Die betreffenden Herzen stammen von nichtdiabetischen Patienten, die sich aufgrund einer terminalen Herzinsuffizienz (NYHA-Stadium IV, gemäß der Klassifizierung der New York Heart Association) einer orthotopen Herztransplantation unterziehen mussten.

Hinsichtlich der Ätiologie der Erkrankung wurde eine Einteilung in drei unterschiedliche Gruppen vorgenommen. Von 38 Patienten litten 23 Patienten an einer dilatativen Kardimyopathie (DCM), 14 an einer ischämischen Kardiomyopathie (ICM) und ein Patient an einer hypertroph-obstruktiven Kardimyopathie (HOCM).

Die durchschnittliche Ejektionsfraktion betrug kurz vor der Transplantation 26,8\% $\pm 33,2 \%$. Das Alter beider Gruppen betrug 53,2 Jahre \pm 41,2 Jahre.

Das Gewebe für die Tierexperimente stammt von weiblichen Kaninchen der Rasse Chinchilla Bastard (Charles River, Sulzfeld). Die Tiere wogen zwischen 1,2 und 1,4 Kilo und waren 8 bis 10 Wochen alt.

\begin{tabular}{|l|l|r|c|c|c|c|l|}
\hline Patient & $\mathrm{m} / \mathrm{w}$ & Alter & $\begin{array}{c}\text { Diagnos } \\
\mathrm{e}\end{array}$ & $\begin{array}{c}\text { PCW } \\
{[\mathrm{mmHG}]}\end{array}$ & $\begin{array}{c}\mathrm{EF} \\
{[\%]}\end{array}$ & $\begin{array}{c}\mathrm{CI} \\
{\left[{ }^{*} \mathrm{~min}-\right.} \\
\left.1 * \mathrm{~m}^{2}\right]\end{array}$ & \\
\hline F.S & $\mathrm{m}$ & 44 & DCM & 22 & 18 & 2,5 & ALD;DIG;AAR;ACE;KAT;NIT \\
\hline K-H.V & $\mathrm{m}$ & 64 & DCM & & 21 & 2,1 & ACE;DIG;BETA \\
\hline J.S. & $\mathrm{m}$ & 44 & DCM & 6 & 20 & 2,48 & BETA;DIG;ALD;KAT;ACE;MTX \\
\hline H.L. & $\mathrm{m}$ & 57 & ICM & 32 & 13 & & DIG;ACE \\
\hline B.M. & $\mathrm{m}$ & 55 & ICM & & 22 & & \\
\hline F.K. & $\mathrm{w}$ & 45 & HOCM & 22 & 36 & 2,4 & BETA;ACE;DIG \\
\hline D.F. & $\mathrm{m}$ & 44 & ICM & & 20 & & NIT;ACE,KAT \\
\hline H.J. & $\mathrm{m}$ & 67 & ICM & 17 & 24 & 1,6 & DIG;BETA;NIT;ALD;ACE \\
\hline E-F.N & $\mathrm{m}$ & 45 & DCM & 20 & 10 & 1,9 & KAT;AAR;DIG;ACE;NIT \\
\hline H-D.S. & $\mathrm{m}$ & 56 & DCM & 17 & 24 & 1,195 & ACE;DIG;KAT;AAR;ALD \\
\hline M.S. & $\mathrm{m}$ & 67 & ICM & 38 & 25 & 1,72 & BETA;ACE;NIT;MOL \\
\hline W.B & $\mathrm{m}$ & 67 & DCM & 15 & 40 & 2,42 & DIG;ACE;AAR;BETA;ALD;ALPH \\
\hline W.P. & $\mathrm{m}$ & 59 & DCM & 8 & 35 & 1,67 & DIG;BETA;AT1;ALD;GLU \\
\hline A.S. & $\mathrm{m}$ & 28 & ICM & 33 & 25 & 2,09 & BETA;ACE;ALD;AT1 \\
\hline B.P. & $\mathrm{m}$ & 61 & DCM & 26 & 15 & 1,92 & KAT;ACE;AAR;DIG;BETA \\
\hline D.E. & $\mathrm{w}$ & 43 & ICM & & 20 & & DIG;ALD \\
\hline H.S. & $\mathrm{m}$ & 62 & ICM & 13 & 15 & 2,35 & KAT;ACE;BETA;ALD \\
\hline H-J.M. & $\mathrm{m}$ & 63 & DCM & 12 & 15 & 2,57 & ACE \\
\hline A.K. & $\mathrm{w}$ & 14 & DCM & 9 & 24, & 2,5 & DIG;BETA;ACE;AAR \\
\hline
\end{tabular}




\begin{tabular}{|c|c|c|c|c|c|c|c|}
\hline & & & & & 6 & & \\
\hline R.B. & $\mathrm{m}$ & & $\mathrm{ICM}$ & & 18 & & BETA;AT1 \\
\hline W.D. & $\mathrm{m}$ & 65 & DCM & 10 & 27 & 2,15 & AAR;BETA;NIT;ALD;GLU \\
\hline S.E. & $\mathrm{m}$ & 63 & DCM & 28 & 32 & 1,46 & DIG;AAR;ACE;ALD \\
\hline R.S. & $\mathrm{m}$ & 62 & $\mathrm{ICM}$ & 9 & 17 & 1,63 & DIG;ACE;BETA \\
\hline R.K. & $\mathrm{m}$ & 64 & ICM & 18 & 25 & 1,82 & DIG;BETA;ACE \\
\hline H-w.C. & $\mathrm{m}$ & 65 & $\mathrm{ICM}$ & 13 & 15 & 2,69 & AAR;KAT;BETA \\
\hline A.D. & $\mathrm{m}$ & 47 & DCM & & & & \\
\hline T.B. & $\mathrm{m}$ & 38 & DCM & & 20 & & ACE;BETA;DIG;AAR \\
\hline J.G. & $\mathrm{m}$ & 45 & DCM & 30 & 15 & 2 & KAT;AAR \\
\hline H-P.D. & $\mathrm{m}$ & 70 & DCM & 18 & 15 & 3 & KAT \\
\hline B.E. & $\mathrm{m}$ & 62 & $\mathrm{ICM}$ & & 27 & 2,8 & DIG;ACE \\
\hline D.P. & $\mathrm{m}$ & 59 & DCM & 18 & 33 & & AAR;ACE; \\
\hline J.K. & $\mathrm{m}$ & 62 & DCM & 9 & 57 & 2,27 & ALD;BETA;KAT; \\
\hline H-M.D & $\mathrm{m}$ & 12 & DCM & 23 & 35 & 3,1 & AAR;BETA;ALD;ACE;DIG;KAT \\
\hline A.J. & $\mathrm{m}$ & 46 & DCM & & 60 & 1,9 & \\
\hline J.R. & w & 45 & DCM & 15 & 30 & 2,81 & BETA;ALD;DIG;AAR \\
\hline G.L. & $\mathrm{m}$ & 66 & $\mathrm{ICM}$ & 12 & 27 & 2,29 & BETA;DIG;AAR;MOL;NIT \\
\hline R-M.J. & $\mathrm{m}$ & 47 & DCM & 22 & 15 & 1,71 & ACE;DIG;KAT;PDE;GLU \\
\hline J.K. & $\mathrm{m}$ & 48 & DCM & 24 & & 1,97 & AAR;BETA;DIG;ACE;NIT; \\
\hline
\end{tabular}

Tab1. Legende: $\mathrm{ALD}=$ Aldosteronrezeptorantagonist; $\mathrm{AT}=$ Katcholamin; MTX=Methylxantin; IOD=Jodid; MOL=Molsidomin; $\quad$ GLU=Glukokortikoid; AT1=AT 1 -Rezeptoranatgonist; ALPH=Alpharezeptorenblocker; $\quad$ PDE=Phosphodiesterasehemmer; $\quad$ NIT=Nitrate; DCM=Dilatative Kardiomyopathie; ICM=Ischämische Kardiomyopathie; HOCM= Hypertroph obstruktive Kardiomyopathie

\subsection{Transport und Präparation}

\subsubsection{Transport}

Das explantierte Gewebe wurde durch den Chirurgen sofort nach der Entnahme in ein gekühltes Gefäß überführt, dass eine mit Carbogen (95\% Sauerstoff, 5\% Kohlendioxid) präoxigenierte Custodiol ${ }^{\circledR}$-Lösung (Dr. Franz Köhler Chemie GmbH, Bensheim, Deutschland) enthielt. Nach Entnahme von Proben für molekularbiologische Untersuchungen wurde das Material in ein verschließbares Transportgefäß mit gekühlter $\left(4^{\circ} \mathrm{C}\right)$, Carbogenbegaster $30 \mathrm{mM}$ Butanedion-Monoxim-haltiger Tyrode (BDM) gelegt.

Nach Explantation durch den Chirurgen konnte das Gewebe, das in Göttingen entnommen wurde, innerhalb von zehn Minuten, das Gewebe aus Bad Qeynhausen innerhalb von wenigen Stunden in einem speziellen Koffer in das Labor transportiert werden.

Dort wurde das Myokard bis zur Weiterverarbeitung, die umgehend nach Ankunft im Labor erfolgte, in $4^{\circ} \mathrm{C}$ kalter BDM-Tyrode (siehe 2.2.3) aufbewahrt und permanent mit Carbogen begast.

Auch die explantierten Kaninchenherzen wurden mittels der oben beschriebenen Verfahren bis zur Präparation vorbereitet und aufbewahrt. 


\subsubsection{Präparation}

Die Präparation des Human- und Kaninchenmyokards erfolgte in einer speziellen Präparierkammer. Diese Präparierkammer enthielt gekühlte, Carbogen-durchperlte BDMTyrode. Unter Verwendung eines Stereomikroskopes mit 10-facher Vergrößerung wurden möglichst unverzweigte, freiliegende und wenig fibrosierte Trabeculae carnea mit einer maximalen Querschnittsfläche von 0,6 mm² (Koch-Weser 1963; Paradise et al. 1981) freipräpariert und möglichst atraumatisch entnommen, indem an beiden Enden wenige Milimeter tief in das umliegende Myokard geschnitten wurde, um an diesen Enden einen Myokardüberstand zu erhalten. Dies vermindert die Verletzung des Muskelstreifens und gewährleistet eine einfachere und schonendere Handhabung des Muskels in der Folge. Der geringe Querschnitt garantiert eine ausreichende Sauerstoffdiffusion aus der Tyrode in das Präparat. Die auf diesem Weg erhaltenen Muskelstreifen wurden mit einer Einwegpipette (Transferpipette $5 \mathrm{ml}$, Fa.Sarstedt AG) in ein BDM-Tyrode enthaltenes Becherglas pipettiert und dort bis zu Versuchsbeginn etwa zehn Minuten im Kühlschrank gelagert.

Zur Präparation wurden mikrochirurgische Scheren und Pinzetten verwendet.

\subsubsection{Tyrode-Lösung}

Die Tyrode-Lösung bestand aus modifizierter Krebs-Henseleit-Lösung mit folgender Zusammensetzung pro Liter:

$\mathrm{NaCl} 127,0 \mathrm{mM}, \mathrm{KCl}$ 2,3 mM, $\mathrm{NaHCO}_{3} 25,0 \mathrm{mM}, \mathrm{MgSO}_{4}$ 0,6 mM, $\mathrm{KH}_{2} \mathrm{PO}_{4} 1,3 \mathrm{mM}, \mathrm{CaCl}_{2}$ 0,2 mM, Glukose 11,2 mM, Altinsulin 5,0 I.E./l, ph 7,40

\subsubsection{Kardioplegie}

Zur Myokardprotektion wurde eine modifizierte Tyrode-Lösung verwendet. Die Modifikation bestand in dem Zusatz der 101,2 Dalton schweren Phosphatase 2-3-Butanedione-Monoxim (BDM). BDM erfüllt in einer Konzentration von $30 \mathrm{mM}$ folgende Anforderungen zum Schutz des Myokards: Durch eine reversible Hemmung der Querbrückeninteraktion durch BDM (Blanchard et al. 1990) und die Verminderung der Kalziumsensitivität der kontraktilen Proteine (Fryer et al. 1988 a, Mulieri et al. 1989) bietet die Substanz einen guten Schutz vor Energieverlusten, Hypoxieschäden beim Transport und Kontrakturen infolge der Traumatisierungen bei der Präparation.

BDM hat keinen Einfluss auf die Kalziumsensitivität von Troponin C (Gwathmey et al. 1991), die Kalziumaufnahme in das Sarkoplasmatische Retikulum (Phillips und Altschuld 
1996), die Höhe der Kalziumtransienten am Herzen (Fryer et al. 1988 b) sowie auf das Membranpotential und den Verlauf von Aktionspotentialen.

Die Hemmung der Querbrückeninteraktion durch BDM ist konzentrationsabhängig. Bei der Verwendung einer 30 mM BDM-Lösung tritt eine vollständige Hemmung der myokardialen Kontraktilität auf (Perreault et al. 1992), was sich in anderen Versuchsbedingungen bereits als optimal erwiesen hat (Mulieri et al. 1989).

$\mathrm{Zu}$ Beginn des Experiments lässt sich das verwendete BDM schnell und vollständig aus dem Präparat auswaschen (siehe Versuchsablauf).

\subsubsection{Verwendete Substanzen}

- Insuman Rapid 100 I.E./ml (Humaninsulin, Hoechst Marion Roussel, Dosierung je nach Protokoll)

- Insulin-like growth factor-1 (IGF-1) receptorantibody ( $\alpha$-IR-3 clone, Oncogene Research Products, gelöst gemäß Herstellerempfehlung)

- Diacylglycerin (DAG-)-kinaseinhibitor II (1 $1 \mu \mathrm{mol} / 1$, Calbiochem, gelöst in DMSO)

- Wortmannin $(0,1 \mu \mathrm{mol} / 1$, Sigma $)$

- GF109203X (Bisindolylmaleimide I, $1 \mu \mathrm{mol} / 1$, Calbiochem, gelöst in DMSO)

- KB-R7943 (5 $\mu \mathrm{mol} / \mathrm{l})$, Tocris: $10^{-2}$ Stamm (50\% DMSO + 50\% Aqua dest. zuerst DMSO)

- Diltiazemhydrochloride (5 $\mu \mathrm{mol} / \mathrm{l}$, Sigma): $10^{-2} \mathrm{Stamm}(100 \%$ Aqua dest)

- Ryanodin (1 $\mu \mathrm{mol} / \mathrm{l}$, Sigma, gelöst in DMSO)

- $\quad$ Iodacatat $(0,5 \mu \mathrm{mol} / \mathrm{l}, \mathrm{Sigma})$

- Chelerythrin $(10 \mu \mathrm{mol} / \mathrm{l}$, Sigma $)$

- Cyclopiazonsäure (10 mmol/l, Sigma, gelöst in DMSO)

\subsection{Versuchsaufbau}

\subsubsection{Muskelstreifenanlage}

- Kraftaufnehmer KG 3 (Scientific Instruments, Cambridge England)

- Stimulator Stimext EXT 2 und Stim 4 (Scientific Instruments, Cambridge England)

- Force Transducer (Signalwandler) BAM 4C (Scientific Instruments, Cambridge England)

- Thermometer 302 K/J (Voltcraft, Conrad Elektronic, Hirschau Deutschland)

- Rollenpumpe MS_CA 4/840 C (Ismatec Zürich, Schweiz)

- Stereomikroskop SD 30 (Olympus, Tokio Japan) 
- Mikrometerschraube 0-25mm (Mitutoyo, Kawasaki Japan)

- Thermostat C1 und K15 (ehemals Haake, jetzte Thermo Scientific, Waltham USA)

- Thermoschreiber Linearcorder WR 3320 (GraphTec, Maryland USA)

- Personalcomputer, Betriebssystem Windows98; Prozessor PII

Zentrales Element der Anlage ist das Organbad. Es besteht aus einer Teflonwanne (Länge x Breite x Tiefe: $21 \mathrm{~mm}$ x $8 \mathrm{~mm}$ x $3 \mathrm{~mm}$ ). Diese Teflonwanne ist von einem hohlgefrästen Aluminiumblock umgeben, der mittels eines Wasserbades mit Thermostat und Pumpe von $37^{\circ} \mathrm{C}$ warmen Wasser durchspült wird und die Temperatur an das zentral liegende Teflonelement weitergibt. Die Teflonwanne wird durch eine Kanüle mit Tyrode-Lösung versorgt, welche auf der gegenüberliegenden Seite abgesaugt wird. Der Tyrode-Kreislauf wird aus einem auf $37^{\circ} \mathrm{C}$ warmen Vorratsgefäß gespeist, welches permanent von Carbogen durchperlt wird und auf einen $\mathrm{pH}-$ Wert von 7,4 eingestellt ist. Von dem Vorratsgefäß gelangt die Tyrode über eine Rollenpumpe in ein Schlauchsystem, welches von einem zweiten Schlauchsystem umgeben ist, um die Tyrode im Organbad mittels Gegenstromprinzip auf einer konstanten Temperatur von $37^{\circ} \mathrm{C}$ zu halten. Dies wird durchgehend von einem Thermometer überwacht. Die Absaugung erfolgt über eine Rollenpumpe mit doppelter Leistung und führt die Tyrode wieder dem Vorratsgefäß zu. Die Tyrode im Vorratsgefäß wird von einem Deckel vor Verdunstung geschützt und gewährleistet eine konstant Menge von 100 ml Tyrode im Kreislauf.

Zentral im Organbad sind zwei Nadeln von 0,1 mm Durchmesser angeordnet. Eine Nadel ist mit einer Mikrometerschraube verbunden, die eine präzise und definierte Dehnung des Präparates ermöglicht. Die zweite Nadel ist mit einem Kraftaufnehmer verbunden, der die isometrische Kontraktionskraft des Muskels misst und in eine elektrische Spannung umwandelt. Die elektrische Spannung wird durch einen Spannungswandler als digitales Signal an die Aufzeichnungssoftware des Computers und als analoges Signal an einen Thermoschreiber weitergegeben.

\subsubsection{RCC-Anlage}

- Kraftaufnehmer KG 3 (Scientific Instruments, Cambridge England)

- Stimulator STIM 2 (Scientific Instruments, Cambridge England)

- Forcetransducer BAM4C (Scientific Instruments, Cambridge England)

- Thermometer ALMEMO 2290-1 (Hugo Sachs Electronic)

- Rollpumpe Mini S-620 (Ismatec Zürich, Schweiz) 
- Heizthermostat M3 (Lauda, Lauda-Königshofen Deutschland)

- Kühlthermostat RM20 (Lauda, Lauda-Königshofen Deutschland)

- $\quad$ Thermoschreiber Linearcorder Mark VII WR 3101 (GraphTec, Maryland USA )

- $\quad$ Stereomikroskop VMT (Olympus, Tokio Japan)

- Mikrometerschraube (Parker Hannifin Daedal Division, Rohnert Park USA)

- Personalcomputer, Betriebssystem Windows95, Prozessor Intel PI

Der Aufbau der RCC-Anlage (RCC, rapid cooling contractures, schnelle Kühlungskontrakturen) differiert von der in 2.3.1 beschrieben Anlage in wenigen Punkten. Das Organbad besteht aus Acryl und weist die Abmessungen von Länge x Breite x Tiefe: 21 $\mathrm{mm}$ x $8 \mathrm{~mm}$ x $3 \mathrm{~mm}$ auf. Ein weiterer Unterschied besteht im Zulauf des Tyrode-Kreislaufes. Dieser Zulauf ist auf den letzten $50 \mathrm{~cm}$ vor dem Organbad in zwei Zuleitungen aufgeteilt, die jeweils von einem größeren und isolierten Schlauch umgeben und im Gegenstromprinzip umspült werden. Eine Zuleitung wird von dem umgebenden Schlauch auf eine konstante Temperatur von $37^{\circ} \mathrm{C}$ erwärmt, die zweite Zuleitung wird von dem umgebenden Schlauch permanent auf $0^{\circ} \mathrm{C}$ gekühlt. Direkt im Organbad münden beide Leitungen in einer gemeinsamen Öffnung. Ein Drei-Wege-Hahn ermöglicht durch Umstellung der Leitungen einen Wechsel der Organbadtemperatur von $37^{\circ} \mathrm{C}$ auf $0^{\circ} \mathrm{C}$ innerhalb einer Sekunde.

\subsubsection{Aequorin-Anlage}

Die Aequorin-Anlage weist einen anderen Aufbau als die beiden vorgenannten Anlagen auf. Auch hier ist die zentrale Einheit der Anlage das Organbad, welches aus einer 1,2 cm langen runden Quartz-Küvette mit einem Lumen von 0,4 cm besteht. Der Muskelstreifen wird mit zwei Klammern eingespannt und zentral in der Küvette angeordnet. Die beiden Klammern sind auf einem Schlitten befestigt und können jeweils über Mikrometerschrauben in drei Dimensionen in ihrer Position variiert werden. Dies ermöglicht einerseits die zentrale Anordnung des Muskelstreifens in der Quartzküvette als auch das definierte Vordehnen des Muskels. Direkt über der Küvette wird nach der Aequorin-Injektion der Photomultiplier positioniert.

Die beschriebene Versuchsanordnung befindet sich während des Experiments in einem lichtundurchlässigen Gehäuse, das eine Beeinflussung aller Versuchparameter von außen zulässt. Die Tyrode-Lösung wurde außerhalb in einem Vorratsgefäß auf $39^{\circ} \mathrm{C}$ erwärmt und 
mit Carbogen oxygeniert und auf einen $\mathrm{pH}$ von 7,4 eingestellt. Mittels einer Rollenpumpe gelangt die Tyrode über ein zu- und ableitendes Schlauchsystem zu der Küvette. Auf diesem Weg passiert die Tyrode vor der Küvette einen Thermoblock (Peltier-Element), welches die Tyrode auf exakt $37^{\circ} \mathrm{C}$ abkühlt. Dies verhindert eine Blasenbildung der oxygenierten Tyrode in der Küvette und schließt eine Beeinträchtigung der Lichtmessung aus. Die Temperatur wird während des Experiments in der Küvette gemessen und angezeigt.

Die Stimulation des Muskels erfolgt über zwei Klemmelektroden und kann in Dauer, Frequenz und Amplitude von außen variiert werden. Sowohl das Kraft- als auch das Lichtsignal wurden mit Hilfe eines Thermoschreibers, einer analog/digitalen-Wandlerkarte am Computer und eines Speicherozilloskopes aufgezeichnet.

\subsection{Versuchsablauf der Muskelstreifenanlage}

Unter stereomikroskopischer Sicht wurde der Muskel mit mirkochirurgischen Pinzetten über den Nadeln positioniert und aufgespießt. Dabei wurde darauf geachtet den Muskel nicht zu dehnen. Der Muskel wurde anschließend noch fünf Minuten ungedehnt im Organbad belassen.

Der Tyrode-Kreislauf wurde mit $140 \mathrm{ml}$ Tyrode befüllt auf $37^{\circ} \mathrm{C}$ vorgeheizt und mit Carbogen begast. Anschließend wurde die im Organbad vorhandene BDM-Tyrode mit $40 \mathrm{ml}$ Tyrode aus dem Vorratsgefäß ausgewaschen und verworfen. Jetzt erfolgte die Kalibrierung der Anlage auf eine diastolische Spannung von $0 \mathrm{mN}$ und es wurde mit dem KalziumKonzentrationsaufbau in den Schritten $(0,5 \mathrm{mM}, 1,0 \mathrm{mM}, 1,5 \mathrm{mM}, 2,0 \mathrm{mM}, 2,5 \mathrm{mM})$ begonnen. Ab einer Konzentration von 1,0 mM wurde mit der elektrischen Stimulation des Muskels begonnen. Die Spannungsamplitude wurde bei einer Frequenz von $1 \mathrm{~Hz}$ und einem Rechteckimpuls von 2,5 ms langsam hochreguliert und die Schwellenspannung zum Auslösen von Kontraktionen bestimmt. Dieser Ausgangswert wurde um $20 \%$ überschritten, um eine sichere Stimulation des Präparates zu gewährleisten. Sobald die Kraftamplitude sich auf einem stabilen Niveau eingependelt (steady state) hatte, wurde mit der Vordehnung des Muskels begonnen. Dies erfolgte in Schritten von etwa 0,05 mm bis keine Kraftzunahme mehr zu verzeichnen war und der Muskel die maximale isometrische Kraft entwickelt (Lmax) hatte. Nach jedem Dehnungsschritt wurde das jeweilige steady state abgewartet bis der nächste Dehnungsschritt eingeleitet wurde. 


\subsubsection{Insulin-Einzeldosisexperimente}

Es wurden Insulin (Insuman Rapid, 100 I.E./ml, Humaninsulin) der Firma Hoechst Marion Roussel verwendet. Vor jedem Versuchsbeginn wurde die Insulin-Stammlösung neu angesetzt, indem $100 \mu \mathrm{l}$ Insulin mit $900 \mu \mathrm{l}$ Tyrode-Lösung versetzt wurden. Von diesem Stamm sind anschließend $30 \mu \mathrm{l}(3 \mu \mathrm{l})$ Insulin-Lösung in die Vorratsgefäße (100 ml) pipettiert worden, so dass sich eine Bad-Konzentration von 3 I.E./l (bzw 0,3 I.E./l) ergab. Ab der Zugabe von Insulin wurde zu definierten Zeitpunkten (6 min, $8 \mathrm{~min}, 12 \mathrm{~min}, 20 \mathrm{~min}$ ) analog und digital gespeichert.

\subsubsection{Insulin-Dosis/Wirkungskurven}

Grundlage für die Untersuchung der Dosis/Wirkungs-Kurve von Insulin waren die Konzentrationen 0,01 I.E./1, 0,03 I.E./1, 0,1 I.E./1, 0,3 I.E./1, 1,0 I.E./1, 3,0 I.E./1, 10 I.E./1 und 30 I.E./l. Beginnend mit der geringsten Konzentration wurde additiv die Insulinkonzentration im Tyrode-Vorratsgefäß hochtitriert. Nach jedem neuen Konzentrationsschritt wurde das steady state des Muskels abgewartet bevor die höhere Konzentration zugegeben wurde.

\subsubsection{Insulinexperimente mit Glukose oder Pyruvat als Energiesubstrat}

Bei den Experimenten zur Untersuchung der Substratabhängigkeit des inotropen Effekts von Insulin wurden jeweils mindestens zwei Muskelstreifen aus einem Herzen präpariert. Dazu wurde ein Muskel in Glukose-haltiger Tyrode (11,2 mmol Glukose) in die Anlage eingespannt, der andere Muskel wurde entsprechend mit Pyruvat-haltiger Tyrode (22,4 mmol Pyruvat) behandelt. Anschließend wurde das in 2.4.1 beschriebene Protokoll gemessen. Dies ermöglichte die direkte Vergleichbarkeit des Insulineffektes bei unterschiedlichen Substraten.

\subsubsection{Insulinexperimente nach Blockade der Glykolyse}

Dieses Messprotokoll wurde ebenfalls zur Untersuchung der Substratabhängigkeit des positiv inotropen Effektes von Insulin durchgeführt. Weiterhin ermöglicht diese Versuchsanordnung zusammen mit den Ergebnissen von 2.4.3 eine Differenzierung zwischen einem positiven Effekt durch verbesserte Glukoseaufnahme und einem substratunabhängigen Effekt.

Grundlage dieses Messprotokolls waren jeweils zwei Muskelstreifen aus identischen Herzen, von denen jeweils ein Muskel in Glukose-haltiger Tyrode und ein Muskel in Pyruvat-haltiger Tyrode inkubiert wurden. Nach Einhängen, Dehnung und mechanischer Stabilisierung der Muskeln wurde Iodacetat $1 \mathrm{mM}$ in das Tyrode-Vorratsgefäß gegeben. Dies bewirkte eine 
vollständige Blockade der Glykolyse. Nach 30 min Inkubationszeit wurde das in 2.4.1 beschriebene Protokoll durchgeführt.

\subsubsection{Insulinexperimente in $5 \mathrm{mmol} / \mathrm{l}$ Glukose-Tyrode}

Zur Untersuchung des Einflusses verschiedener Substratkonzentrationen wurden Insulinexperimente in den Konzentrationen 3 I.E./l und 0,3 I.E./l Insulin in Glukose-Tyrode mit einer Glukosekonzentration von $5 \mathrm{mmol} / \mathrm{l}$ durchgeführt. Aus jedem Herzen wurde ein Kontrollmuskel in 11,2 mmol/l Glukose-Tyrode und 3 I.E./l Insulin gemessen.

\subsubsection{Signaltransduktionsblockade}

Die Blockade möglicher Signaltransduktionswege von Insulin wurde mit den in der Folge aufgeführten Substanzen einzeln durchgefürt. Die erfolgte nach Einhängen, Dehnen und mechanischer Stabilisierung der Muskeln, indem die entsprechende Substanz in der beschriebenen Konzentration in das Vorratsgefäß pipettiert wurde. Die Muskeln wurden 30 min inkubiert. Konnte nach 30 min keine steady state erreicht werden, wurde die vollständige mechanische Stabilisierung des Muskels abgewartet, bevor mit dem in 2.4.1. beschriebenen Protokoll fortgefahren wurde. Es wurde zu jedem Blockade-Experiment ein Kontrollmuskel aus dem gleichen Herzen gemessen.

- Insulin-like growth factor-1 (IGF-1) receptorantibody ( $\alpha$-IR-3 clone, Oncogene Research Products, gelöst gemäß Herstellerempfehlung)

- Diacylglycerin (DAG-)-kinaseinhibitor II (1 $\mu \mathrm{mol} / 1$, Calbiochem, gelöst in DMSO)

- Wortmannin $(0,1 \mu \mathrm{mol} / 1$, Sigma $)$

- GF109203X (Bisindolylmaleimide I, 1 $\mu \mathrm{mol} / \mathrm{l}$, Calbiochem, gelöst in DMSO)

- KB-R7943 (5 $\mu \mathrm{mol} / \mathrm{l})$, Tocris: $10^{-2}$ Stamm (50\% DMSO + 50\% Aqua dest. zuerst DMSO)

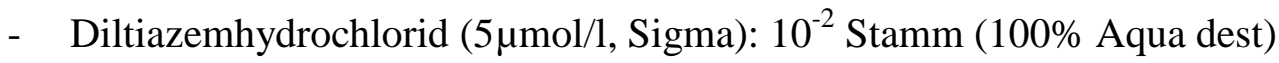

- Chelerythrin $(10 \mu \mathrm{mol} / 1$, Sigma $)$

\subsection{Versuchsablauf der RCC-Anlage}

Die Untersuchung zur Kalziumbeladung des Sarkoplasmatischen Retikulums (SR) erfolgte an der Anlage für schnelle Kühlungskontrakturen (rapid cooling contractures, RCC). Dazu wurde ein Muskelstreifen nach dem vorbeschriebenen Protokoll (2.4.1) auf zwei Nadeln zwischen dem Kraftaufnehmer eingespannt, das BDM ausgewaschen, die Anlage kalibriert und behutsam vorgedehnt. Der Versuchsablauf entspricht soweit dem an der 
Muskelstreifenanlage. Der Unterschied besteht in dem parallel geschalteten Kühlungskreislauf. Sobald der Muskel vorgedehnt und mechanisch stabil war, wurde eine Probekühlung des Präparates vorgenommen.

Der Tyrode-Kreislauf wurde mittels eines Drei-Wege-Hahnes von $37^{\circ} \mathrm{C}$ auf $0^{\circ} \mathrm{C}$ umgestellt und sofort bei Beginn der Kühlung die Stimulation abgeschaltet. Der Temperaturverlauf von $37^{\circ} \mathrm{C}$ auf $0^{\circ} \mathrm{C}$ konnte in Echtzeit auf dem Schreiber, Computer und dem digitalen Thermometer nachvollzogen werden. Mit dem Einsetzen der Kühlung werden alle aktiven Transportmechanismen der Zelle blockiert und die $\mathrm{Ca}^{2+}$-Freisetzungskanäle des SR öffnen sich. Dies führte zur Freisetzung von Kalzium in das Zytosol und zur Kontraktur des Muskels. Die Amplitude der Kontraktur spiegelt den SR-Kalziumgehalt wider. Sobald die Kontraktur des Muskels ein Plateau erreicht hatte, wurde das Präparat erwärmt und ein zweites mal gekühlt mit der Folge einer zweiten morphologisch kleineren Kontraktur. Die Differenz zur ersten Kontraktur wird als Maß für den Kalziumtransport nach extrazellulär während der kurzen Erwärmungsphase gewertet.

Nachdem auch bei der zweiten Kontraktur ein Plateau erreicht worden war, wurde der Tyrode-Kreislauf auf warm gestellt und die Stimulation wieder eingeschaltet. Nach etwa zwei Minuten stabilisierte sich das Präparat auf dem vorherigen Ausgangsniveau.

Nun wurden drei Kühlungskontrakturen vor der Intervention durchgeführt und aufgezeichnet. Direkt nach der mechanischen Stabilisierung des Präparates, die auf die letzte Kühlung folgte, wurde die Intervention vorgenommen. Zum Zeitpunkt des maximalen Effektes wurden wieder drei Kühlungskontrakturen durchgeführt. Nach Beendigung des Experiments wurden jeweils die drei Kühlungskontrakturen gemittelt und die so erhaltenen Werte verglichen.

\subsubsection{Insulinexperimente nach Blockade des SR}

Die Untersuchungen zu dem Effekt von Insulin nach Blockade des SR wurden an der RCCAnlage durchgeführt. Die Muskeln wurden eingehängt, gedehnt und die mechanische Stabilisierung abgewartet. Anschließend erfolgte die funktionelle Blockade des SR mittels Ryanodine (1 $\mu \mathrm{mol} / \mathrm{l}$, Sigma, gelöst in DMSO) und Cyclopiazonsäure (10 mmol/l, Sigma, gelöst in DMSO). Nach Erreichen des steady states wurden mehrere Kühlungskontrakturen durchgeführt. Eine vollständige Blockade des SR war an der fehlenden Kontraktur nach der Kühlung zu erkennen. Nach dieser Verifizierung der SR-Blockade wurde Insulin in der Konzentration 3 I.E./l zugegeben. 


\subsection{Versuchsablauf der Aequorin-Anlage}

Nach der Präparation eines geeigneten Trabekels aus dem Myokard wurde dieser zwischen den beiden Klemmelektroden fixiert. Im Anschluss an die Fixierung wurde sofort die Küvette über das Präparat geschoben und der Muskel mit oxygenierter BDM-Tyrode umspült. Dies ermöglicht dem Muskel eine Erholung von der Traumatisierung durch das Einspannen. Nach etwa fünf Minuten wurde ein Tyrode-Wechsel vorgenommen und die BDM-Tyrode ausgewaschen. Nach dem Auswaschen der BDM-Tyrode erfolgte die Kalibrierung des Thermoschreibers und der Software am Computer.

Nach vollständiger mechanischer Stabilisierung des Präparates wurde die Stimulation für fünf Minuten abgeschaltet und nach Ende dieser Ruhephase wurde auch die Pumpe abgeschaltet und die Küvette zur Seite geschoben. Mit Hilfe eines Stereomikroskopes wurden $5 \mu$ l Aequorinlösung subendokardial injiziert. Diese Verfahren der Makroinjektion ist von Kihara und Morgan detailliert beschrieben worden (Kihara und Morgan 1989). Im Anschluss an die Injektion wurde die Küvette wieder über den Muskel geschoben und die Pumpe wieder eingeschaltet. Nach erneuten fünf Minuten Ruhephase wurde auch die Stimulation des Muskels auf dem vorher definierten Niveau begonnen. An diesem Moment wurde der Photomultiplier über dem Trabekel positioniert, das lichtdichte Gehäuse der Anlage geschlossen und eine Spannung von mindestens $800 \mathrm{~V}$ an den Photomultiplier angelegt. Innerhalb weniger Minuten stabilisierte sich das Aequorinsignal, da das Protein entweder verbraucht, ausgewaschen oder in die Zelle aufgenommen wurde. Auch das Kraftsignal erreichte schnell ein stabiles, mechanisches Niveau. Zeigten sowohl Kraft- als auch Lichtsignal eine ausreichend große Amplitude wurde mit dem Experiment begonnen.

\subsubsection{Aequorin}

Das Photoprotein Aequorin wird aus der freilebenden Salzwasser-Hydromeduse Aequorea forskolea gewonnen. 1962 wurde das 21.000 Dalton schwere Molekül erstmals von Shimomura und Johnson isoliert und wird seit 1970 als als Indikator für intrazelluläres Kalzium verwendet (Shimomura und Johnson 1970).

Das Aequorin-Molekül besitzt drei $\mathrm{Ca}^{2+}$-Bindungsstellen identischer Affinität. Emission von blauem Licht der Wellenlänge $469 \mathrm{~nm}$ erfolgt, wenn alle drei Bindungsstellen besetzt sind. Dabei erfährt das Molekül eine Konformationsänderung, Photonen werden freigesetzt und das Apoprotein Coelenterazin wird irreversibel gewandelt. Unter in vitro-Bedingungen kann daher ein Aequorinmolekül nur einmal aktiviert werden (Blinks 1992). Die Lichtemission ist 
direkt proportional zu den Molekülen, deren drei Bindungsstellen mit $\mathrm{Ca}^{2+}$-Ionen besetzt sind (Blinks et al. 1978).

Die hohe Spezifität für Kalzium, die schnelle Reaktionskinetik sowie die erfassbare Lichtemission gewährleisten eine hohe zeitliche Auflösung der intrazellulären Kalziumhomöostase.

Außerdem benötigt Aequorin weder andere Kofaktoren noch Sauerstoff, der Bestandteil des Proteins ist, noch sind toxische Effekte oder Einflüsse auf zelluläre Vorgänge bekannt.

Der annähernd lineare Anteil der doppellogarithmischen Reaktionskurve liegt im Bereich der $10^{-7}$ bis $10^{-5}$ molaren Kalziumkonzentration und umfasst somit den relevanten Bereich im Myozyten und ermöglicht besonders während der Systole wegen des steilen Verlaufs der Kurve eine sichere Unterscheidung der Konzentrationsunterschiede.

Das Aequorin wird in hochgereinigter Form von Prof. Dr. J. Blinks (Friday Harbour, Washington, U.S.A) zur Verfügung gestellt.

Bei der Vorbereitung der Aequorin-Lösung wurde jeweils $1 \mathrm{mg}$ lyophiliertes, hochreines Aequorin in $700 \mu \mathrm{l}$ organisch reinem, destillierten Wasser gelöst (nominell Kalzium-frei: Kalziumkonzentration < 0,005 ppm) und in Eppendorf-Cups zu je $100 \mu$ umgefüllt.

Die entstandenen Aliqouts wurden bei $-80^{\circ} \mathrm{C}$ gelagert. Zum Vermeiden von Kalziumkontaminationen während dieses und allen folgenden Arbeitsschritten wurden alle Hilfsmittel und die Arbeitsfläche mit einer 10 mM EDTA-Lösung und destilliertem Wasser abgewischt.

Zur Makroinjektion des Aequorins wurde zu Versuchsbeginn jeweils ein $100 \mu$ EppendorfCup aufgetaut. Die zur Injektion erforderlichen Mikropipetten und Injektionsnadeln wurden vor dem ersten Kontakt mit dem Protein jeweils dreimal von innen und außen mit EDTALösung und anschließend mit destilliertem Wasser gespült und anschließend $5 \mu$ Aequorin in die Injektionsnadel pipettiert und die beschriebene Makroinjektion vorgenommen.

\subsection{Auswertung der Versuche}

Die Auswertung der Versuche erfolgte mittels des Programms LabView (National Instruments, Austin/Texas, USA) und bezog sich auf die folgenden Parameter:

- Systolische Kraft $\quad\left(\mathrm{mN} / \mathrm{mm}^{2}\right)$ Amplitude der isometrischen Kontraktion pro Querschnitt

- TPT (ms) Zeit bis zum Maximum der Kraftentwicklung

- Diastolische Kraft $\quad\left(\mathrm{mN} / \mathrm{mm}^{2}\right)$ Kraft zum Zeitpunkt der Relaxation 
$-+\mathrm{dF} / \mathrm{dtmax} \quad(\mathrm{mN} / \mathrm{s})$ maximale Kraftanstiegsgeschwindigkeit

$--\mathrm{dF} / \mathrm{dtmin} \quad(\mathrm{mN} / \mathrm{s})$ maximale Relaxationsgeschwindigkeit

- RT50 (ms) Zeit zum Zeitpunkt des maximalen Kraftsignals bis zum 50\%igen Abfalls des Signals

- TT90 (ms) Zeit vom Beginn der Kontraktion bis zur 90\%igen Relaxation des Muskels

Die Kraftdaten wurden jeweils auf die Querschnittsfläche des Muskels normiert. Die Querschnittsfläche wurde aus der mittels Stereomikroskopes gemessenen Breite und Dicke errechnet. Die Rechnung erfolgte durch das Programm LabView und bezog sich auf eine imaginäre Ellipse. Die Querschnittsfläche wurde in $\mathrm{mm}^{2}$ angegeben.

\subsection{Normierung der Daten}

Die Messwerte der Kraft, der Kühlungskontraktur und des Lichtsignals wurden jeweils in Prozent des Ausgangswertes angegeben. Dies ermöglichte, die Änderung der jeweiligen Parameter besser in Bezug setzen zu können.

\subsection{Statistische Auswertung}

Die erhobenen Daten und wurden mit MS Excel 2000® gesammelt und ausgewertet. Die graphische Aufarbeitung erfolgte mit dem Statistikprogramm SigmaPlot@ (Systat Software Inc, San Jose, USA).

Alle Werte wurden in Mittelwert \pm Standardfehler des Mittelwertes (SEM) angegeben. Veränderungen wurden nach Durchführung einer einfaktoriellen Varianzanalyse mit dem tTest je nach Protokoll für ungebundene (Einzeldehnung) oder gepaarte Stichproben (Doppeldehnung) auf Signifikanz geprüft. Unterschiede mit einer Irrtumswahrscheinlichkeit von $\mathrm{p}<0,05$ wurden als signifikant angesehen. 


\section{ERGEBNISSE}

\subsection{Ergebnisse am humanen Myokard}

\subsubsection{Wirkung von Insulin auf die isometrische Kraftentwicklung}

In diesem Messprotokoll wurde die Wirkung von Insulin auf die isometrische Kontraktionskraft bei einer Konzentration von 3 I.E./l Insulin untersucht (siehe 2.4.1). Abbildung 1 zeigt den zeitlichen Ablauf der insulinbedingten Kraftzunahme.

Nach Zugabe von Insulin (0 min), ausgehend von der auf $100 \%$ normierten Ausgangskraft, ist eine signifikante Erhöhung der systolische Kraft mit einem Maximum von 27,8 $\pm 3,1 \%$ bei acht Minuten zu beobachten. Die systolische Kraft fällt nach dem Maximum ab bis auf ein Niveau von $12,6 \pm 1,7 \%$ bei 20 min nach der Intervention.

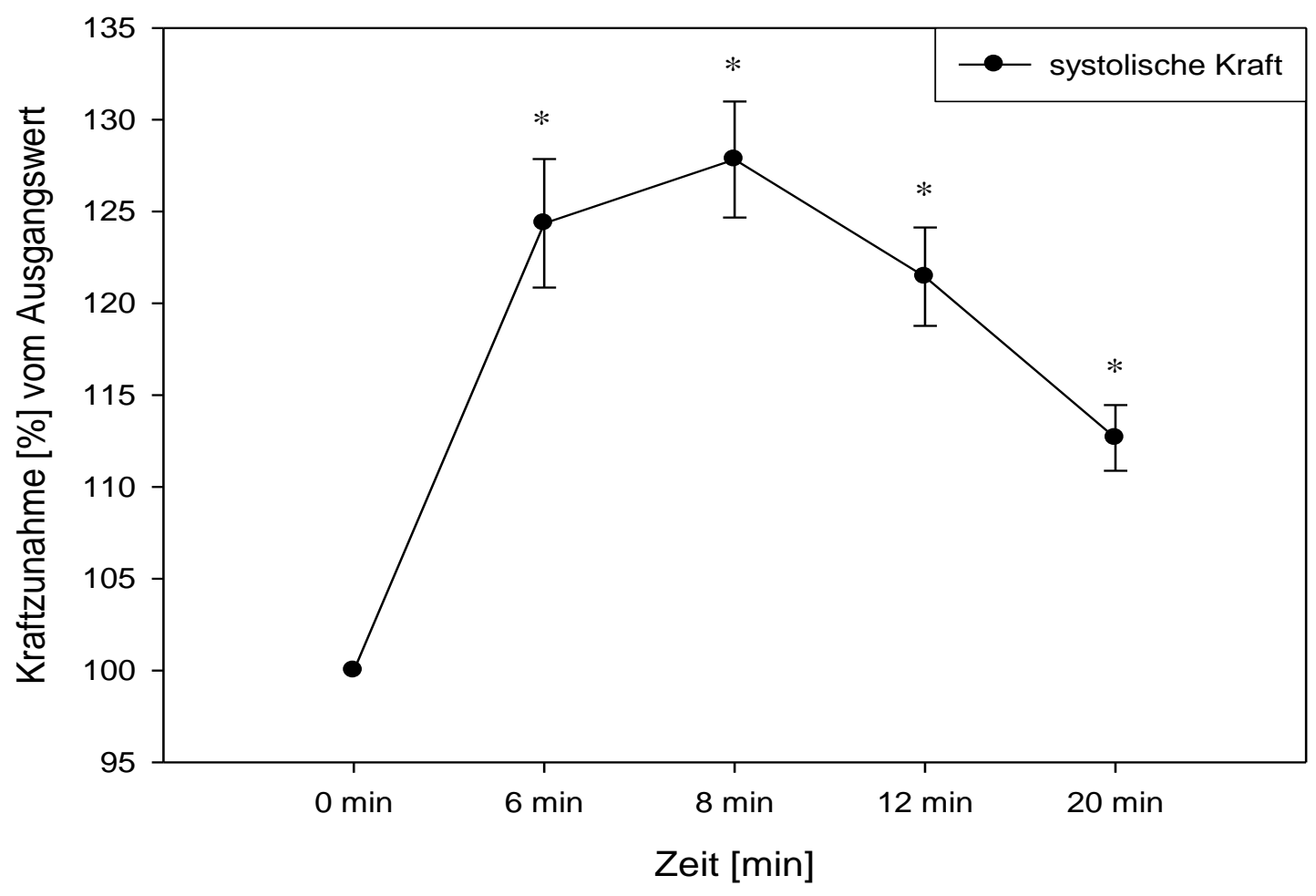

Abb. 1: Die Inkubation mit 3 I.E. Insulin pro Liter bewirkt einen Anstieg der isometrischen Kraftzunahme ( $\mathrm{n}=8)$.

Abbildung 2 ist eine quantitative Zusammenfassung aller Kontrollexperimente, das heißt aller Ansätze der einzelnen Messprotokolle (siehe 2.4 bis 2.5), die jeweils mit 3 I.E./l Insulin und ohne weitere Intervention durchgeführt wurden. Gezeigt sind in Abb.2 die Parameter der 
Kontraktionskinetik. Der Parameter Kraft ist in Abhängigkeit zum jeweiligen Parameter der Kontraktionskinetik zum Zeitpunkt der maximalen Kraftzunahme ( 8 min nach Insulinzugabe) aufgetragen. $\mathrm{Zu}$ erkennen ist, dass mit der Zunahme der systolische Kraft auch die maximale Kraftanstiegsgeschwindigkeit $(28,1 \pm 3,3 \%)$ und die maximale Relaxationsgeschwindigkeit $(26,3 \% \pm 4,5 \%)$ signifikant zunehmen. Die übrigen zeitlichen Parameter der Kontraktion bleiben von der Intervention mit Insulin unbeeinflusst.

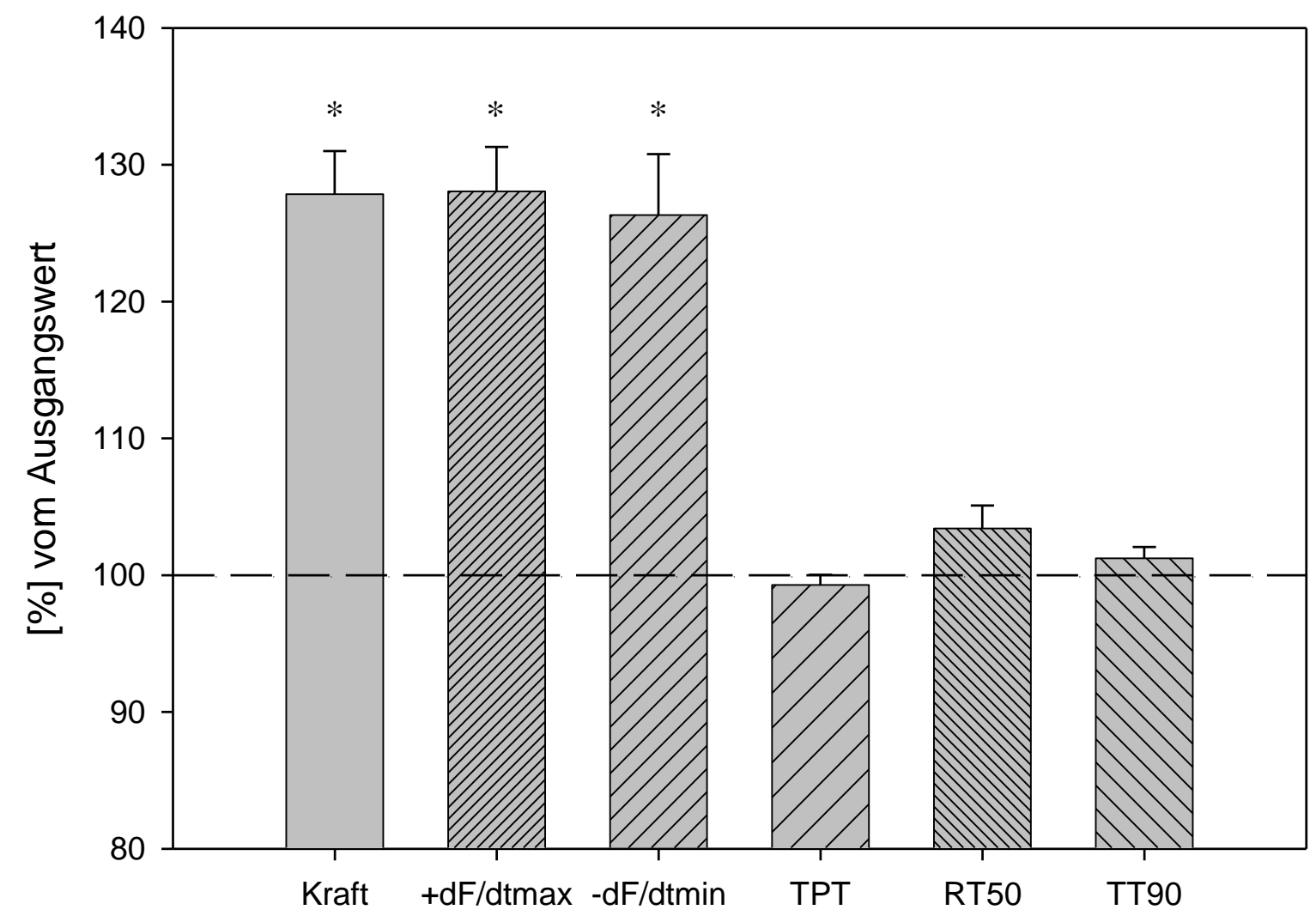

Abb. 2: Darstellung der Kraftentwicklung und Zeitparameter der gemittelten Kontrollansätze. Insulin bewirkt einen Anstieg der isometrischen Kontraktionskraft, die maximale Kraftanstiegsgeschwindigkeit und maximale Relaxationsgeschwindigkeit nehmen im gleichen Maße zu. TPT, RT50 und TT90 bleiben unbeeinflusst (n=31).

\subsubsection{Konzentrationsabhängiger Effekt von Insulin}

In diesem Messprotokoll wurden zwei Insulinkonzentrationen (3 I.E./l und 0,3 I.E./l) gemessen.

Bei einer Insulin-Konzentration von 3 I.E./l nimmt die Kontraktionskraft um 25,8 \pm 5,6 \% zu. Nach Intervention mit einer zehnfach geringeren Konzentration beträgt die Kraftzunahme noch $12,0 \pm 1,4 \%$. In beiden Gruppen ergibt sich somit jeweils eine signifikante 
Kraftzunahme, der Unterschied beider Gruppen gegeneinander erreicht jedoch nicht das Signifikanzniveau von $\mathrm{p}>0,05$ (Abb.3).

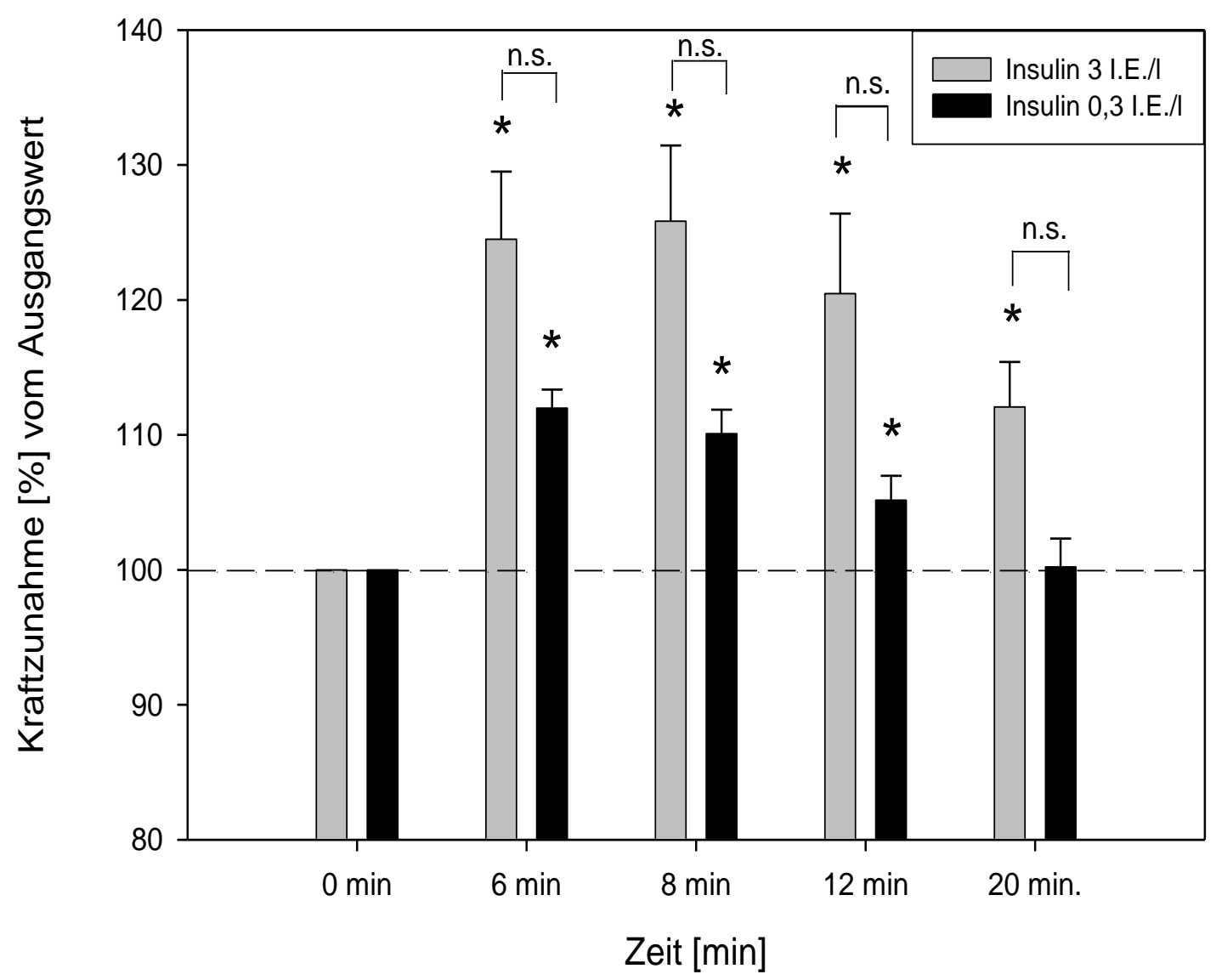

Abb. 3: Aufgetragen sind die insulinbedingten Kraftzunahmen bei zwei verschiedenen Insulinkonzentrationen von 3 I.E./1 $(n=7)$ und 0,3 I.E./1 $(n=4)$.

\subsubsection{Insulin-Dosis/Wirkungskurve}

Am humanen Myokard wurden Konzentrationswirkungskurven ermittelt. Dabei wurde ausgehend von einer Insulinkonzentration von 0,01 I.E./1 Insulin gemäß dem Kapitel 2.4.2 die Insulinkonzentration in der Tyrode-Lösung auftitriert. In Glukose-Tyrode lässt sich kein Effekt nachweisen, währende bei hohen Insulindosen in der Pyruvat-Tyrode tendenziell eine Kontraktionskraftabnahme zu verzeichnen ist (Abb.4). Dieser Effekt ist auf die bereits 1993 von Sethi et al. beschriebene Tachyphylaxie von Insulin für den kontraktilen Effekt am Myokard beschrieben worden. Aufgrund der hier bestätigten Tachyphylaxie wurden in den übrigen Messprotokollen nur Einzeldosen von Insulin verwendet. 


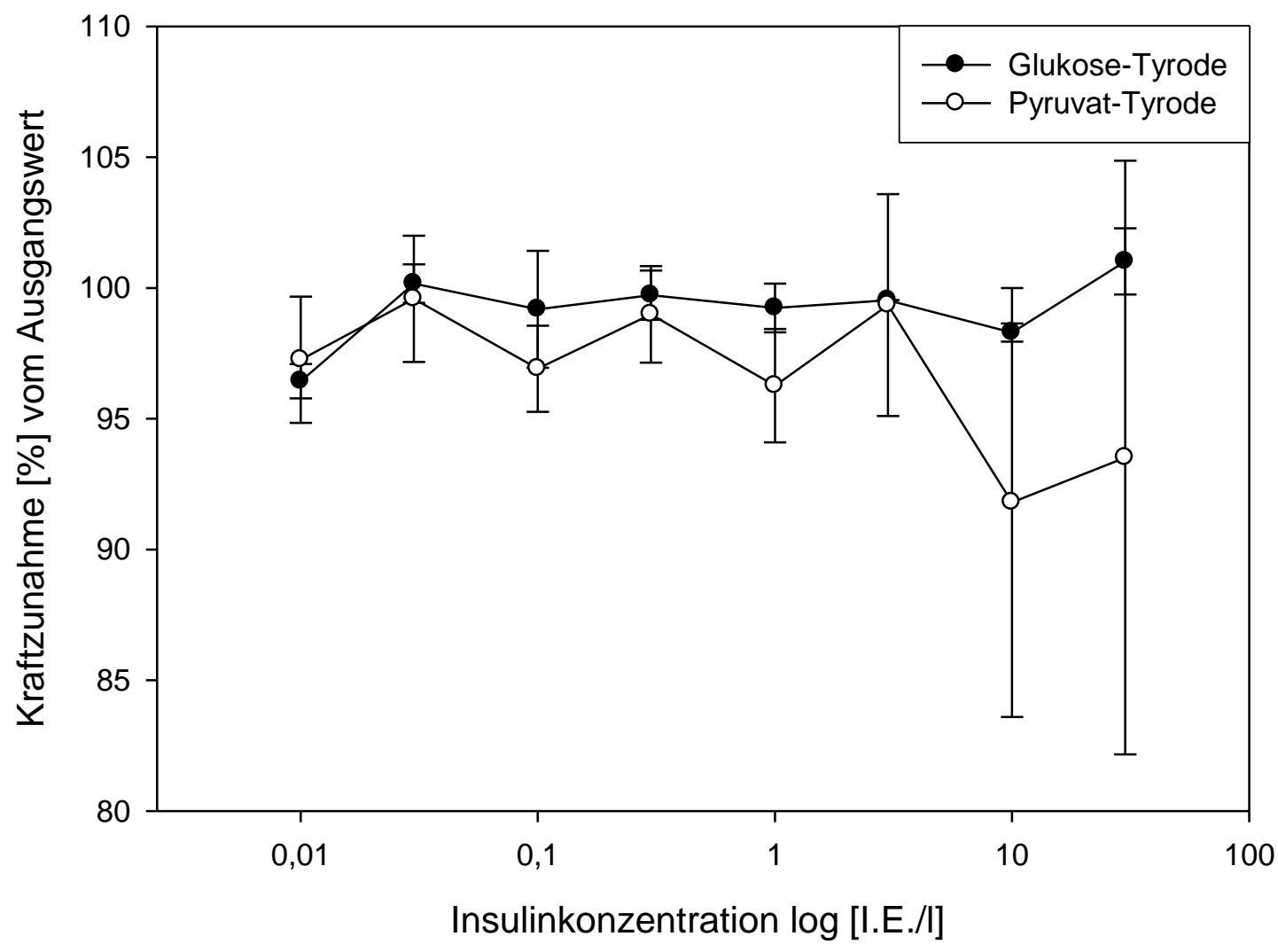

Abb. 4: Insulin-Dosis/Wirkungskurve am humanen Myokard in Glukose- und PyruvatTyrode $(n=2)$.

\subsubsection{Wirkung von Insulin in Abhängigkeit von verschiedenen Energiesubstraten}

Des Weiteren wurden Untersuchungen an Muskelstreifen mit der Konzentration 3 I.E.Insulin/l durchgeführt. Es wurden zwei Gruppen gebildet, wobei jede ein anderes Energiesubstrat (Glukose versus Pyruvat) erhielt (siehe 2.4.3). Das Ergebnis ist in Abbildung 5 dargestellt.

$\mathrm{Zu}$ erkennen ist in der Gruppe mit Glukose-Tyrode die schon oben beschriebene insulinabhängige signifikante Kraftzunahme mit einem Maximum von 25,8 \pm 5,6 \% bei acht Minuten. Der Wert differiert von Abbildung 2, da es sich, im Gegensatz zu dieser Messreihe $(n=9)$, dort um eine Zusammenfassung aller Kontrollmuskeln $(n=31)$ handelt (siehe 3.1.1). Die Pyruvat-Gruppe zeigt die gleiche zeitliche Kinetik der Kraftzunahme auf einem anderen Kraftniveau. Das Maximum der Kontraktionskraft wird bei sechs Minuten mit einem Wert von $10,9 \pm 3,2 \%$ erreicht. Die Kraftzunahme ist zu allen Zeiten, bis auf den Wert bei 20 Minuten signifikant gegenüber dem Ausgangswert.

Die Glukose-Gruppe erreicht einen 2,5fach höheren maximalen Kraftzuwachs als die PyruvatGruppe. Dieser Unterschied hat nahezu über die gesamte Dauer des Experimentes Bestand. 


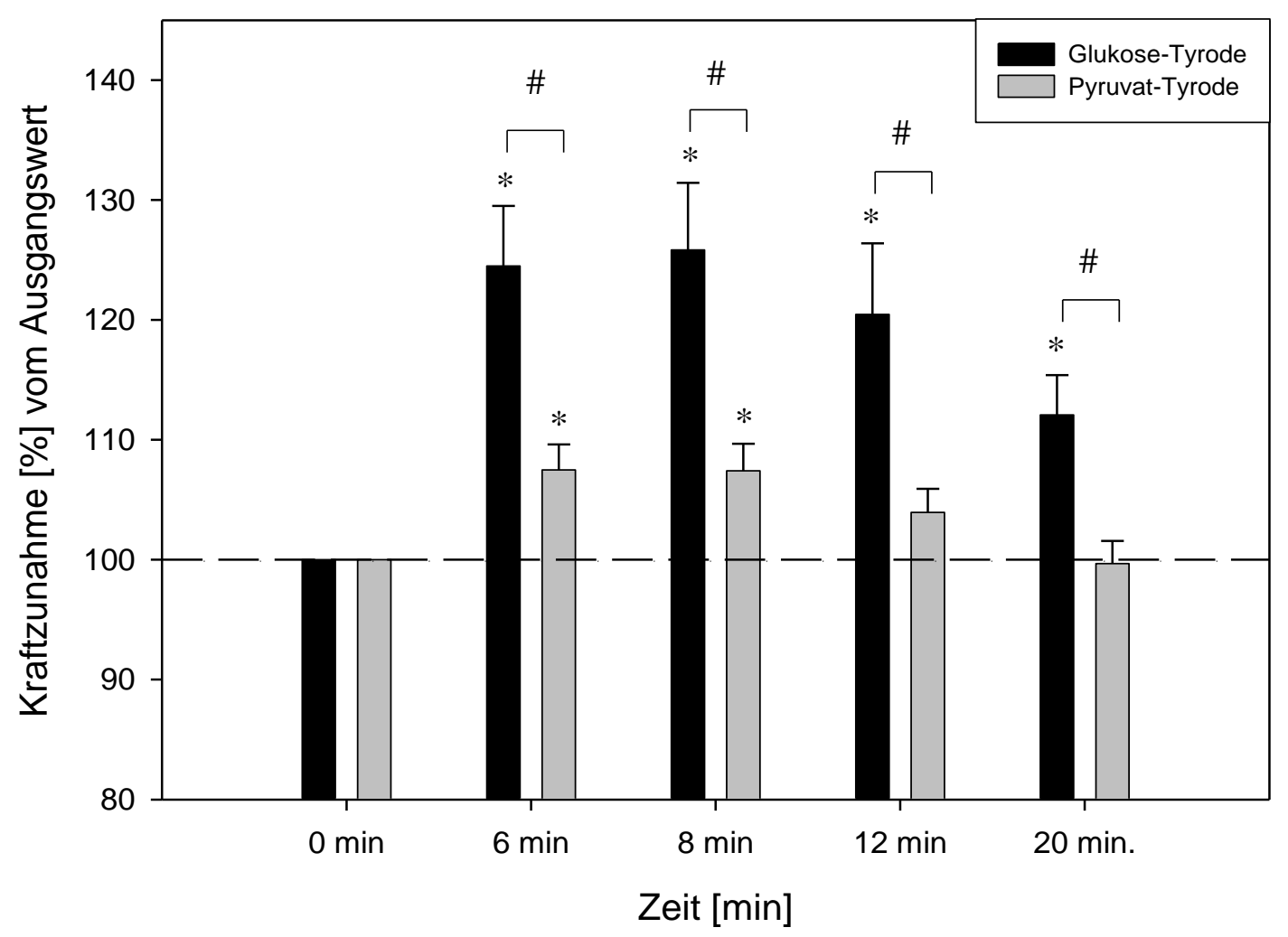

Abb. 5: Abhängig von den unterschiedlichen Energiesubstraten zeigen 3 I.E./l Insulin eine geringere Kraftzunahme in Pyruvat-Tyrode im Vergleich zu Glukose-Tyrode (GlukoseTyrode $n=9$; Pyruvat-Tyrode $n=7$ ).

Nachfolgend wurden Experimente mit geringeren Dosen (0,3 I.E./l) von Insulin in GlukoseTyrode und Pyruvat-Tyrode durchgeführt.

Beide Gruppen zeigen einen kinetisch ähnlichen Verlauf wie bei höheren Insulinkonzentrationen. Die Reduktion der Insulinkonzentration bewirkt in der GlukoseGruppe eine Reduktion des insulinbedingten Kraftanstieges. Das Maximum von $12 \pm 1,4 \%$ liegt bei sechs Minuten.

Die maximale Kraftzunahme der Pyruvat-Gruppe wird durch die Verringerung der Insulinkonzentration nur gering beeinflusst. Das Maximum wird bei sechs Minuten nach Insulininkubation mit einem Wert von $10,5 \pm 3,1 \%$ erreicht.

Abbildung 6 zeigt die Ergebnisse für Glukose-Tyrode und Pyruvat-Tyrode bei einer Konzentration von 0,3 I.E. Insulin pro Liter. Insulin bewirkt sowohl in Glukose- als auch in Pyruvat-Tyrode einen signifikanten Anstieg der Kontraktionskraft. Es zeigt sich jedoch anders als bei Verwendung höherer Insulin-Dosen kein Unterschied zwischen den beiden Gruppen. 


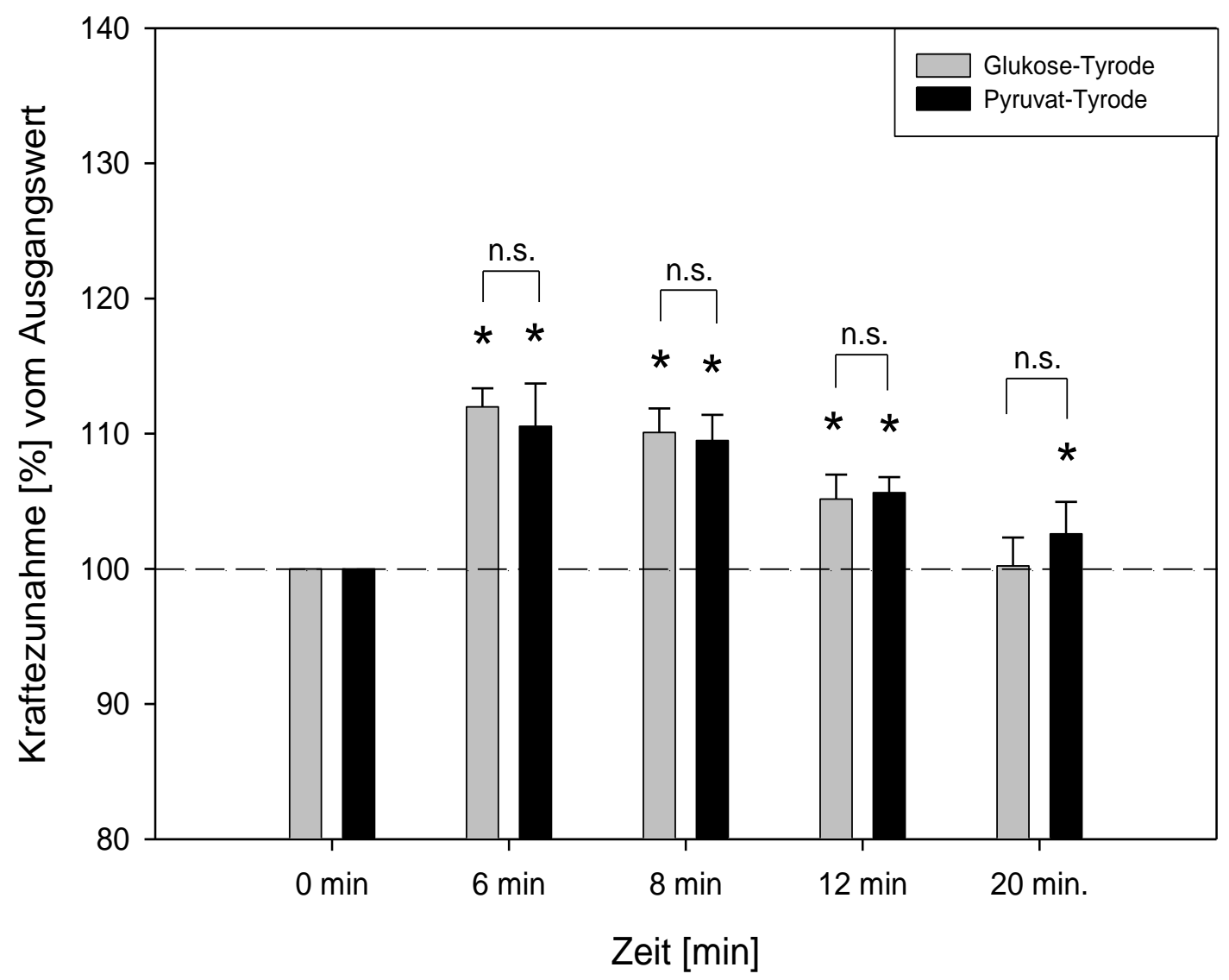

Abb. 6: Durch die geringere Insulinkonzentration (0,3 I.E./1) zeigt sich in beiden Gruppen eine geringere, allerdings noch signifikante Kraftzunahme im Vergleich zum Ausgangswert (je $n=4)$.

\subsubsection{Kraftentwicklung in $5 \mathrm{mmol} / \mathrm{l}$ Glukose-Tyrode}

Um eine mögliche Subtratabhängigkeit des Effektes von Insulin weiter zu charakterisieren, wurden Experimente mit einer geringeren Glukose-Konzentration von $5 \mathrm{mmol} / \mathrm{l}$ durchgeführt. Nach Zugabe von 3 I.E./l Insulin ( $n=4)$ zeigte sich eine signifikante Kraftzunahme von 46,51 $\pm 17,61 \%$.

Dies wurde wiederum einer geringeren Insulinkonzentration von 0,3 I.E./l $(\mathrm{n}=2)$ gegenübergestellt. Dort zeigte sich ein tendenzieller Kraftanstieg von 25,94 $\pm 24,06 \%$. Aufgrund der kleinen Anzahl wird kein signifikanter Anstieg erreicht. Auch der Test beider Gruppen gegeneinander ist nicht signifikant (Abb.7). Die kontraktile Antwort ist aber vergleichbar mit den Untersuchungen in der Standard-Glukose-Tyrode (siehe 3.1.4). 


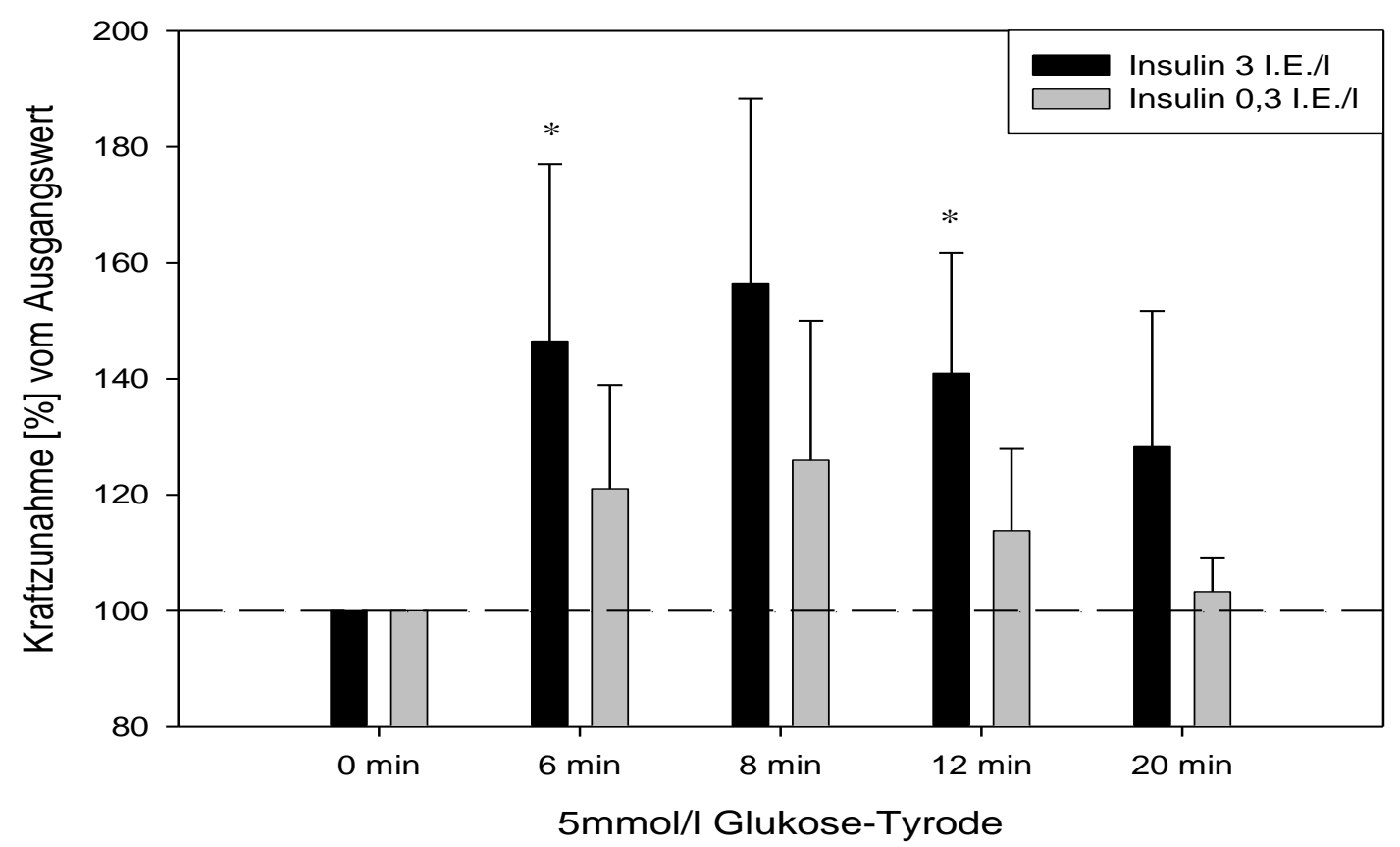

Abb. 7: In einer Tyrode mit geringerer Glukose-Konzentration $(5 \mathrm{mmol} / \mathrm{l})$ zeigt sich nach Zugabe von 3 I.E./l Insulin $(n=4)$ eine signifikante Kraftzunahme und nach Inkubation mit 0,3 I.E./l $(n=2)$ eine tendenzielle Kraftzunahme.

\subsubsection{Kraftentwicklung nach Hemmung der Glykolyse}

Durch die Inkubation der Muskeln mit Iodacetet kann die Glykolyse blockiert werden. So kann in der Folge überprüft werden, ob die durch Insulin vermittelte Kraftsteigerung durch eine Aktivierung der Glykolyse stattfindet. Die Untersuchung gestaltete sich schwierig, da ein relevanter Anteil der Muskeln nach Zugabe von Iodacetat in Kontraktur ging und für Messungen nicht mehr verwertbar war. Bessere Untersuchungsergebnisse ließen sich durch geringere Glukose-Konzentrationen in der Tyrode erreichen. Daher wurden alle Muskeln mit der geringeren Glukose-Konzentration von $5 \mathrm{mmol} / \mathrm{l}$ gemessen. Aufgrund der Kontrakturen konnten in diesem Protokoll nicht Muskeln aus identischen Herzen direkt gegeneinander gemessen werden. Die Kontrollen sind aus anderen Versuchsreihen gepoolt worden. Aufgrund der geringen Anzahl der Kontrollen ( $n=4)$ kann zwar festgestellt werden, dass die positiv inotrope Antwort nach Blockade der Glykolyse mit einem Kraftanstieg von 8,72 \pm 2,89\% zwar signifikant zunimmt, aber kein signifikanter Unterschied zu den Kontrollen besteht, obwohl diese eine Kraftzunahme von 51,63 \pm 9,98\% zeigen. Der tendenzielle Unterschied zeigt sich in der Abbildung 8. 


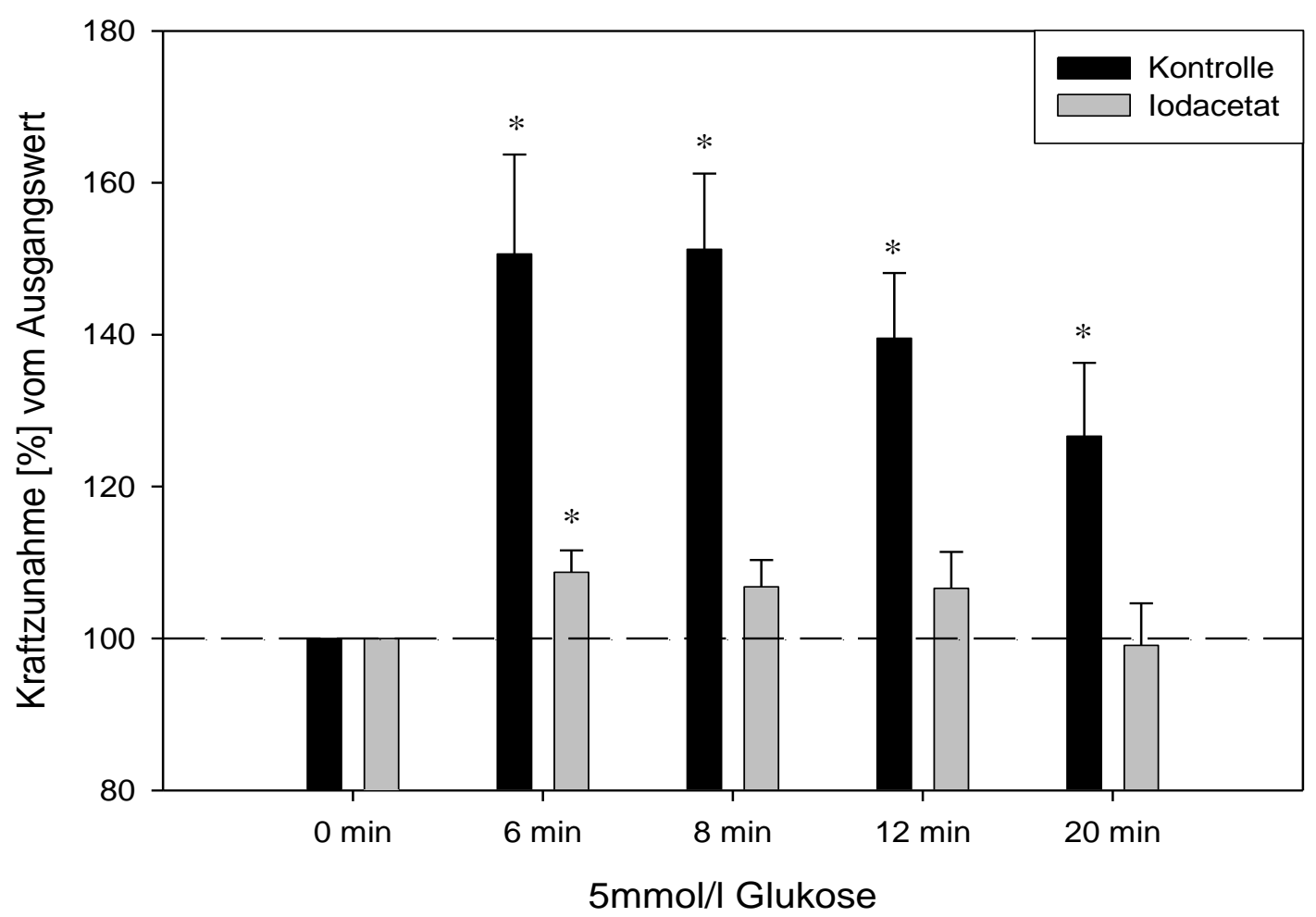

Abb. 8: Messung der Kraftzunahme bei Verwendung von 3 I.E./l Insulin in $5 \mathrm{mmol} / \mathrm{l}$ Glukose-Tyrode. Die Kontrollen ( $\mathrm{N}=4$, gepoolt) zeigen eine signifikante Kraftzunahme nach Inkubation mit Insulin. Nach Blockade mit Iodacetat $(n=6)$ ist die Kraftzunahme tendenziell geringer. Aufgrund der geringen Anzahl an Kontrollen wird kein signifikanter Unterschied erreicht.

\subsubsection{Einfluss von Insulin auf die SR-Kalziumbeladung}

Die folgenden Untersuchungen richten ihr Augenmerk auf den Kalziumstoffwechsel des Präparates.

Messprotokoll dieses Teils waren die schnellen Kühlungskontrakturen (RCC; rapid cooling contrature, siehe 2.5) in Glukose-Tyrode und Inkubation mit 3 I.E. Insulin pro Liter. Abbildung 9 zeigt einen Originalmitschrieb von zwei schnellen Kühlungskontrakturen (RCC 1 und RCC 2), jeweils vor und nach Inkubation mit 3 I.E./1 Insulin.

Abbildung 10 repräsentiert die quantitative Zusammenfassung mehrerer Einzelexperimente. $\mathrm{Zu}$ sehen ist ein signifikanter Kraftzuwachs von 47,1 $\pm 8 \%$. Parallel zu dem Kraftanstieg nimmt die SR-Kalizumbeladung, repräsentiert durch die erste RCC (RCC 1), um 14,5 \pm 4,9 \% signifikant zu. Es wurde im Anschluss eine zweite Kühlungskontraktur (RCC 2) durchgeführt, um die Kalziumaufnahme in das SR zu quantifizieren, dabei ist ein tendenzieller Kraftanstieg um 9,2 \pm 7,2 \% im Vergleich zur Ausgangskraft zu beobachten. 


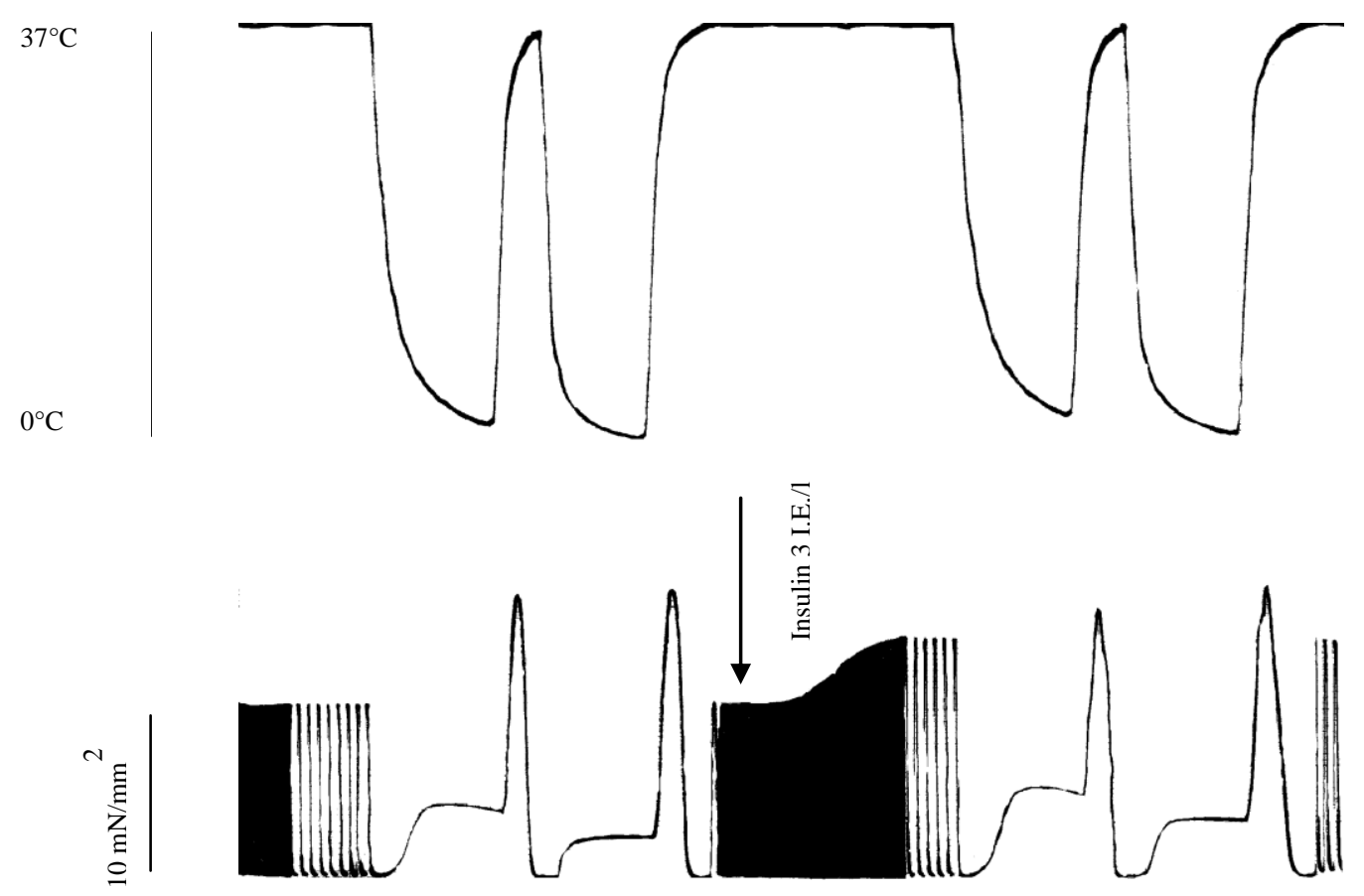

Abb. 9: Originalregistrierung an der schnellen Kühlungskontrakturanlage. Die obere Schreiberspur ist eine Registrierung der Temperatur. Die untere Spur zeigt die entwickelte Kraft des Muskelstreifens. Nach Inkubation mit 3 I.E./l Insulin ist sowohl eine Kraftzunahme als auch eine Zunahme der Kühlungskontrakturen (RCC) 1 und 2 zu erkennen.

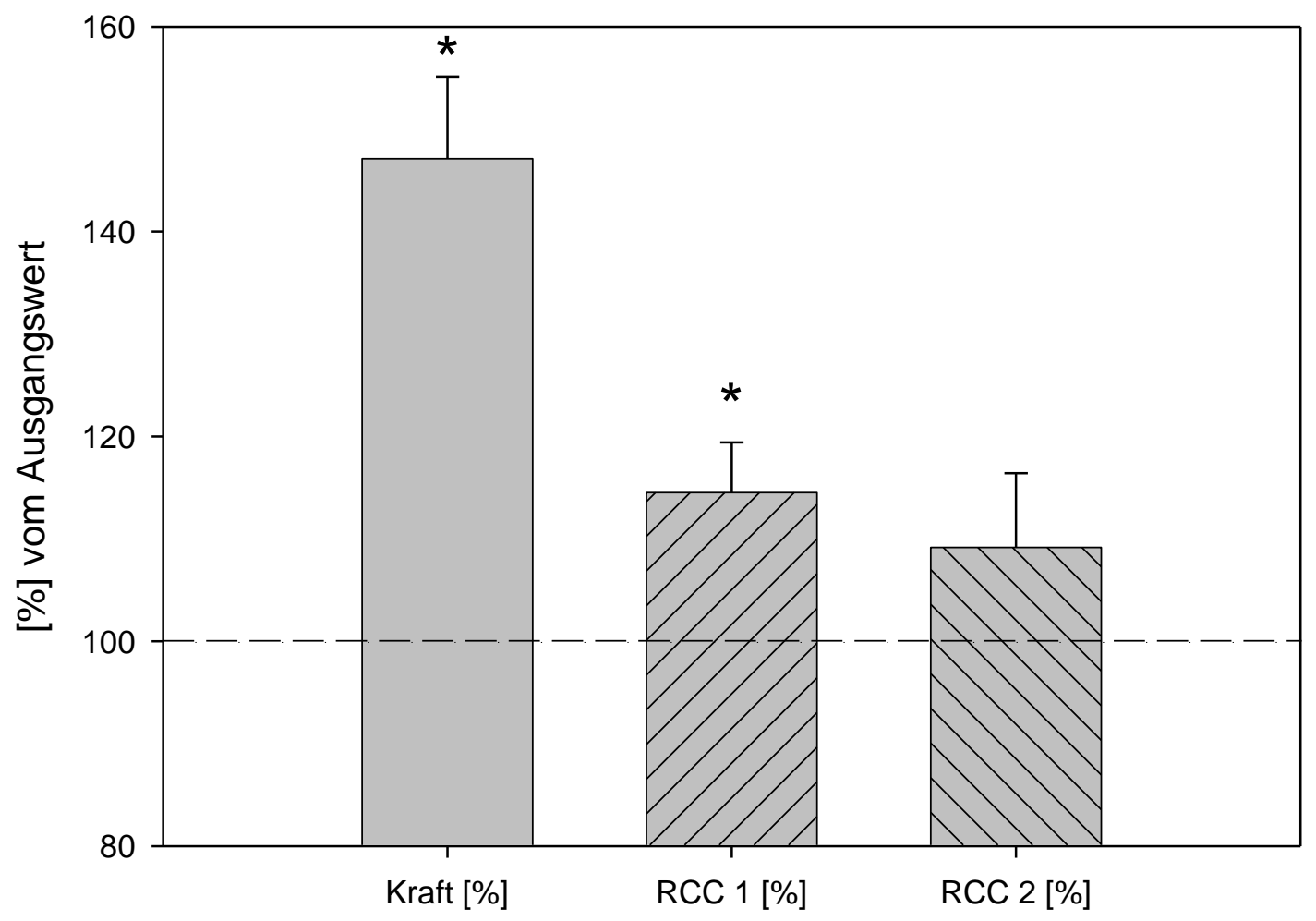

Abb. 10: Nach Zugabe von 3 I.E. Insulin pro Liter nimmt sowohl die Kontraktionskraft als auch die SR-Kalziumbeladung zu $(\mathrm{n}=8)$. 
In dem gleichen Messprotokoll wurde die Glukose-Tyrode durch Pyruvat-Tyrode ersetzt und die Muskelstreifen mit 3 I.E./l Insulin inkubiert (Abb. 11). Nach Inkubation zeigt sich ein Kraftanstieg von 13,6 \pm 3,2 \%. Die Kühlungskontraktur 1 (RCC1) nimmt um $13 \pm 4,6 \%$ signifikant ab. Die zweite Kühlungskontraktur zeigt eine tendenzielle Verringerung um 11,4 \pm 7,8 \% im Vergleich zur Ausgangskraft.

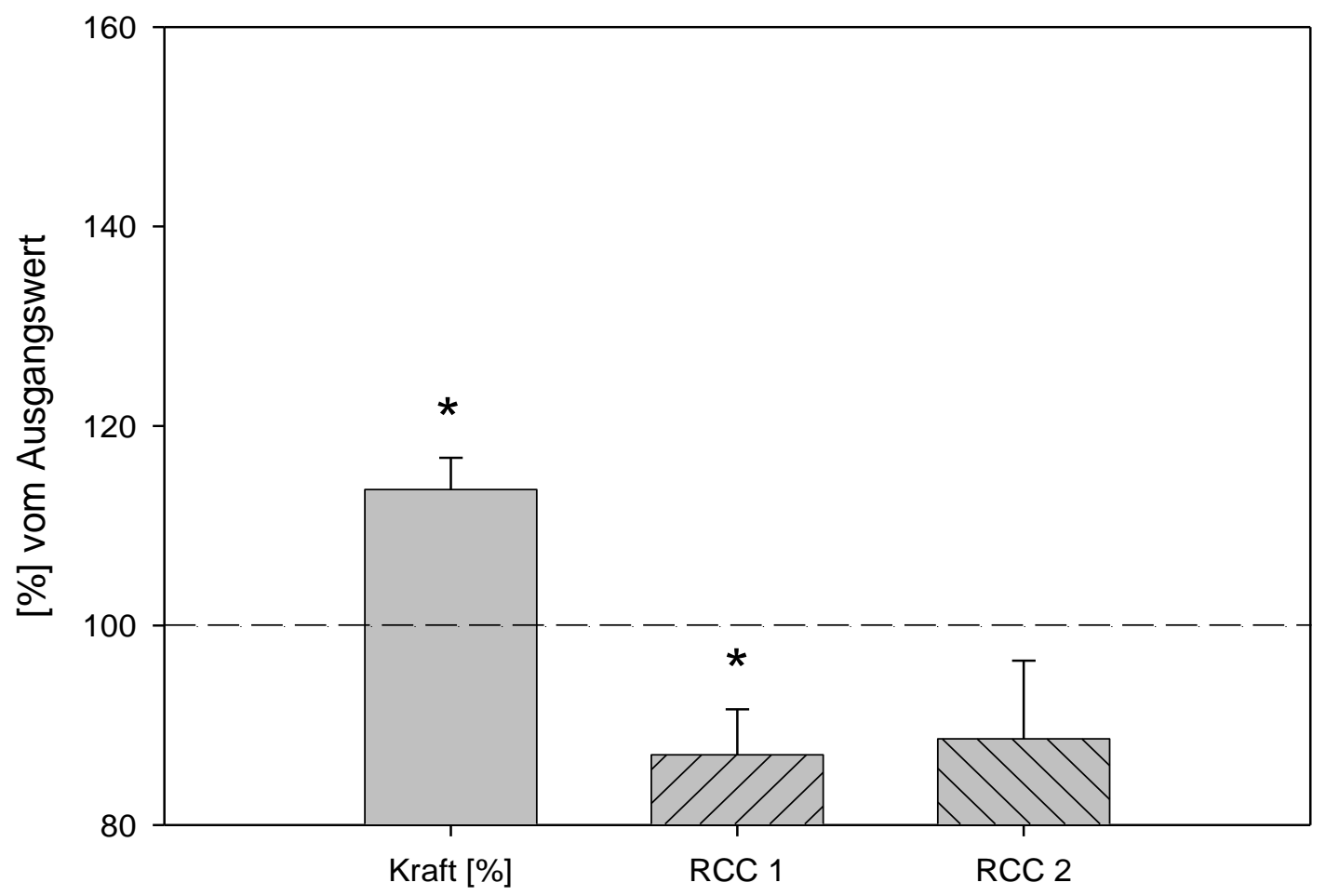

Abb. 11: Intervention mit Insulin (3 I.E./l) in Pyruvat-Tyrode zeigt eine positive Inotropie und eine parallele Abnahme des SR-Kalziumgehaltes $(n=6)$.

\subsubsection{Einfluss von Insulin auf die Kraftentwicklung unabhängig vom SR-Kalziumgehalt}

Nach den oben beschriebenen Protokollen mit Schwerpunkt auf den Kalziumstoffwechsel des Sarkoplasmatischen Retikulums (SR) wurde nun ein Messprotokoll mit vollständiger SRBlockade durchgeführt (siehe 2.5.1). Dazu wurden die Muskeln mit CPA (Cyclopiazonsäure) und Ryanodin vorinkubiert.

Abbildung 12 ist eine Zusammenfassung der Einzelexperimente mit SR-Blockade. Trotz blockiertem SR ist nach Zugabe von 3 I.E./l Insulin ein signifikanter Kraftanstieg um 22,7 \pm 6,5 \% vom Ausgangswert $100 \%$ zu beobachten, wobei der Kraftzuwachs in der Kontrollgruppe 47,1 $\pm 8 \%$ beträgt. Damit verringert sich durch die Blockade des SR die Kraftzunahme signifikant um $52 \%$ gegenüber der Kontrolle. 
Durch die funktionelle Blockade des SR sind keine Kühlungskontrakturen mehr nachzuweisen.

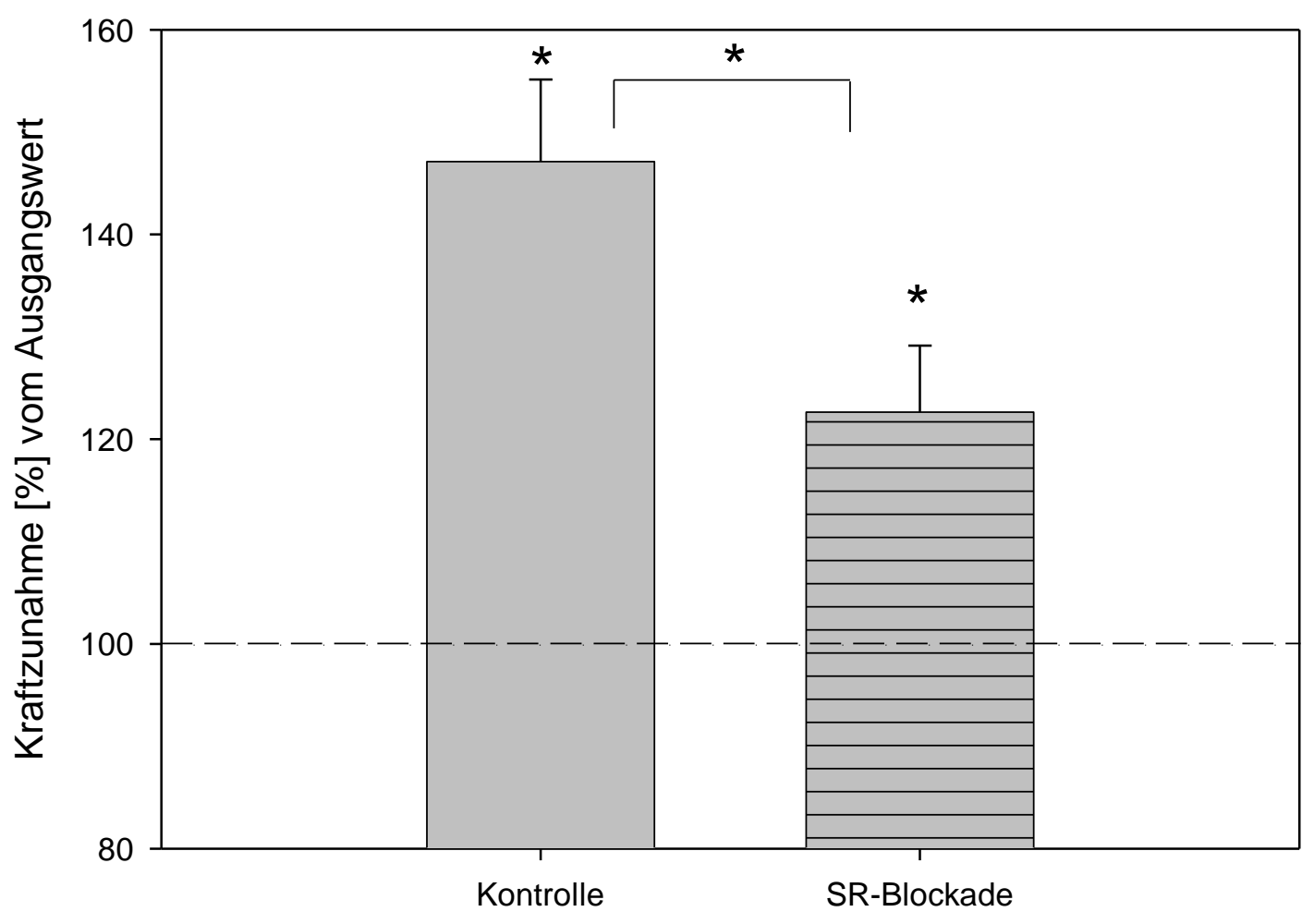

Abb. 12: Zusammenfassung mehrerer Einzelexperimente ohne $(n=8)$ und nach $(n=6)$ SRBlockade, zeigt ein um $52 \%$ verringerten Kraftanstieg nach Insulinzugabe (3 I.E./l).

\subsubsection{Wirkung von Insulin auf intrazelluläre Kalziumtransienten}

Grundlage dieser Ergebnisse waren Untersuchungen an der Aequorinanlage (siehe 2.6).

Abbildung 13 zeigt auf der linken Hälfte die Registrierung der Kontraktionskraft von zwei Stimulationen vor und nach Inkubation mit 3 I.E./l Insulin. Die rechte Hälfte zeigt den entsprechenden intrazellulären Kalziumtransienten, welcher mittels Aequorin gemessen wurde. Die roten Kurven repräsentieren deutlich die Zunahme von Kraft und Kalziumtransienten nach Zugabe von Insulin.

Abbildung 14 zeigt eine Originalregistrierung eines Aequorin-Versuches. Die obere Schreiberspur entspricht den aufgezeichneten Aequorinsignalen und ist den intrazellulären Kalziumtransienten gleichzusetzen. Die untere Spur ist eine parallel dazu geführte Aufzeichnung der isometrischen Kontraktionskraft, die ihr Korrelat in der Amplitude des Balkens findet. 

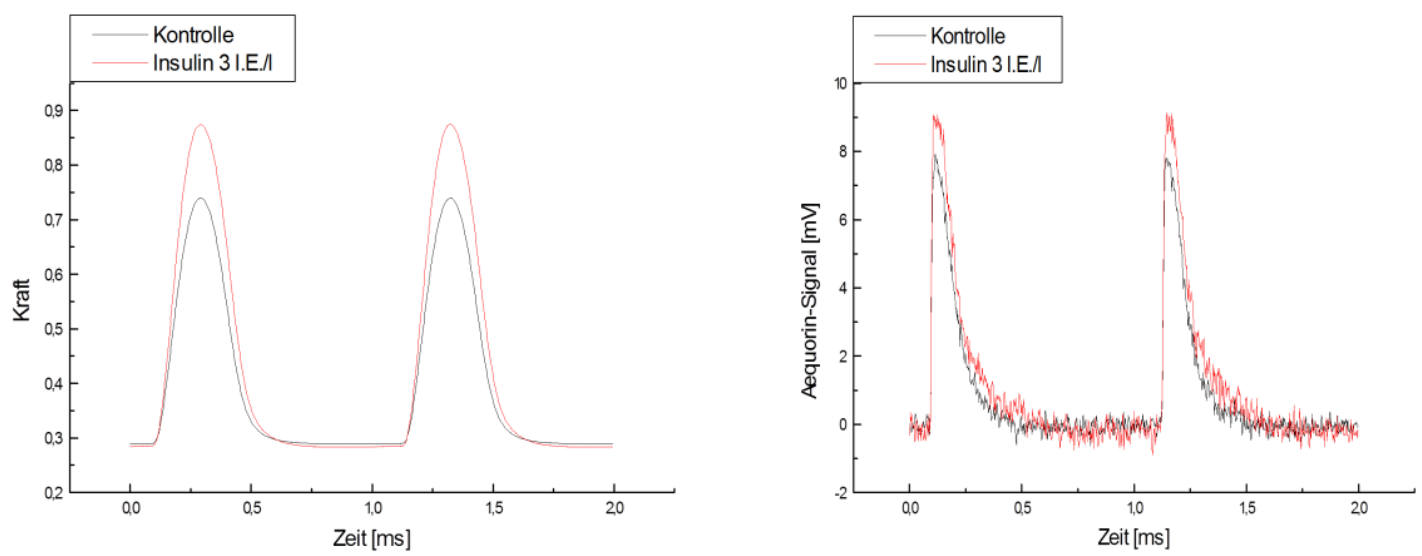

Abb. 13: Jeweils zwei Einzelkontrakturen eines Muskelstreifenpräparates vor und nach Inkubation mit 3 I.E./l Insulin. Die linke Grafik zeigt die Kontraktionskraft, die rechte Grafik die ensprechenden Kalziumtransienten.
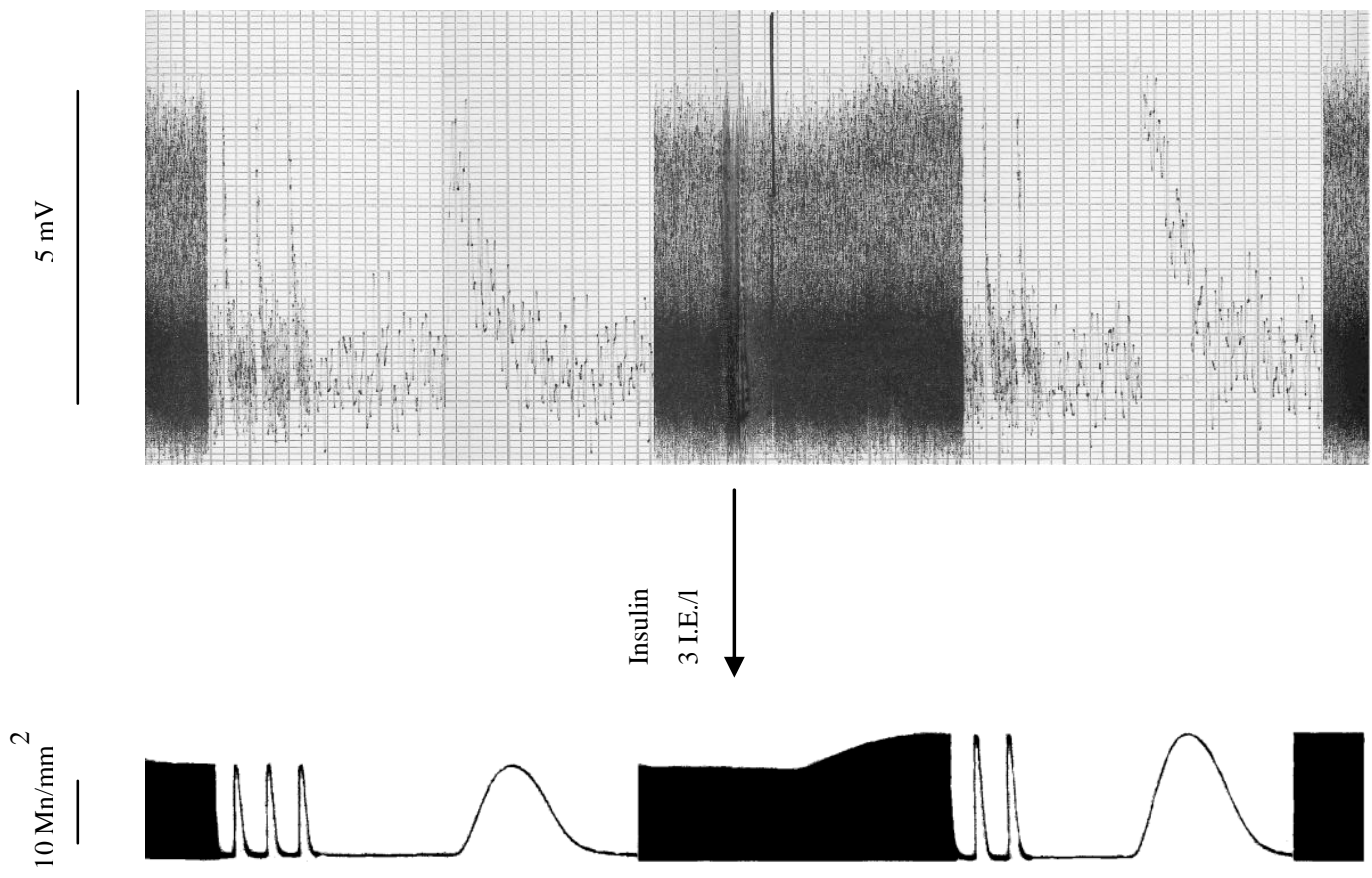

Abb. 14: Abgebildet ist einen Originalregistrierung der Aequorinanlage. Die obere Schreiberspur zeigt das Aequorinsignal, die untere Schreiberspur die isometrische Kontraktionskraft. Nach Insulinzugabe ist sowohl ein Anstieg der Kontraktionskraft als auch ein Anstieg des Aequorinsignals zu erkennen. 
Abbildung 15 ist eine quantitative Zusammenfassung mehrerer Aequorin-Einzelexperimente. Die Inotropie nimmt nach der Intervention mit 3 I.E. Insulin/l um $29 \pm$ 4,6 \% zu. Parallel ist ein Anstieg des Aequorin-Signals um 15,9 $\pm 3,6 \%$ zu erkennen.

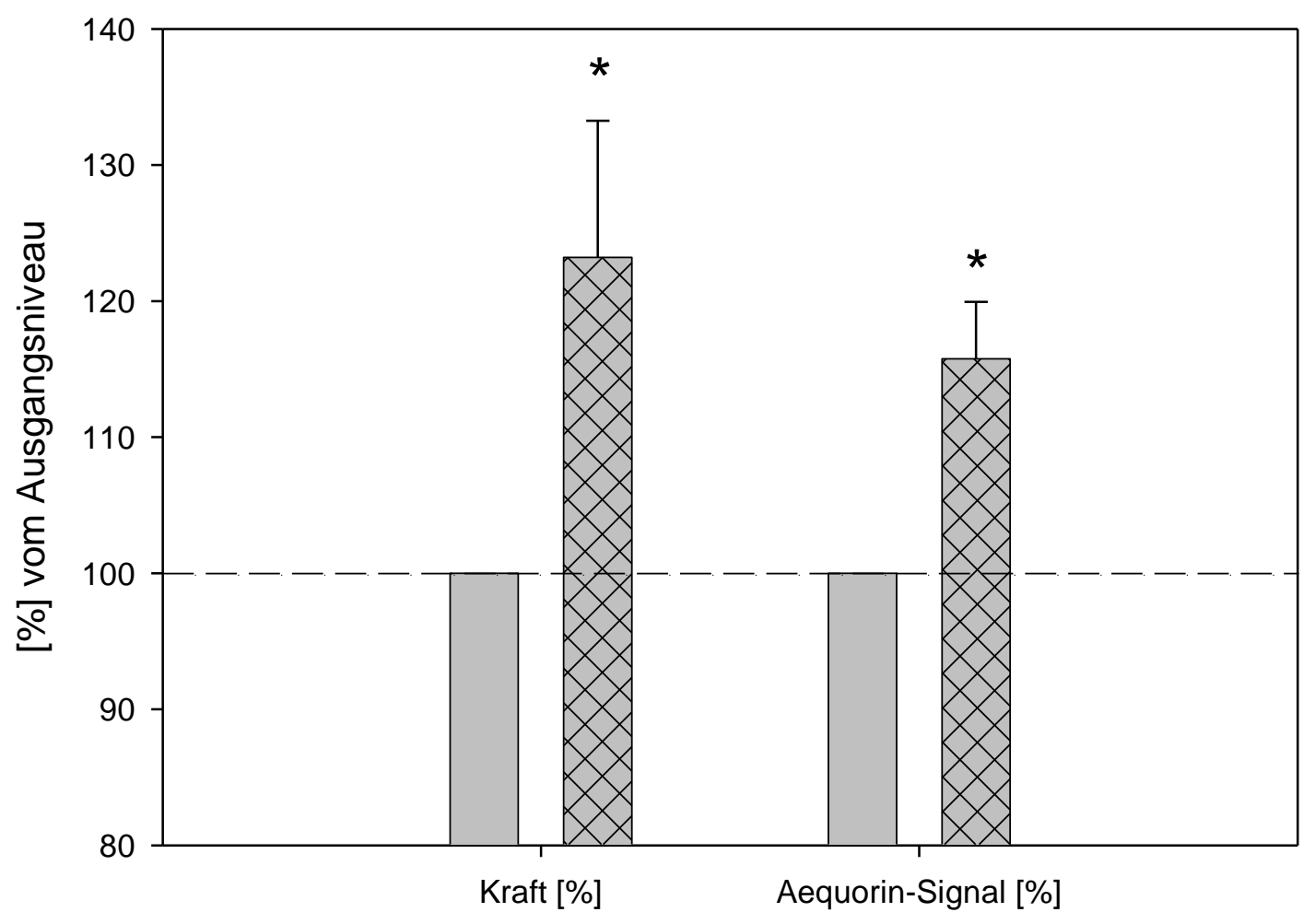

Abb. 15: Dargestellt sind die Kontraktionskraft sowie das Aequorin-Signal. Die Darstellungen beziehen sich jeweils auf die Signale vor Inkubation mit 3 I.E./l Insulin (grau) als auch auf die Signale nach Insulininkubation (grau-gestreift) $(n=5)$.

\subsubsection{Untersuchung potentieller Signaltransduktionswege}

Die Ergebnisse der folgenden Untersuchungen stützen sich auf die in Kapitel 2.4.6 beschriebenen Messprotokolle und stellen eine Untersuchung der potentiellen Signaltransduktionswege von Insulin im Myozyten dar. Die Abbildungen dazu werden funktionell in membranständige- und intrazelluläre Signalwege unterteilt werden.

So wird durch Zugabe von IGF-1-RA der membranständige IGF-1 Rezeptor blockiert, durch KBR der membranständige NCX und durch Diltiazem findet eine Blockade des L-Typ-Ca ${ }^{2+}$ Kanals statt (Abb.16).

Wortmannin (Blockade $\mathrm{PI}_{3}$-Kinase), GF109203x (Blockade der Proteinkinase C) und der DAG-Kinase-Inhibitor blockieren intrazelluläre Signaltransduktionswege (Abb. 17). 


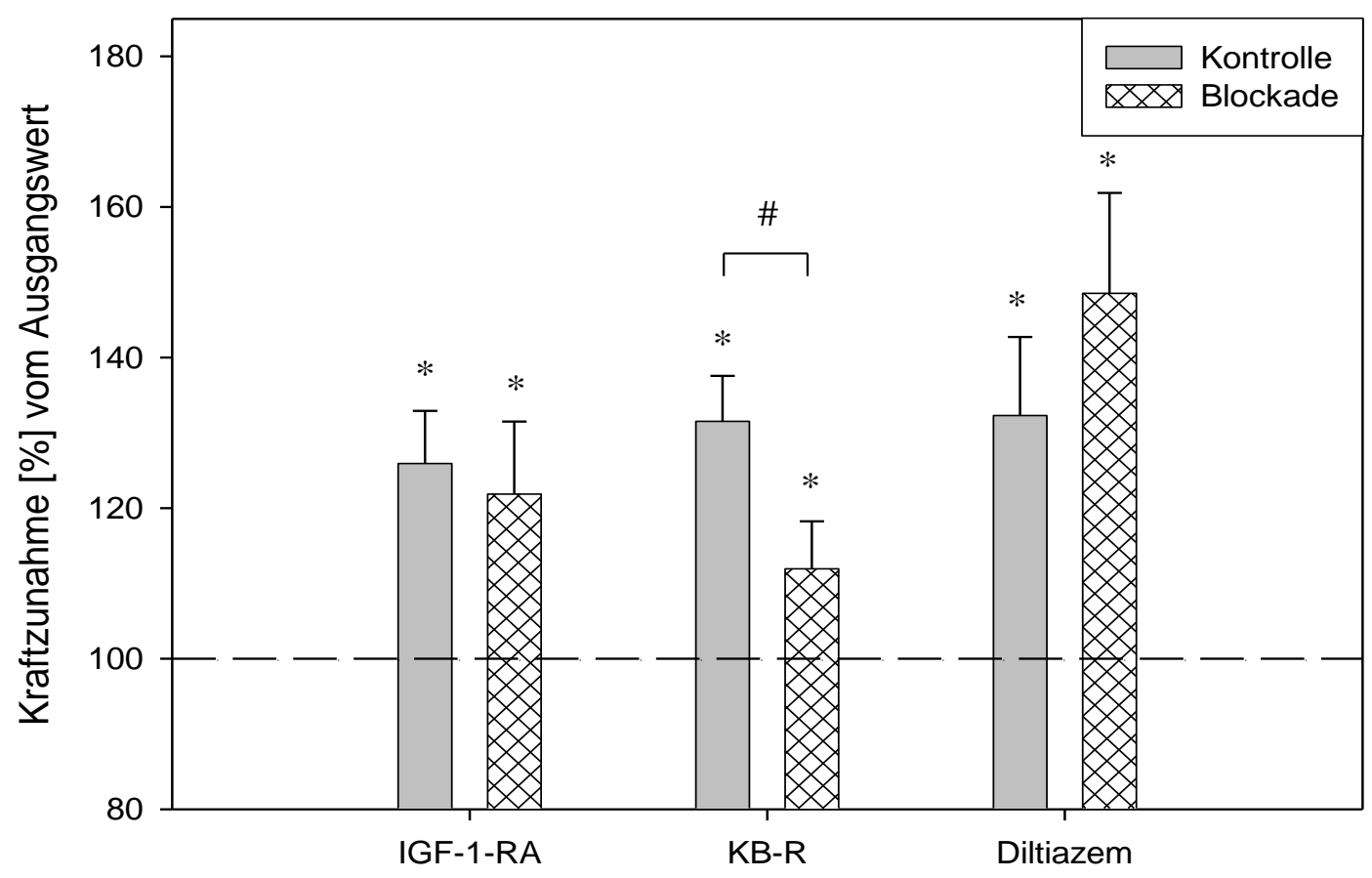

Abb. 16: Dargestellt ist die Kranftzunahme nach Inkubation mit 3 I.E./l Insulin, mit und ohne Blockade membranärer Signaltransduktionswege durch den jeweiligen Hemmstoff. Aufgetragen sind die Kontrollmuskeln im Vergleich zur Interventionsgruppe.

Die Blockade des IGF-1 Rezeptors (mittels IGF-1-RA, n=9), der Proteinkinase C (durch GF 109203X, n=7), DAG-Kinase (DAG-Kinase-Inhibitor, $\mathrm{n}=5$ ) sowie des L-Typ-Ca ${ }^{2+}$-Kanals (Diltiazem, $n=4$ ) zeigen keinen Effekt auf die durch Insulin hervorgerufene Kontraktionskraftzunahme.

Die Blockade des reverse mode des NCX durch KB-R $(n=9)$ reduziert die insulinbedingte Kraftzunahme. So zeigen die mit KB-R vorinkubierten Muskeln nach Insulingabe eine signifikant geringere Kraftzunahme von 11,9 $\pm 6,3 \%$, die Kontrollmuskeln aus dem selben Herzen eine Zunahme von $31,5 \pm 6,0 \%$.

Die Blockade der $\mathrm{PI}_{3}$-Kinase mittels Wortmannin $(\mathrm{n}=7)$ zeigt eine Abnahme der Kontraktionskraftsteigerung. So nimmt die Kraft der mit Wortmannin vorbehandelten Muskeln nur um 8,1 $\pm 2,0 \%$ zu. Die entsprechenden Kontrollmuskeln aus dem gleichen Herzen zeigen dagegen eine Kraftsteigerung um 30,4 \pm 7,5\%. Der Unterschied der Kraftzunahme ist signifikant.

Insgesamt lässt sich daraus schließen, dass Insulin am Myokard einen intrazellulären $\mathrm{PI}_{3}$ Kinase- und einen membranständigen NCX- vermittelten Signaltransduktionsweg hat. 


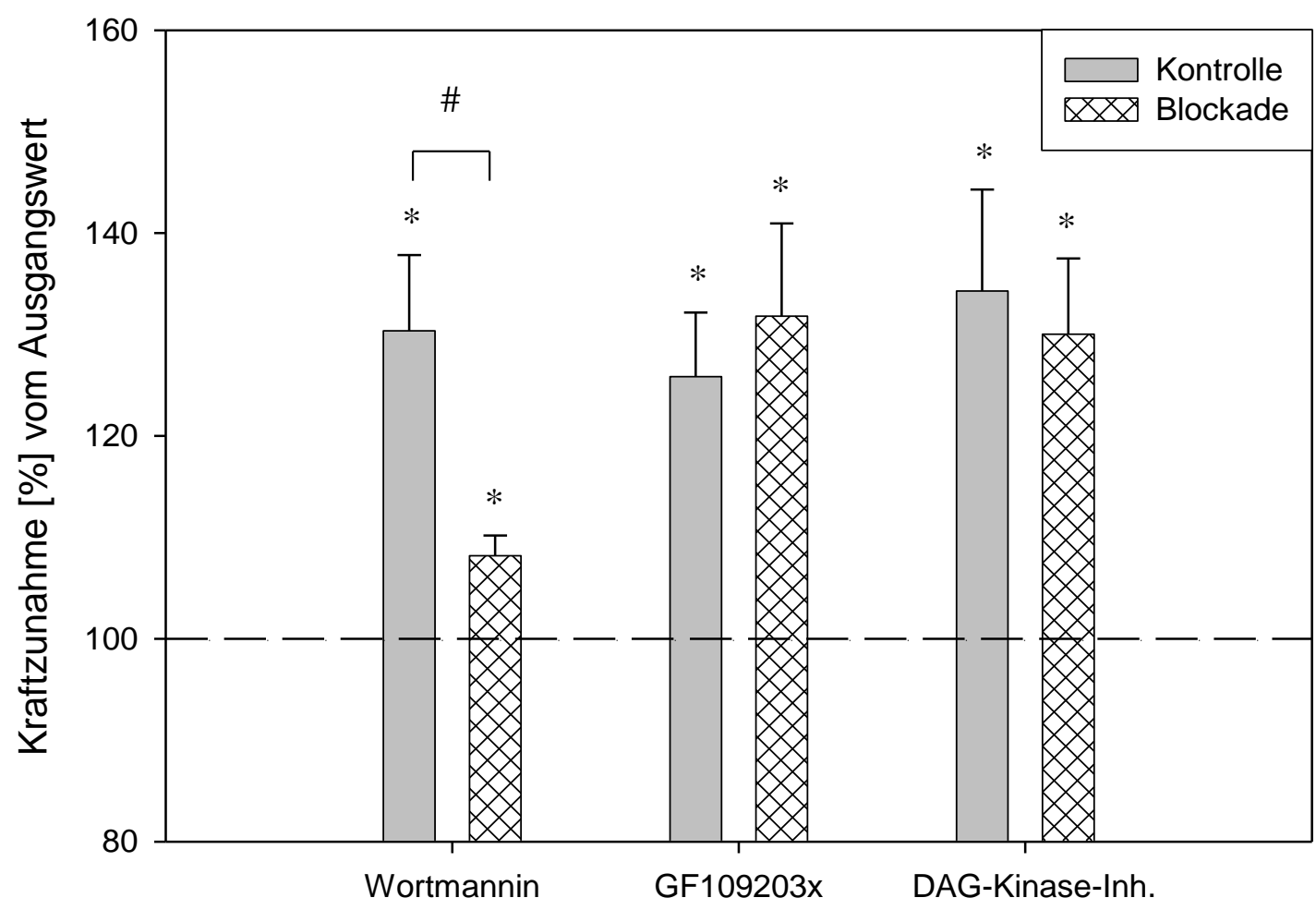

Abb. 17: Dargestellt sind die Ergebnisse der Blockade intrazellulärer Signaltransduktionswege von Insulin. Es sind jeweils die Kontrollmuskeln gegen die mit dem entsprechenden Hemmstoff vorinkubierten Muskeln aufgetragen.

\subsection{Ergebnisse am Kaninchenmyokard}

\subsubsection{Insulin-Einzeldosisexperimente}

Die Muskeln wurden zunächst in Glukose-Tyrode inkubiert. Zum Zeitpunkt 0 min wurden 3 I.E. Insulin/l zugegeben. Die anschließende Kontraktionskraftänderung wurde gegen die Zeit aufgetragen. Nach Applikation von Insulin zeigt sich eine signifikante Kraftabnahme bei 6 min nach Inkubation am Kaninchenmyokard. Dieser Effekt nimmt zwischenzeitlich leicht ab, um dann bei 20 min wieder signifikant vermindert zu sein (Abb. 18).

Nach Inkubation der Muskelstreifen mit 3 I.E. Insulin/l in Pyruvat-Tyrode zeigt sich ein signifikanter Abfall der Kontraktionskraft bereits nach 6 min. Dieser Effekt hält bis zum Ende des Versuchsprotokolls bei 20 min an (Abb.19). 


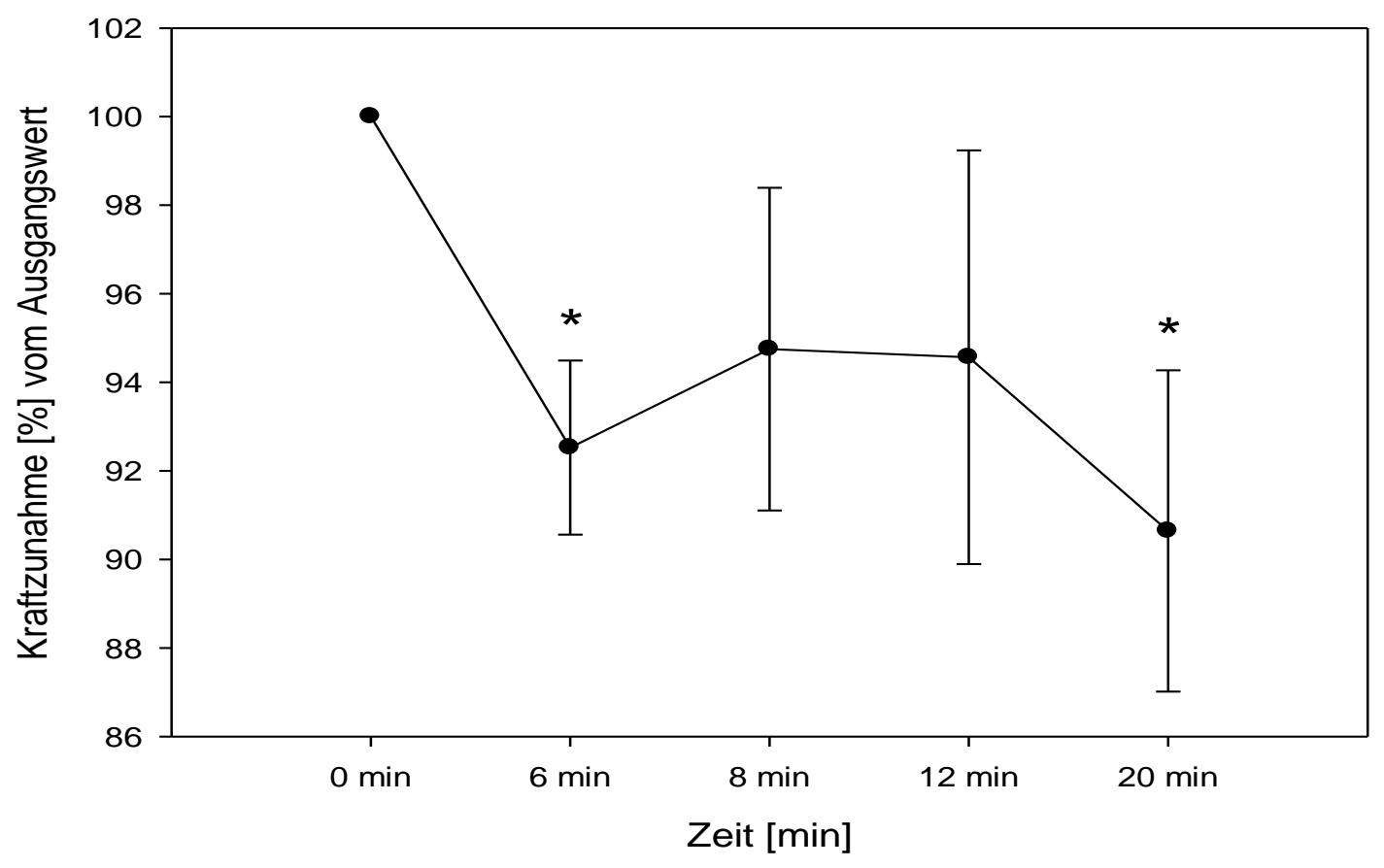

Abb. 18: Zeitlicher Verlauf der Kraftentwicklung am Kaninchenmyokard nach Inkubation mit 3 I.E. Insulin/l in Glukose-Tyrode $(n=6)$.

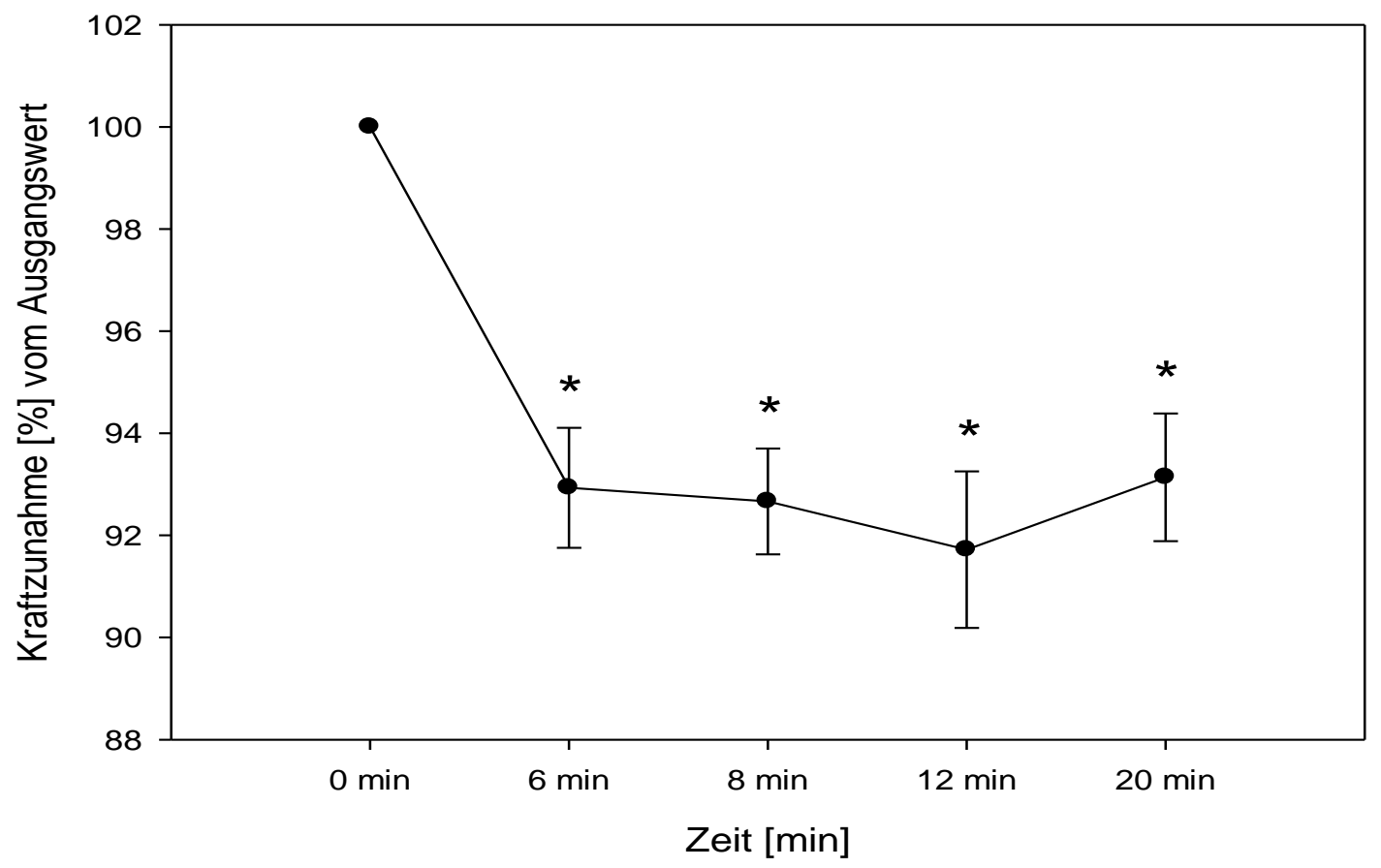

Abb. 19: Zeitlicher Verlauf der Kraftentwicklung am Kaninchenmyokard nach Inkubation mit 3 I.E. Insulin/l in Pyruvat-Tyrode ( $n=7)$. 


\subsubsection{Insulin-Dosis/Wirkungskurve}

Abbildung 20 zeigt den Effekt einer kumulativen Insulinerhöhung in Glukose-Tyrode. Die Menge an Insulin wurde in den in der x-Achse dargestellten Konzentrationen hochtitriert und ist halblogarithmisch gegen die Kontraktionskraft in der y-Achse aufgetragen.

Es ist festzustellen, dass die Kontraktionskraft am Kaninchenmyokard nach Applikation von Insulin in ansteigenden Dosierungen einen signifikanten Abfall hervorruft. Die Kontraktionskraft stabilisiert sich im Verlauf bei 30 I.E. Insulin/l auf Höhe des Ausgangsniveaus.

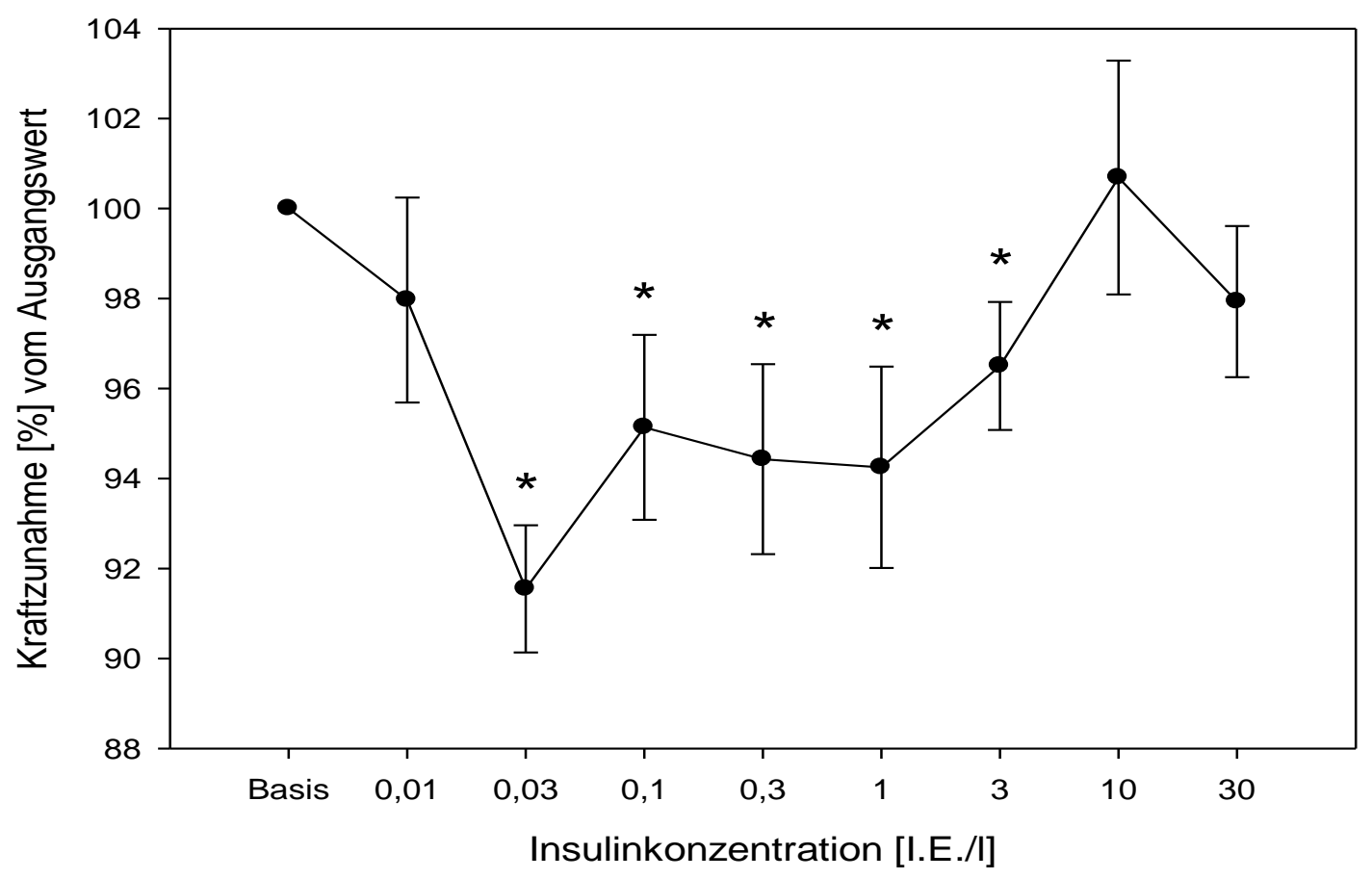

Abb. 20: Konzentrationswirkungskurve von Insulin am Kaninchenmyokard in GlukoseTyrode $(\mathrm{n}=8)$

In einem zweiten Arm wurden die Muskeln in Pyruvat-Tyrode inkubiert. Nach kumulativer Zugabe der auf der x-Achse angegebenen Insulinkonzentrationen fällt die Kontraktionskraft signifikant ab, um sich bei der Maximalkonzentration von 30 I.E.Insulin/l leicht unterhalb des Ausgangsniveaus zu stabilisieren (Abb. 21). 


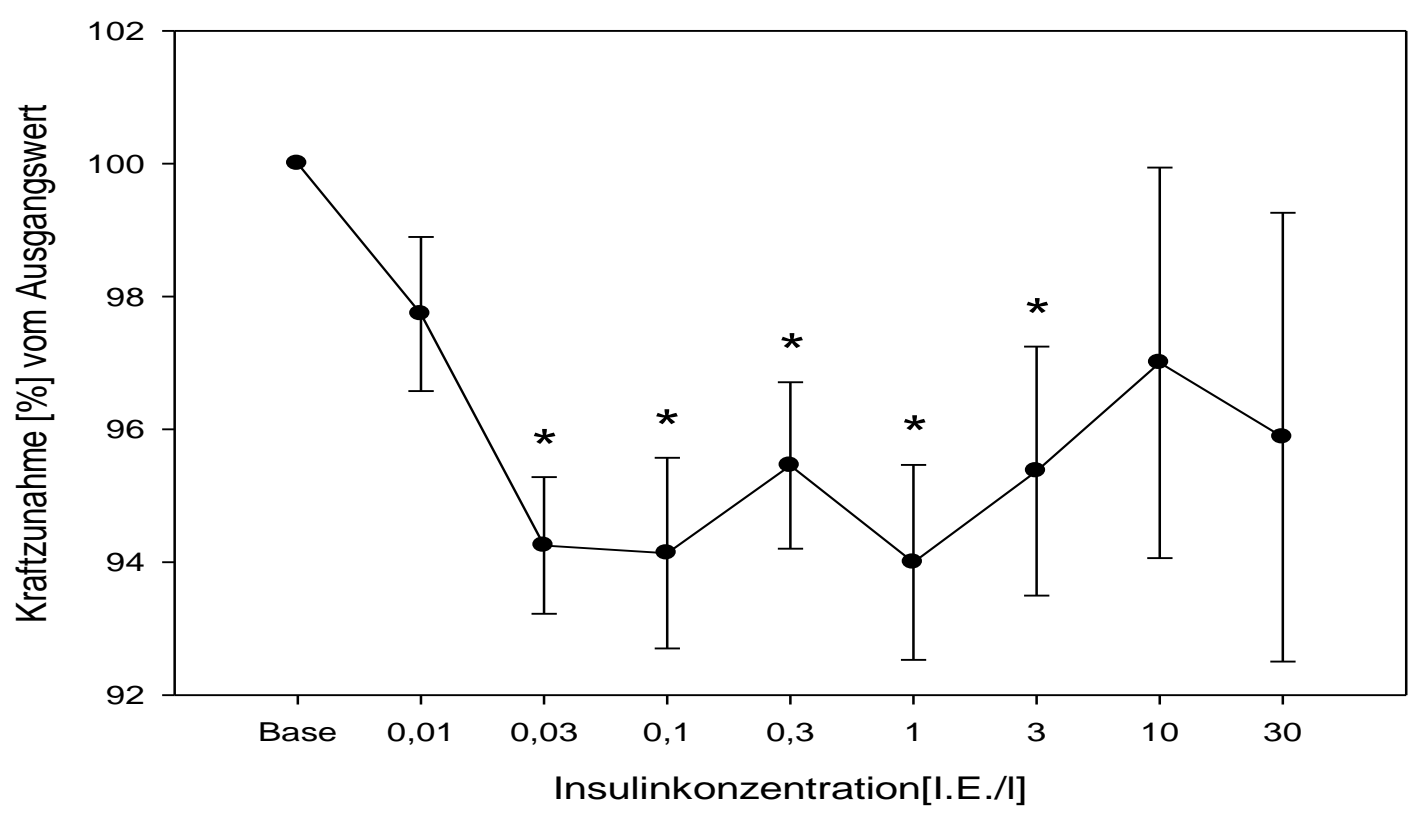

Abb. 21: Kraftentwicklung am Kaninchenmyokard abhängig von der Insulinkonzentration in Pyruvat-Tyrode $(\mathrm{n}=8)$.

\subsubsection{Einfluss von Insulin auf die SR-Kalziumbeladung}

Nach Inkubation mit 3 I.E./l Insulin zeigt sich in Glukose-Tyrode die vorbeschriebene signifikante Kraftabnahme. Durch die schnelle Kühlungskontraktur (RCC1) kann zudem eine signifikante Abnahme der SR-Kalziumbeladung gezeigt werden (Abb. 22). So beläuft sich die Kraftentwicklung auf lediglich 75,4 $\pm 6,2 \%$, die Kühlungskontraktur zeigt eine Kraftentwicklung von $83,4 \pm 4,4 \%$.

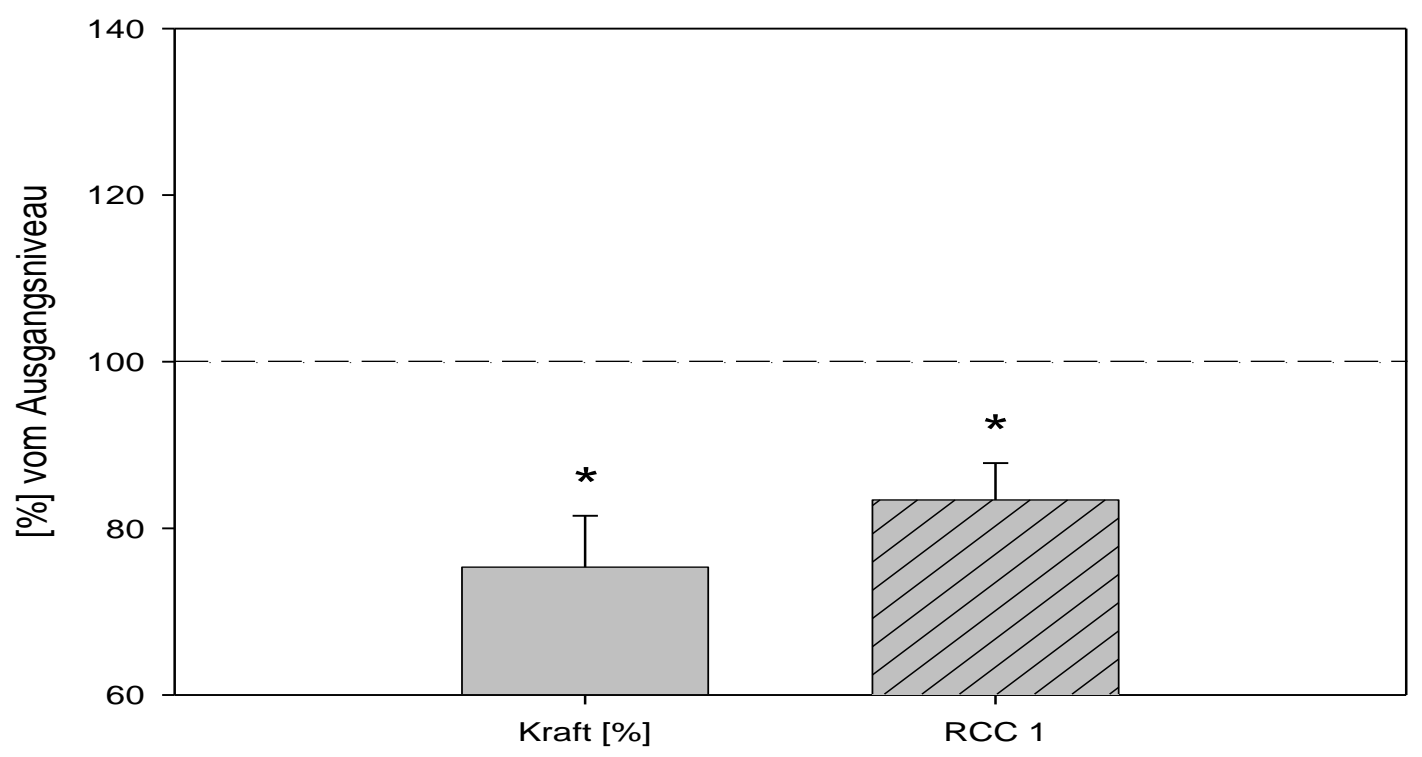

Abb. 22: Prozentuale Auftragung der Kraft und der SR-Kalziumbeladung nach Inkubation mit 3 I.E./l Insulin am Kaninchenmyokard in Glukose-Tyrode $(n=5)$. 
Auch unter Verwendung von Pyruvat-Glukose ist nach Inkubation mit 3 I.E./l Insulin am Kaninchenmyokard ein negativ inotroper Effekt nachweisbar. Im Vergleich zum Ausgangswert sinkt die Kraft auf 86,9 $\pm 2 \%$. Parallel zeigt sich auch hier eine signifikante Abnahme der SR-Kalziumbeladung (Abb. 23). Nach der Kühlungskontraktur befindet sich die Kraftentwicklung nur noch auf 81,6 $\pm 5,9 \%$ des Ausgangswertes.

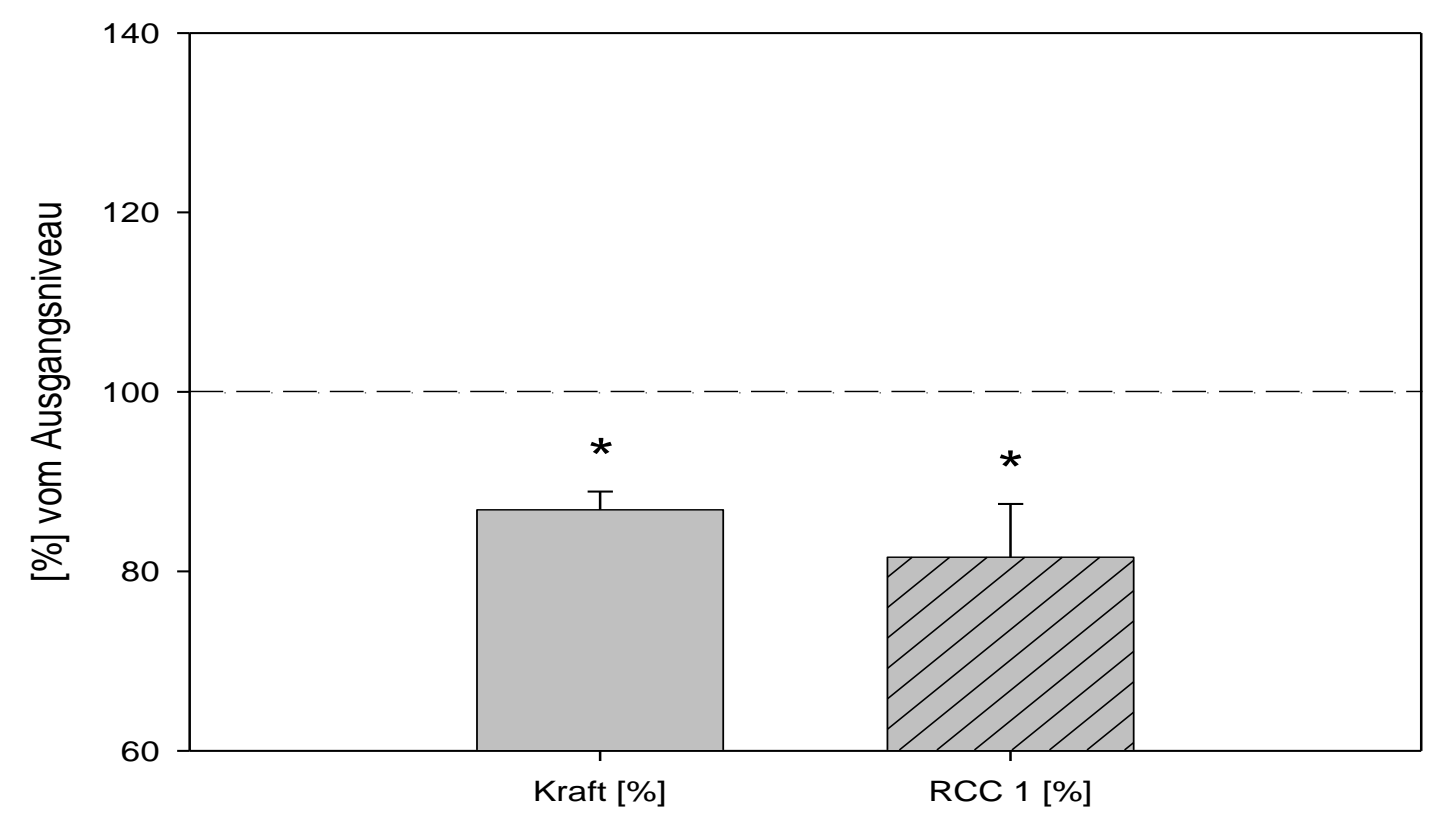

Abb. 23: Prozentulale Auftragung der Kraft und der SR-Kalziumbeladung nach Inkubation mit 3 I.E./l Insulin am Kaninchenmyokard in Pyruvat-Tyrode $(n=6)$. 


\section{DISKUSSION}

Die Verwendung ventrikulärer Muskelstreifenpräparate bietet im Vergleich zum Tiermodell eine große Anzahl an Vorteilen. Eine Limitation besteht in der begrenzten Verfügbarkeit.

Daher bedarf es zwar einer umfassenden Logistik, um diese vollständig ausnutzen zu können, andererseits erhält man so die Möglichkeit, isometrisch kontrahierende Muskeln unter normierten und konstanten Versuchbedingungen untersuchen zu können. Außerdem können die Messergebnisse im Vergleich zu In-vivo-Untersuchungen unter konstanter Vor- und Nachlast sowie Frequenz ermittelt werden. Diese Untersuchungsmethode ermöglicht des Weiteren die direkte pharmakologische Beeinflussung des sich kontrahierenden Muskels und gestattet eine direkte Untersuchung des jeweiligen funktionellen Effektes.

Ein weiterer großer Vorteil liegt in der unzureichenden Übertragbarkeit von tierexperimentell ermittelten Daten auf die Situation am humanen Myokard (Böhm et al. 1989). Wie bereits in der Einleitung angesprochen finden sich Untersuchungen von Insulin an einer Vielzahl von unterschiedlichen Spezies mit zum Teil uneinheitlichen Ergebnissen. So zeigen auch unsere Untersuchungen am Kaninchen ein anderes Bild im Vergleich zu den Untersuchungen am menschlichen Myokard.

Kritisch anzumerken bleibt jedoch die Tatsache, dass die untersuchten Myokardproben nur bedingt untereinander vergleichbar sind. Die Patiententabelle in Kapitel 2.1. spiegelt diese Varianz der Proben wider. Zwar wurden alle Patienten der gleichen NYHA-Klassifikation zugeordnet (NYHA IV), doch unterschied sich jeder Patient in Hinblick auf Medikation, Ejektionsfraktion und Alter. Auch wurden keine geschlechtsspezifischen Gruppen gebildet. Trotzdem zeigen die Ergebnisse ein einheitliches Bild, und die große Zahl an Kontrollen lässt Rückschlüsse auf das statistische Mittel zu und ermöglicht die Bewertung von Versuchsreihen mit kleinerem Umfang.

Grundlage der Arbeit war die Untersuchung des funktionellen Effektes von Insulin am menschlichen Myokard. Es hat sich gezeigt, dass Insulin Einfluss auf den intrazellulären Kalziumstoffwechsel, den SR-Kalziumgehalt, die Substratverwertung sowie die intrazelluläre Signaltransduktion hat. Um diese Effekte nachweisen zu können, bedarf es einer Reihe von Untersuchungsmethoden. 


\subsection{Direkte funktionelle Effekte von Insulin am humanen Myokard}

Der direkte funktionelle Effekt von Insulin am humanen Myokard zeigte einen konzentrationsabhängigen Effekt.

Bei den in dieser Arbeit verwendeten geringen Konzentrationen (0,3 I.E./l) ließ sich ein positiv inotroper Effekt von $11 \%$ nach Applikation nachweisen. Dieser Effekt ließ sich durch eine Erhöhung der Insulinkonzentration auf 3 I.E./l in Glukose-Tyrode auf 28 \% steigern. Auffällig ist, dass der positive Effekt von Insulin in Pyruvat-Tyrode bei Konzentrationssteigerung keine Zunahme erfährt.

Die durch Insulin vermittelte Kontraktionskraftsteigerung in Pyruvat-Tyrode beträgt 11\% (sowohl bei Insulinkonzentrationen von 0,3 I.E./l als auch bei 3 I.E./l) verglichen mit 28 \% Kontraktionskraftsteigerung in Glukose-Tyrode (bei 3 I.E./l). Dies lässt vermuten, dass Insulin sowohl über einen subtratabhängigen Effekt die positive Inotropie vermittelt, als auch über einen substratunabhängigen Effekt in Pyruvat-Tyrode.

Des Weiteren fiel auf, dass die Kraftentwicklung zu Beginn der Intervention in der PyruvatGruppe signifikant höher ist $\left(50.3 \pm 10.6 \mathrm{mN} / \mathrm{mm}^{2}\right)$ gegenüber $25,7 \pm 6,5 \mathrm{mN} / \mathrm{mm}^{2}$ in Glukose-Tyrode. Eine Veränderung der Relaxationsparameter fand dabei nicht statt.

Grundlage für diese Untersuchungen war eine Glukose-Konzentration von 11,2 mmol/l bzw. eine Pyruvat-Konzentration von 22,4 mmol/l. Diese Konzentrationen entsprechen hohen Plasmaspiegeln der jeweiligen Substanz in vivo.

Die durchgeführten Dosis/Wirkungs-Kurven am humanen Myokard konnten die Ergebnisse der kontraktilen Antwort von Sethi et al. 1993 bestätigen. Auch in dieser Arbeit wurde keine Kraftzunahme bei sukzessiver Steigerung der Insulinkonzentration nachgewiesen. Bereits Sethi hat eine Tachyphylaxie bei der funktionellen Antwort von Insulin beschrieben.

Die Größe korreliert dabei mit den bisher beschriebenen inotropen Antworten von Insulin an isolierten Meerschweinchen- (Schmidt und Koch 2002) und Rattenherzen (Ren et al. 2000, Schmidt und Koch 2002).

Die von uns untersuchten Insulinkonzentrationen von 0,3 und 3 I.E./l sind vergleichbar mit den Konzentrationen, die bisher am Meerschweinchen oder an der Ratte (8-16 I.E./l) gemessen wurden (Schmidt und Koch 2002).

Allerdings ist sogar die geringere Insulinkonzentration etwa fünf mal höher als postprandiale Plasmainsulinspiegel in gesunden Probanden (Luef et al. 2002). Höhere Insulinspiegel werden bei Insulin-Kalium-Glukose-Infusionen erreicht (Bruemmer-Smith et al. 2002, Russell-Jones et al 1997). 


\subsection{Signaltransduktionswege von Insulin im humanen Myokard}

Von Insulin ist bekannt, dass es neben dem Insulinrezeptor auch an beide IGF-Rezeptoren (Pandini et al. 2002) binden kann. In einer vorhergehenden Arbeit konnte nachgewiesen werden, dass die Bindung von IGF-1 an den IGF-1-Rezeptor einen vergleichbaren Kalziumabhängigen, positiv inotropen Effekt vermittelt (von Lewinski et al. 2003). Allerdings zeigte die Vorinkubation mit dem selektiven IGF-1-Rezeptor-Antikörper $\alpha$ IR-3 keinen nachweisbaren Effekt. Dies lässt einen IGF-Rezeptor-unabhängigen-, über eine direkte Aktivierung von Insulinrezeptoren vermittelten Effekt vermuten. Von beiden Rezeptoren ist eine Signalübermittlung über die Aktivierung des Insulin-Rezeptor-Substrat (IRS) bekannt. Die Tyrosin-abhängige Phosphorylierung des IRS akitviert Verbindungen mit SH2-Domänen, wie die $\mathrm{PI}_{3}$-Kinase (White 1998, Ren et al. 1999).

Der $\mathrm{PI}_{3}$-Kinase-Signaltransduktionsweg vermittelt antiapoptotische und trophische Effekte über die Aktivierung von AKT (Proteinkinase B). Dieser Weg der $\mathrm{PI}_{3}$-Kinase-Aktivierung bei der Vermittlung der metabolischen Effekte von Insulin wird uneinheitlich beschrieben (Krook et al. 1997, Baumann et al. 2000, Zaha et al. 2003). In dieser Arbeit konnten wir zeigen, dass die Vorinkubation mit dem selektiven $\mathrm{PI}_{3}-$ Kinase-Inhibitor Wortmannin den Insulin bedingten, positiv inotropen Effekt nahezu vollständig verringert. Vergleichbare Daten konnten wir bei der Verwendung von IGF-1 erheben. Dies zeigt, dass die Aktivierung der $\mathrm{PI}_{3^{-}}$ Kinase eine Schlüsselposition in der Signaltransduktion der durch Insulin und IGF-1 vermittelten funktionalen Effekte einnimmt.

Die Blockade der DAG-Kinase zeigte hingegen keine Abschwächung des durch Insulin vermittelten inotropen Effektes. Weder die unspezifische Blockade der Proteinkinase C durch Chelerythrin noch die spezifischere Blockade der $\left(\alpha, \beta_{1}, \delta\right.$ und $\left.\varepsilon\right)$ der PKC-Isoformen mit GF109203X konnte eine signifikante Verringerung erreichen. Es war allerdings nach Inkubation mit GF109203X eine tendenziell geringere Inotropie $(22,2 \pm 5,4 \%)$ im Vergleich zur Kontrolle $(26,8 \pm 6,4 \%)$ nachzuweisen. Die Daten beziehen sich auf Kontrollen aus identischem Myokard ( $\mathrm{n}=9$ ).

Ein Teil des intrazellulären Kalziumstoffwechsels wird durch den $\mathrm{Na}^{+} / \mathrm{Ca}^{2+}$-Austauscher (NCX) bestimmt. Dieser Transporter kann (siehe Einleitung) in zwei Richtungen arbeiten. Die Inkubation der Muskelstreifen mit KB-R 7943 ( $n=8)$ reduziert den positiv inotropen Effekt von Insulin um 62,1 $\pm 6,3 \%$ (p < 0,05). Daraus resultiert, dass ein Teil der inotropen Antwort durch eine Aktivierung des NCX reverse-modes stattfindet. 


\subsection{Der Einfluss von Insulin auf die intrazelluläre Kalziumhomöostase}

Der funktionelle Effekt von Insulin wird begleitet von einem Anstieg der intrazellulären Kalziumtransienten. Ein Anstieg der intrazellulären Kalziumkonzentration, als der grundlegende Effekt der durch Insulin vermittelten positiven Inotropie, konnte ebenfalls an einem Rattenherzmodell gezeigt werden (Ren et al. 2000). An Schweineherzen konnte gezeigt werden, dass Insulin die Aktivität der SERCA (Gupta et al. 1989) steigert, was indirekt die SR-Kalziumbeladung und -ausschüttung steigern kann. Die Mechanismen des durch Insulin vermittelten Kalziumanstiegs sind unbekannt. Deshalb stützt sich ein weiterer Teil der in dieser Arbeit durchgeführten Untersuchungen auf die Charakterisierung des SRKalziumgehaltes sowie der intrazellulären Kalziumtransienten.

\subsubsection{Der Einfluss von Rapid Cooling Contractures auf den SR-Kalziumgehalt des}

\section{Myokards}

Die schnelle Kühlung des Präparates im Organbad auf etwa $0^{\circ} \mathrm{C}$ bewirkt eine reversible Kontraktur des Muskels. Grundlage für die Kontraktur ist die durch die Kühlung ausgelöste schlagartige Öffnung aller Kalziumfreisetzungskanäle im sarkoplasmatischen Retikulum. Gleichzeitig werden durch die Kälte alle aktiven Kalziumeliminations-Systeme blockiert. Die Kühlungskontraktur ist ein semi-quantitatives Maß für die Kalziumbeladung des sarkoplasmatischen Retikulums (Pieske et al. 1999). Erstmals beschrieben wurde diese Methode von Sakai im Jahr 1965. Allerdings führte Sakai bei den Myokardproben verschiedener Tierspezies vor der Kühlung eine Behandlung mit geringen Mengen von Koffein $(0,3$ bis $1 \mathrm{mmol} / \mathrm{l})$ durch. Diese Vorbehandlung fördert über eine Interaktion mit den SR-Ca ${ }^{2+}-$ Kanälen eine Ausschüttung des Kalziums in das Zytosol. Koffein führt an der Herzmuskulatur zu einer konzentrationsabhängigen Abnahme der Kühlungskontrakturen. 10 mmol/l Koffein bewirken eine vollständige Aufhebung der Speicherfähigkeit des SR für Kalzium und macht damit eine RCC unmöglich (Bers 1987, Bers und Bridge 1988). Allerdings ist diese Vorbehandlung mit Koffein nicht notwendig, wie weitere Untersuchungen zeigten (Kurihara und Sakai 1985, Bridge 1986, Bers et al. 1987).

Die folgenden Befunde sprechen für die Fähigkeit der RCC's zur Entleerung der SRKalziumspeicher.

So ist nachzuweisen, dass nach Applikation von Substanzen (Koffein, Ryanodin, CPA), die eine Entleerung des SR-Kalziums zur Folge haben, keine Kühlungskontrakturen mehr auslösbar sind (Bers 1987). Auch lange Stimulationspausen bzw. -intervalle haben eine Entleerung des SR zur Folge und verhindern eine Auslösung von Kühlungskontrakturen. 
Um den Einfluss von sarkolemmalen Faktoren oder der extrazellulären Kalziumkonzentration auf den Effekt der Kühlungskontrakturen auszuschließen, erfolgten Untersuchungen in Kalzium-freier Tyrode-Lösung und an selektiv gehäuteten Muskelstreifen, die zwar keine sarkolemmale Membran jedoch ein intaktes SR besitzen (Bers et al. 1989, Herland et al. 1996). Auch in diesen Versuchsaufbauten konnten Kühlungskontrakturen nachgewiesen werden. Direkte Untersuchungen der Öffnungswahrscheinlichkeit des SR-Ca ${ }^{2+}$-Kanals zeigten bei Temperaturen von $5^{\circ} \mathrm{C}$ eine stark erhöhte Öffnungswahrscheinlichkeit (Sitsapesan et al. 1991).

Ein weiterer Vorteil der RCC ist die Möglichkeit, indirekt die Kalzium-Eliminationssysteme des Myozyten untersuchen zu können. Wird direkt im Anschluss an die Relaxation des unstimulierten Muskels während der Wiedererwärmung eine zweite Kühlungskontraktur durchgeführt, so fällt diese geringer aus als die erste. Wie bereits im ersten Teil dieser Arbeit besprochen, betragen die relativen Anteile der Kalziumelimination im Myozyten von SERCA zu NCX zu sarkolemmaler $\mathrm{Ca}^{2+}$-ATPase zu mitochondrialer Kalziumaufnahme 72:27:1:1. Dies bedeutet, dass im Wesentlichen zwei Systeme um das zytoplasmatische Kalzium konkurrieren: die SERCA und der NCX.

Dies ist der Grund für die geringere zweite Kontraktur, da ein Teil des Kalziums durch den NCX nach extrazellulär eliminiert wird und nur ein geringerer Kalziumanteil in das SR transportiert werden kann und für die Kontraktur zur Verfügung steht. Wird der NCX mittels einer $\mathrm{Na}^{+}$-freien Tyrode-Lösung blockiert, so fällt die zweite Kontraktur ähnlich der ersten aus (Hryshko et al. 1989).

Während der Kühlungsphase sind nahezu alle Transportmechanismen des Myozyten blockiert. Daraus resultiert, dass das aus dem SR freigesetzte Kalzium im Zytosol zu einer Aktivierung der kontraktilen Elemente führt, wobei die Menge des freien Kalziums mit der Höhe der Kontraktionsamplitude korreliert werden kann. Nach der Kontraktur wird der Muskel wieder erwärmt, was zu einer kurzzeitigen Überhöhung der Kontraktur führt. Dieser sogenannte rewarming spike ist auf eine Sensibilitätssteigerung der Myofilamente für Kalzium (Harrison und Bers 1989) und nicht etwa auf eine stärkere Kalziumfreisetzung zurückzuführen. Erst jetzt beginnen der NCX und die SERCA mit der Elimination des Kalziums aus dem Cytosol (Bers 1989). Nach der Wiedererwärmung und dem Elimination des Kaliums aus dem Zellplasma, erfolgt die Relaxierung des Muskels.

Im Normalfall ist im vorgedehnten Muskelpräparat die RCC geringer als die Kontraktionsamplitude bei $37^{\circ} \mathrm{C}$. Bei Verringerung der Vorlast durch Entdehnung wird die RCC im Verhältnis größer. Ursächlich kommt hierfür eine Vergrößerung der Querbrücken- 
Kraft-Zeit-Integrals, im nicht ausreichend vorgedehnten Muskels in Betracht. Dies ermöglicht eine stärkere Kraftentwicklung während der Kühlungskontraktur (Hryshko et al. 1989). Des Weiteren müssen bei der Kontraktur nur noch die geringeren elastischen Parameter des unvorgedehnten Präparates überwunden werden (Niggli 1987).

Somit stellt die RCC eine valide, reversible, verhältnismäßig einfache und reproduzierbare Methode zur Bestimmung des SR-Kalziumgehaltes dar.

Der Vorteil zu Koffein-Kontrakturen liegt in der Reversibilität der Kühlung und der Möglichkeit eine große Zahl an Kühlungkontrakturen an ein und demselben Muskelstreifenpräparat durchführen zu können. Dies ist bei Koffein-induzierten Kontrakturen in diesem Maße nicht möglich. Zusätzlich besteht bei Koffein ein Nachteil darin, dass nicht ausgeschlossen werden kann, dass extrazelluläres Kalzium über nicht inhibierte sarkolemmale Ionenpumpen zur Kontraktur beiträgt. Eine weitere Schwierigkeit bei der Verwendung von Koffein am multizellulären Präparaten liegt in der zum Teil großen Diffusionstrecke die überwunden werden muss, um eine homogene Verteilung im Präparat zu gewährleisten, was notwendig ist, um alle SERCA im gleichen Maße zu beeinflussen.

In der vorliegenden Arbeit wurde sowohl die SR-Kalziumbeladung von humanem Myokard in Glukose-Tyrode als auch in Pyruvat-Tyrode gemessen.

Die Ergebnisse der Untersuchungen in Glukose-Tyrode zeigen sowohl eine signifikante Zunahme der Kontraktionskraft $(42 \pm 7,1 \%)$ als auch eine signifikante Zunahme der SRKalziumbeladung (15,7 \pm 4,9 \%). Nach Blockade des SR durch Ryanodin und Cyclopiazonsäure (CPA) konnte der Insulin-vermittelte, inotrope Effekt um ca. $46 \%$ reduziert werden. Kühlungskontrakturen waren nach der Blockade des SR durch diese Substanzen nicht mehr nachweisbar. Daraus resultiert, dass Insulin sowohl einen SRunabhängigen, positiv inotropen Effekt, als auch einen an das SR gebunden Effekt besitzt. Einen großen Anteil scheint dabei die erhöhte Kalziumbeladung des SR zu tragen. Das Verhältnis der Kühlungskontrakturen zueinander (RCC2/RCC1) betrug $47 \%$ vor Insulingabe und $47 \%$ nach Insulin (3 I.E./1). Nach Pieske (Pieske et al. 1999) kann daraus geschlossen werden, das etwa $47 \%$ des zytosolischen Kalziums in das SR wiederaufgenommen werden, während ca. $53 \%$ über den NCX nach extrazellulär eliminiert werden.

Die Versuche in Pyruvat-Tyrode zeigten ebenfalls eine Zunahme der Kontraktionskraft, allerdings auch einen Abfall der SR-Kalziumbeladung. Hypothetisch kommen im Wesentlichen zwei Ursachen dafür in Betracht.

Entweder es besteht bereits eine starke Steigerung der SERCA-Aktivität, so dass keine weitere Zunahme der Aktivität durch Insulin erfolgen kann, oder es werden von Insulin 
funktionell antagonisierende Effekte über verschiedene $\mathrm{PI}_{3}-$ Kinasen vermittelt. Bei Pyruvat ist es wahrscheinlich, dass nur der antagonisierende Effekt zum Tragen kommt.

\subsubsection{Aequorin}

Weitere Aufschlüsse über den zellulären Kalziumstoffwechsel liefert die simultane Bestimmung von intrazellulären Kalziumtransienten und der isometrischen Kontraktionskraft. Wir konnten nachweisen, dass in Glukose-Tyrode der inotrope Effekt $(23,2 \pm 10 \%$; $<0,05)$ mit einem direkten Anstieg der Lichtemissionen (15,8 \pm 4,2 \%; $p<0,05)$ verbunden war. Diese Daten beeinhalten, dass der inotrope Effekt von Insulin zum Teil mit einer erhöhten Kalziumfreisetzung während der Kontraktur verbunden ist.

Die Kalziumfreisetzung wurden mit vorhergehenden Aequorin-Experimenten verglichen. In diesen wurde die myokardiale Kontraktilität über einen erhöhten Kalziumgehalt in der Tyrode beeinflusst (von Lewinski et al. 2003). Der extrazelluläre Kalziumgehalt betrug 3,2 mmol/l. Auffällig war ein nahezu identischer Kraftzuwachs $(23,7 \pm 4,3 \%)$, verglichen mit InsulinIntervention $(23,2 \pm 10 \%)$. Das Aequorinlichtsignal stiegt jedoch durch die erhöhte extrazelluläre Kalziumkonzentration stärker an, als bei Inkubation mit Insulin $(20,5 \pm 7,2 \%$ verglichen mit $15,8 \pm 4,2 \%)$.

Eine Quantifizierung kann über das Verhältnis des realtiven Kraftzuwachses $\Delta \mathrm{F}$ zum Anstieg der Lichtemission über Aequorin $\Delta \mathrm{L}$ erfolgen. $\Delta \mathrm{F} / \Delta \mathrm{L}$ betrug $0.98 \pm 0,05$ bei erhöhtem Kalziumgehalt im Medium im Vergleich zu 1,34 \pm 0,18 $(\mathrm{p}<0,05)$ im Insulin-Medium. Diese Ergebnisse weisen auf eine zusätzliche Erhöhung der Kalziumsensitivität durch Insulin hin.

Von Lewinski et al. konnten 2003 in der bereits zitierten Arbeit zeigen, dass IGF-1 keinen Effekt auf die Kalziumsensitivität hat. Während über die schnellen Kühlungskontrakturen eine indirekte Aussage über das freigesetzte Kalzium zu treffen ist, gelingt es mit der Messung der Kalziumtransienten mittels Aequorin, direkt eine Aussage über die nicht abgepufferten Kalziumkonzentrationsänderungen während der Kontraktur zu treffen. Der zu messende Kalziumtransient repräsentiert dabei etwa 1-10\% des Kalziums während der Kontraktur. Der größere Anteil bindet sofort an Troponin C, den mitochondrialen $\mathrm{Ca}^{2+}$-Kanal oder andere Kalziumpuffer im Zytosol (Hannon et al. 1992, Kirichok et al. 2004).

Fünf wesentliche Methoden zur Bestimmung von intrazellulären Kalziumkonzentrationen wurden bisher beschrieben (Hannon et al. 1992).

Langsame Registrierungsmethoden wie Kalzium-sensitive Mirkoelektroden und die NMRSpektroskopie besitzen ein zu geringes zeitliches Auflösungsvermögen und sind daher für die Bestimmung von Transienten ungeeignet. Metallchromatische Farbstoffe sind anfällig für 
Bewegungsartefakte und scheiden daher am kontrahierenden Muskel zur Bestimmung der Transienten aus.

Übrig bleiben fluoreszierende Farbtstoffe (z.B. Fura-2, Indo-1) und lumineszierende Farbstoffe (z.B. Aequorin).

Fluoreszierende Farbstoffe haben am multizellulären Muskelpräparat entscheidende Nachteile. So kann die Beladung des Präparates mit dem Farbstoff durch Inkubation nicht gewährleisten, dass das Zytosol spezifisch beladen wird. Die Inkubation färbt dabei ebenfalls die subzellulären Kompartimente an. Des Weiteren ist die Beladung des Präparates durch eine ein- bis zweistündige Inkubation nicht homogen, sondern es ist zu erwarten, dass die äußeren Zellschichten nach Abschluss eine stärkere Beladung aufweisen.

Lumineszensfarbstoffe - wie das in dieser Arbeit verwendete Aequorin - bieten in diesem Versuchsaufbau entscheidende Vorteile.

Der aus der Salzwasser-Hydromeduse Aequorea forskolea gewonnene BiolumineszenzFarbstoff Aeqourin ist ein Kalzium-reguliertes Protein, das unter physiologischen Bedingungen Kalzium-spezifisch ist. Eine kompetitive Bindung zum Kalzium am Aequorinmolekül ist von $\mathrm{Mg}^{2+}$ und $\mathrm{Sr}^{2+}$ bekannt. Allerdings ist die Lichtreaktion von $\mathrm{Sr}^{2+}$ etwa um den Faktor 100 geringer als bei Kalzium (Shimomura und Johnson 1970, Shimomura et al. 1974, Loschen und Chance 1971). Auch Lokalanästhetika und Narkotika kann ein reaktionssteigernder Effekt nachgewiesen werden (Baker und Schapira 1980). Jedoch wird dieser Effekt erst signifikant ab Konzentrationen, die weitaus höher sind als die im klinischen Gebrauch. So sind Beeinflussungen durch diese Größen als gering einzuschätzen.

Aequorin weist eine schnelle Reaktionskinetik auf. So ist bereits circa $10 \mathrm{~ms}$ nach Bindung des Kalziums eine Lichtemission nachzuweisen (Hastings et al. 1969, Blinks et al. 1982). Die Emissionsdauer beträgt etwa $7 \mathrm{~ms}$ und ist somit für die Messung von Kalziumtransienten bei der Herzmuskelkontraktion ausreichend schnell. Im Konzentrationsbereich von $10^{-7}$ bis $10^{-5} \mathrm{M}$ sind wegen des steilen Verlaufs der Kurve auch kleine Konzentrationsunterschiede in doppellogarithmischer Auftragung zu erfassen.

Die Bindung des Kalziums an das Aequorinmolekül und die damit verbundene Lichtemission benötigt keinen externen Sauerstoff oder andere Cofaktoren, da diese Bestandteile des Aequorins sind. Zudem sind keine toxischen Effekte des Moleküls auf Myozyten bekannt, und es besteht keine Empfindlichkeit bei simultaner Messung der isometrischen Kontraktionskraft für Bewegungsartefakte (Hannon et al. 1992). Zudem besteht die Möglichkeit, durch die in dieser Arbeit angewendete Makroinjektionstechnik, das Aequorin relativ schonend in das Präparat einzubringen (Kihara und Morgan 1989). 
Das Makromolekül Aequorin bindet irreversibel $\mathrm{Ca}^{2+}$-Ionen. Dies stellt einen Nachteil dar, da sich das Aequorin während des Experimentes verbraucht und somit die zeitliche Dauer des Experiments begrenzt. Der Verbrauch äußert sich während des Experimentes in einem run down des Lichtsignals. Das heißt, über die Dauer des Experimentes nimmt die Signalintensität konstant ab. Bei Fröschen ist der run down am Myokard mit etwa $4 \%$ pro Stunde (Blatter und Blinks 1991) und beim Menschen am insuffizienten Myokard mit etwa $10 \%$ pro Stunde beschrieben (Gwathmey und Hajjar 1990). Trotzdem ist es möglich, bei einer Temperatur von $37{ }^{\circ} \mathrm{C}$ über mehrere Stunden mit einer gleichbleibend konstanten Signalabnahme reproduzierbare Messungen durchzuführen.

Der Mechanismus der Aequorinaufnahme nach intrazellulär liegt weiterhin im Unklaren. Fakt ist, dass aktive Transportmechanismen ausscheiden. So ist bei geringen Temperaturen, die einen aktiven Transport verhindern, eine Aufnahme von Aequorin nachgewiesen (Morgan et al. 1984). Es besteht die Möglichkeit, dass das Molekül durch spezielle Membranbereiche nach intrazellulär gelangt (Mullins 1966).

Alternativ wird eine Permeabilitätssteigerung der Membran diskutiert. Fabiato konnte 1983 geskinnte Myozyten allein durch Inkubation in Aequorinlösung beladen.

In diesem Zusammenhang kann, speziell bei der Makroinjektionstechnik, eine reversible Permeabilitätssteigerung der Membran durch die mechanische Beeinflussung erreicht werden (Perreault et al. 1992).

Methodisch sehr aufwendig stellt sich die Umrechnung der Lichtemission in Kalziumtransienten dar und ist zudem mit einer großen Ungenauigkeit behaftet (Neering und Morgan 1980, Urthaler et al. 1993).

\subsection{Pyruvat}

In der vorliegenden Arbeit wurde in einem Teil der Versuche Pyruvat in der Tyrode als Energiesubstrat anstelle von Glukose verwendet. Der grundlegende Gedanke für diese Substitution liegt darin begründet, den positiv inotropen Effekt von Insulin unabhängig von einer möglicherweise verbesserten Glukoseaufnahme zu untersuchen.

In diesem Versuchsaufbau darf nicht vernachlässigt werden, dass Pyruvat selbst direkt Effekte auf das humane Myokard ausübt, die einer Berücksichtigung bedürfen.

Pyruvat, das Salz der Brenztraubensäure, ist ein Produkt der Glykolyse und ein Substrat des Citrat-Zyklus sowie des Cori-Zyklus. Unter aeroben Bedingungen kann Pyruvat in den CitratZyklus eingeschleust werden und wird dort unter einem hohen Wirkungsgrad verstoffwechselt. Alternativ kann unter anaeroben Bedingungen Pyruvat zu Laktat 
verstoffwechselt werden und auch in dieser Form den Herzmuskelzellen als Energiesubstrat zur Verfügung stehen.

Es ist bekannt, dass Pyruvat die mechanischen Parameter des Myokards positiv beeinflussen kann, sowohl bei ausreichender Perfusion (Zweier und Jacobus 1987, Mentzer et al. 1989, Bünger et al. 1989, Mallet und Bünger 1994, Yanos et al. 1994, Tejero-Taldo et al. 1999, Mallet und Sun 1999) als auch während der post-ischämischen Reperfusionsphase (Bünger et al. 1989, Mallet et al. 1990, Zhou et al. 1995, Mallet 2000).

So hat Pyruvat direkt positiv inotrope Effekte am insuffizienten menschlichen Myokard (Hasenfuss et al. 2002). Dieser positiv inotrope Effekt hat keinen negativen Einfluss auf die Sauerstoffbilanz des Myokards. Weder die direkte intrakoronare Applikation von Pyruvat an sich (Hermann et al. 1999), noch die mit B-Stimulation kombinierte Applikation am Myokard zeigte einen erhöhten Sauerstoffverbrauch (Bersin et al. 1994).

Der zelluläre Mechanismus der durch Pyruvat vermittelten Inotropie kann auf verschiedene Vorgänge zurückgeführt werden. Untersuchungen am Herzen haben gezeigt, dass Pyruvat in den Stoffwechsel der Mitochondrien eingreift (Mallet und Sun 1999) und zu einer effektiveren ATP-Synthese durch Erhöhung des Phosphorylisationspotentials führt (Laughlin und Heineman 1994, Scholz et al. 1995, Zweier und Jacobus 1987, Bünger et al. 1989, Mallet und Bünger 1994).

Dieser Effekt bedingt eine erhöhte Bereitstellung des Energiesubstrates ATP und dieses wiederum führt zu einer höheren Effizienz der ATP-abhängigen Vorgänge in der Zelle. Unter anderem wird der Kalziumgradient zwischen SR und Zytosol erhöht. Verantwortlich dafür ist die gesteigerte Pumpaktivität der SERCA (Chen et al. 1998).

Im Meerschweinherzen zeigte dieser stärkere Kalziumumsatz auch eine Zunahme der Inotropie (Mallet und Bünger 1994, Mallet und Sun 1999).

Verstäkte Kalziumspeicherung im SR zieht eine verstärkte Kalziumfreisetzung ins Zytosol nach sich, was sich in erhöhten Kalziumtransienten äußert (Zima et al. 2003).

Pyruvat wirkt über einen sarkolemmalen $\mathrm{H}^{+}$-Monocarboxylate-Symporter (Poole und Halestrap 1993). Über diesen Transporter nimmt Pyruvat Einfluss auf den intrazellulären $\mathrm{pH}$ Wert und führt zu einem Absinken des pH-Werts. Hierüber wird ebenfalls die Kontraktilität beeinflusst (Bers 2002).

Das Absinken des pH-Wertes zieht mehrere Effekte nach sich. Durch die Azidose verringert sich zum einen die Empfindlichkeit der kontraktilen Proteine für Kalzium (Fabiato und Fabiato 1978). Zusätzlich kommt es zu einer Aktivitätsabnahme des $\mathrm{Ca}^{2+}$-Freisetzungskanals des SR (Xu 1996) und der SERCA (Mandel et al. 1982). Kompensiert wird dies durch eine 
geringere Kalziumelimination über den NCX nach extrazellulär (Bountra und Vaughan-Jones 1989, Harrison et al. 1992).

Weitere Pyruvat-Effekte auf den pH-Wert im Zytosol sind eine vorrübergehende Ansäuerung, welche von einer anhaltenden Alkalose gefolgt wird (Hasenfuss et al. 2002).

\subsection{Limitationen der Arbeit}

Eine Limitation der Arbeit stellt die Messung der intrazellulären Kalziumtransienten dar. So wurden die Aequorinsignale nicht in den Kalziumeinstrom umgerechnet. Dieses stellt kein grundlegendes Problem dar, erschwert aber die Vergleichbarkeit der Daten bei verschiedenen inotropen Interventionen am Myokard.

Die Rapid Cooling Contractures sind eine gut validierte Methode am Myokard zur Messung der SR-Kalziumbeladung, allerdings kann trotz der Kühlung ein nicht messbarer Kalziumrest im SR verbleiben.

Zum anderen stellen die RCC eine indirekte Methode zur Messung der SR-Kalziumbeladung dar. Aspekte wie mögliche subzelluläre Veränderungen oder Insulin-bedingte Sensibilitätsveränderungen der Myofilamente können die RCC beeinflussen. KB-R7943 wurde zur Blockade des NCX-reverse mode benutzt. KB-R7943 ist keine ideale Substanz, da die Blockade weiterer $\mathrm{K}^{+}$-, $\mathrm{Na}^{+}$- oder $\mathrm{Ca}^{2+}$-Transportsysteme stattfinden kann. Die Selektivität der Substanz bezüglich des Auswärtsstroms gegenüber dem Einwärtsstrom des NCX ist nicht eindeutig aufgeklärt. Allerdings gibt es derzeit keine bessere Substanz zur Blockade des NCX-reverse mode. 


\section{ZUSAMMENFASSUNG}

Insulin zeigt am humanen Myokard einen transienten positiv inotropen Effekt ohne Einfluss auf die diastolische Spannung des Muskels. Die Effekte von Insulin sind konzentrationsabhängig in Glukose-haltiger Tyrode-Lösung. In Pyruvat-Tyrode war die maximale Kraftzunahme geringer, allerdings unabhängig von der verwendeten Insulinkonzentration. Die daraufhin durchgeführten Experimente am humanen Myokard mit Blockade der Glykolyse in Glukose-Tyrode zeigten einen um ca. $50 \%$ geringeren positiven Effekt, welcher vergleichbar ist mit den Ergebnissen in Pyruvat-Tyrode. Aus diesen Daten kann gefolgert werden, dass Insulin teilweise einen substratunabhängigen Effekt am Myokard vermittelt.

Im Weiteren wurden die Kalzium-abhängigen Mechanismen des Insulineffektes untersucht. Durch Messungen mit Aequorin konnte gezeigt werden, dass parallel zur Kraftzunahme des Muskels ein Anstieg der intrazellulären Kalziumtransienten stattfindet.

Anhand der Rapid Cooling Contractures konnte gezeigt werden, dass Insulin zu einer ca.

15 \%igen Zunahme der SR-Kalziumbeladung führt. Nach Blockade des SR waren die Kühlungskontrakturen komplett aufgehoben, allerdings konnte weiterhin eine Insulinvermittelte Inotropie nachgewiesen werden, welche allerdings um ca. $46 \%$ reduziert ist. Dies deutet darauf hin, dass Insulin neben der vermehrten SR-Kalziumspeicherung weitere Effekte auf die Kalziumhomöostase hat. Ein Einfluss auf die SR-Kalzium-Wiederaufnahme konnte nicht beobachtet werden. Das Verhältnis von RCC1/RCC2 ist vor und nach InsulinInkubation gleich geblieben.

Die Untersuchung der subzellulären Mechanismen zeigte, dass der Insulin-vermittelte Effekt weder durch Stimulation des IGF-1-Rezeptors, des L-Typ-Ca ${ }^{2+}$-Kanals, der DAG-Kinase noch der Proteinkinase $\mathrm{C}$ (einschließlich der Untereinheiten) bedingt ist.

Nach Blockade der $\mathrm{PI}_{3}$-Kinase ist der positiv inotrope Effekt nahezu aufgehoben, woraus geschlussfolgert werden kann, dass dies der Hauptsignaltransduktionsweg von Insulin ist. Eine teilweise Blockade des Effekts konnte nach Inhibition des reverse mode des NCX erreicht werden. Daher ist ein geringerer Teil der Insulinantwort durch diesen Mechanismus zu erklären. 


\section{LITERATURVERZEICHNIS}

Airaksinen J, Lahtela JT, Ikaheimo MJ, Sotaniemi EA, Takkunen JT (1985): Intravenous insulin has no effect on myocardial contractility or heart rate in healthy subjects. Diabetologia $\underline{28}, 649-652$

Allen DG, Blinks JR (1978): Calcium transients in aequorin-injected frog cardiac muscle. Nature $\underline{273}, 509-513$

Allen DG, Kentish JC (1985): The cellular basis of the length-tension relation in cardiac muscle. J Mol Cell Cardiol 17, 821-840

Anderson JL, Carlquist JF, Lutz JR, DeWitt CW, Hammond EH (1984): HLA A, B and DR typing in idiopathic dilated cardiomyopathy: a search for immune response factors. Am $\mathbf{J}$ Cardiol 53, 1326-1330

Anker SD, Al-Nasser FO (2000): Chronic heart failure as a metabolic disorder. Heart Fail Monit $\underline{1}, 42-49$

Arcaro G, Cretti A, Balzano S, Lechi A, Muggeo M, Bonora E, Bonadonna RC (2002): Insulin causes endothelial dysfunction in humans: sites and mechanisms. Circulation $\underline{105}$, $576-582$

Avruch J (1998): Insulin signal transduction through protein kinase cascades. Mol Cell Biochem 182, 31-48

Baker PF, Schapira AH (1980): Anaesthetics increase light emission from aequorin at constant ionised calcium. Nature 284, 168-169

Baumann CA, Ribon V, Kanzaki M, Thurmond DC, Mora S, Shigematsu S, Bickel PE, Pessin JE, Saltiel AR (2000): CAP defines a second signaling pathway required for insulinstimulated glucose transport. Nature $\underline{407}, 202-207$ 
Bean BP (1989): Classes of calcium channels in vertebrate cells. Annu Rev Physiol 51, 367384

Bers DM (1987): Ryanodine and the calcium content of cardiac SR assessed by caffeine and rapid cooling contractures. Am J Physiol 253, 408-415

Bers DM (1989): SR Ca loading in cardiac muscle preparations based on rapid-cooling contractures. Am J Physiol 256, 109-120

Bers DM (2000): Calcium fluxes involved in control of cardiac myocyte contraction. Circ Res $\underline{87}, 275-281$

Bers DM (2002): Cardiac excitation-contraction coupling. Nature $\underline{415}, 198-205$

Bers DM, Bridge JH (1988): Effect of acetylstrophanthidin on twitches, microscopic tension fluctuations and cooling contractures in rabbit ventricle. J Physiol 404, 53-69

Bers DM, Bridge JH, MacLeod KT (1987): The mechanism of ryanodine action in rabbit ventricular muscle evaluated with Ca-selective microelectrodes and rapid cooling contractures. Can J Physiol Pharmacol $\underline{65}$, 610-618

Bers DM, Bridge JH, Spitzer KW (1989): Intracellular Ca2+ transients during rapid cooling contractures in guinea-pig ventricular myocytes. J Physiol $\underline{417}, 537-553$

Bers DM, Bassani JW, Bassani RA (1993): Competition and redistribution among calcium transport systems in rabbit cardiac myocytes. Cardiovasc Res $\underline{27}, 1772-1777$

Bersin RM, Wolfe C, Kwasman M, Lau D, Klinski C, Tanaka K, Khorrami P, Henderson GN, de Marco T, Chatterjee K (1994): Improved hemodynamic function and mechanical efficiency in congestive heart failure with sodium dichloroacetate. J Am Coll Cardiol $\underline{23}$, $1617-1624$

Bertrand L, Horman S, Beauloye C, Vanoverschelde JL (2008): Insulin signalling in the heart. Cardiovasc Res $\underline{79}$, 238-248 
Beuckelmann DJ, Erdmann E (1992): Ca(2+)-currents and intracellular [Ca2+]i-transients in single ventricular myocytes isolated from terminally failing human myocardium. Basic Res Cardiol $\underline{87}, 235-243$

Beuckelmann DJ, Nabauer M, Erdmann E (1992): Intracellular calcium handling in isolated ventricular myocytes from patients with terminal heart failure. Circulation $\underline{85}, 1046-1055$

Blanchard EM, Smith GL, Allen DG, Alpert NR (1990): The effects of 2,3-butanedione monoxime on initial heat, tension, and aequorin light output of ferret papillary muscles. Pflugers Arch $\underline{416}, 219-221$

Blatter LA, Blinks JR (1991): Simultaneous measurement of $\mathrm{Ca} 2+$ in muscle with $\mathrm{Ca}$ electrodes and aequorin. Diffusible cytoplasmic constituent reduces $\mathrm{Ca}(2+)$-independent luminescence of aequorin. J Gen Physiol 98, 1141-1160

Blinks JR, Endoh M (1986): Modification of myofibrillar responsiveness to $\mathrm{Ca}++$ as an inotropic mechanism. Circulation $\underline{73}, 85-98$

Blinks JR, Rudel R, Taylor SR (1978): Calcium transients in isolated amphibian skeletal muscle fibres: detection with aequorin. J Physiol 277, 291-323

Blinks JR, Wier WG, Hess P, Prendergast FG (1982): Measurement of Ca2+ concentrations in living cells. Prog Biophys Mol Biol $\underline{40}, 1-114$

Böhm M, Beuckelmann D, Brown L, Feiler G, Lorenz B, Nabauer M, Kemkes B, Erdmann E (1988): Reduction of beta-adrenoceptor density and evaluation of positive inotropic responses in isolated, diseased human myocardium. Eur Heart J $\underline{9}, 844-852$

Böhm M, Diet F, Pieske B, Erdmann E (1989): Screening of positive inotropic agents in isolated cardiac preparations from different sources. J Pharmacol Methods $\underline{21}$, 33-44

Bountra C, Vaughan-Jones RD (1989): Effect of intracellular and extracellular pH on contraction in isolated, mammalian cardiac muscle. J Physiol 418, 163-187 
Bowditch HP (1871): Über die Eigentümlichkeiten der Reizbarkeit welche die Muskeln des Herzens zeigen. Ber Sachs Ges (Akad) Wiss $\underline{23}$, 652-689

Bowles NE, Rose ML, Taylor P, Banner NR, Morgan-Capner P, Cunningham L, Archard LC, Yacoub MH (1989): End-stage dilated cardiomyopathy. Persistence of enterovirus RNA in myocardium at cardiac transplantation and lack of immune response. Circulation $\underline{80}, 1128$ 1136

Brenner B, Eisenberg E (1987): The mechanism of muscle contraction. Biochemical, mechanical, and structural approaches to elucidate cross-bridge action in muscle. Basic Res Cardiol $\underline{82}, 3-16$

Bridge JH (1986): Relationships between the sarcoplasmic reticulum and sarcolemmal calcium transport revealed by rapidly cooling rabbit ventricular muscle. J Gen Physiol $\underline{88}$, 437-473

Bridge JH, Smolley JR, Spitzer KW (1990): The relationship between charge movements associated with ICa and INa-Ca in cardiac myocytes. Science $\underline{248}, 376-378$

Brillantes AB, Ondrias K, Scott A, Kobrinsky E, Ondriasová E, Moschella MC, Jayaraman T, Landers M, Ehrlich BE, Marks AR (1994): Stabilization of calcium release channel (ryanodine receptor) function by FK506-binding protein. Cell 구, 513-523

Bristow MR, Ginsburg R, Minobe W, Cubicciotti RS, Sageman WS, Lurie K, Billingham ME, Harrison DC, Stinson EB (1982): Decreased catecholamine sensitivity and betaadrenergic-receptor density in failing human hearts. N Engl J Med 307, 205-211

Brodde OE (1991): Beta 1- and beta 2-adrenoceptors in the human heart: properties, function, and alterations in chronic heart failure. Pharmacol Rev $\underline{43}, 203-242$

Bruemmer-Smith S, Avidan MS, Harris B, Sudan S, Sherwood R, Desai JB, Sutherland F, Ponte J (2002): Glucose, insulin and potassium for heart protection during cardiac surgery. Br J Anaesth. $\underline{88}, 489-495$ 
Buckley NM, Penefsky ZJ, Litwak RS (1972): Comparative force-frequency relationships in human and other mammalian ventricular myocardium. Pflugers Arch $\underline{332}$, 259-270

Bünger R, Mallet RT, Hartman DA (1989): Pyruvate-enhanced phosphorylation potential and inotropism in normoxic and postischemic isolated working heart. Near-complete prevention of reperfusion contractile failure. Eur J Biochem 180, 221-233

Callewaert G (1992): Excitation-contraction coupling in mammalian cardiac cells. Cardiovasc Res $\underline{26}, 923-932$

Cambridge G, MacArthur CG, Waterson AP, Goodwin JF, Oakley CM (1979): Antibodies to Coxsackie B viruses in congestive cardiomyopathy. Br Heart J $\underline{41}$, 692-696

Carafoli E (1985): The homeostasis of calcium in heart cells. J Mol Cell Cardiol 17, 203-212

Chen W, London R, Murphy E, Steenbergen C (1998): Regulation of the Ca2+ gradient across the sarcoplasmic reticulum in perfused rabbit heart. A 19F nuclear magnetic resonance study. Circ Res $\underline{83}, 898-907$

Chidsey CA, Sonnenblick EH, Morrow AG, Braunwald E (1966): Norepinephrine stores and contractile force of papillary muscle from the failing human heart. Circulation $\underline{33}, 43-51$

Cody RJ, Haas GJ, Binkley PF, Capers Q, Kelley R (1992): Plasma endothelin correlates with the extent of pulmonary hypertension in patients with chronic congestive heart failure. Circulation $\underline{85}, 504-509$

Cohn JN, Levine TB, Olivari MT, Garberg V, Lura D, Francis GS, Simon AB, Rector T (1984): Plasma norepinephrine as a guide to prognosis in patients with chronic congestive heart failure. N Engl J Med $\underline{311}, 819-823$

Cowburn PJ, Cleland JG, McArthur JD, MacLean MR, McMurray JJ, Dargie HJ, Morton JJ (1999): Endothelin B receptors are functionally important in mediating vasoconstriction in the systemic circulation in patients with left ventricular systolic dysfunction. J Am Coll Cardiol $\underline{33}, 932-938$ 
Cybulsky MI, Gimbrone MA Jr. (1991): Endothelial expression of a mononuclear leukocyte adhesion molecule during atherogenesis. Science $\underline{251}, 788-91$

Daly PA, Sole MJ (1990): Myocardial catecholamines and the pathophysiology of heart failure. Circulation $\underline{82}, 35-43$

Davies CH, Davia K, Bennett JG, Pepper JR, Poole-Wilson PA, Harding SE (1995): Reduced contraction and altered frequency response of isolated ventricular myocytes from patients

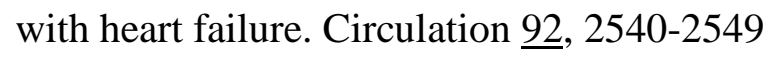

de Lemos JA, Morrow DA, Bentley JH, Omland T, Sabatine MS, McCabe CH, Hall C, Cannon CP, Braunwald E (2001): The prognostic value of B-type natriuretic peptide in patients with acute coronary syndromes. N Engl J Med $\underline{345}$, 1014-1021

de Lemos JA, McGuire DK, Drazner MH (2003): B-type natriuretic peptide in cardiovascular disease. Lancet $\underline{362}, 316-322$

De Nicola L, Bellizzi V, Cianciaruso B, Minutolo R, Colucci G, Balletta M, Fuiano G, Conte G (1997): Pathophysiological role and diuretic efficacy of atrial natriuretic peptide in renal patients. J Am Soc Nephrol $\underline{8}, 445-455$

Despa S, Islam MA, Weber CR, Pogwizd SM, Bers DM (2002): Intracellular Na(+) concentration is elevated in heart failure but $\mathrm{Na} / \mathrm{K}$ pump function is unchanged. Circulation $\underline{105}, 2543-2548$

Diamond I (1989): Alcoholic myopathy and cardiomyopathy. N Engl J Med 2ㅜㅇ, 458-460

Dipla K, Mattiello JA, Margulies KB, Jeevanandam V, Houser SR (1999): The sarcoplasmic reticulum and the $\mathrm{Na}^{+} / \mathrm{Ca}^{2+}$ exchanger both contribute to the $\mathrm{Ca}^{2+}$ transient of failing human ventricular myocytes. Circ Res $\underline{84}$, 435-444

Dorn GW 2nd (2009): Apoptotic and non-apoptotic programmed cardiomyocyte death in ventricular remodelling. Cardiovasc Res $\underline{81}$, 465-473 
Downing SE, Lee JC (1979): Myocardial and coronary vascular responses to insulin in the diabetic lamb. Am J Physiol 237, 514-519

Eisenberg E, Greene LE (1980): The relation of muscle biochemistry to muscle physiology. Annu Rev Physiol 42, 293-309

Elton TS, Stephan CC, Taylor GR, Kimball MG, Martin MM, Durand JN, Oparil S (1992): Isolation of two distinct type I angiotensin II receptor genes. Biochem Biophys Res Commun $\underline{184}, 1067-1073$

Endoh M, (1998): Regulation of myocardial contractility by a downstream mechanism. Circ Res $\underline{83}, 230-232$

Endoh M (2004): Force-frequency relationship in intact mammalian ventricular myocardium: physiological and pathophysiological relevance. Eur J Pharmacol 500, 73-86.

Engelhardt S, Hein L, Wiesmann F, Lohse MJ (1999): Progressive hypertrophy and heart failure in 31 -adrenergic receptor transgenic mice. Proc Natl Acad Sci USA $\underline{96}$, 7059-7064

Erickson JR, Joiner ML, Guan X, Kutschke W, Yang J, Oddis CV, Bartlett RK, Lowe JS, O'Donnell SE, Aykin-Burns N, et al. (2008): A dynamic pathway for calcium-independent activation of CaMKII by methionine oxidation. Cell $\underline{133}$, 462-474

Esler M, Kaye D, Lambert G, Esler D, Jennings G (1997): Adrenergic nervous system in heart failure. Am J Cardiol $\underline{80}, 7-14$

Fabiato A (1983): Calcium-induced release of calcium from the cardiac sarcoplasmic reticulum. Am J Physiol 245, 1-14

Fabiato A, Fabiato F (1978): Effects of $\mathrm{pH}$ on the myofilaments and the sarcoplasmic reticulum of skinned cells from cardiace and skeletal muscles. J Physiol 276, 233-255 
Feldmann MD, Aldermann JD, Aroesty JM, Royal HD, Ferguson JJ, Owen RM, Grossman W, McKay RG (1988 a): Depression of systolic and diastolic myocardial reserve during atrial pacing tachycardia in patients with dilated cardiomyopathy. J Clin Invest $\underline{82}$, 1661-1669

Feldmann MD, Gwathmey JK, Phillips P, Schoen FJ, Morgan JP (1988 b): Reversal of the force-frequency relationship in working myocardium from patients with endstage heart failure. J Appl Cardiol $\underline{3}$, 273-283

Francis GS, Benedict C, Johnstone DE, Kirlin PC, Nicklas J, Liang CS, Kubo SH, RudinToretsky E, Yusuf S (1990): Comparison of neuroendocrine activation in patients with left ventricular dysfunction with and without congestive heart failure. A substudy of the Studies of Left Ventricular Dysfunction (SOLVD). Circulation 82, 1724-1729

Frank O (1895): Zur Dynamik des Herzmuskels. Z Biol 32, 370-437

Friehs I, Moran AM, Stamm C, Colan SD, Takeuchi K, Cao-Danh H, Rader CM, McGowan FX, del Nido PJ (1999): Impaired glucose transporter activity in pressure-overload hypertrophy is an early indicator of progression to failure. Circulation $\underline{100}, 187-193$

Fryer MW, Gage PW, Neering IR, Dulhunty AF, Lamb GD (1988 a): Paralysis of skeletal muscle by butanedione monoxime, a chemical phosphatase. Pflugers Arch $\underline{411}$, 76-79

Fryer MW, Neering IR, Stephenson DG (1988 b): Effects of 2,3-butanedione monoxime on the contractile activation properties of fast- and slow-twitch rat muscle fibres. J Physiol 407 , $53-75$

Gomez AM, Valdivia HH, Cheng H, Lederer MR, Santana LF, Cannell MB, McCune SA, Altschuld RA, Lederer WJ (1997): Defective excitation-contraction coupling in experimental cardiac hypertrophy and heart failure. Sience $\underline{276}, 800-806$

Gomez AM, Guatimosim S, Dilly KW, Vassort G, Lederer WJ (2001): Heart failure after myocardial infarction: altered excitation-contraction coupling. Circulation 104, 688-693 
Goodison S, Kenna S, Ashcroft SJ (1992): Control of insulin gene expression by glucose. Biochem J 285, 563-8.

Gordon AM, Huxley AF, Julian FJ (1966 a): The variation in isometric tension with sarcomere length in vertebrate muscle fibres. J Physiol 184, 170-192

Gordon AM, Huxley AF, Julian FJ (1966 b): Tension development in highly stretched vertebrate muscle fibres. J Physiol 184, 143-169

Gupta MP, Lee SL, Dhalla NS (1989): Activation of heart sarcoplasmic reticulum Ca++stimulated adenosine triphosphatase by insulin. J Pharmacol Exp Ther 249, 623-630

Gwathmey JK, Hajjar RJ (1990): Relation between steady-state force and intracellular [Ca2+] in intact human myocardium. Index of myofibrillar responsiveness to $\mathrm{Ca} 2+$. Circulation $\underline{82}$, $1266-1278$

Gwathmey JK, Copelas L, MacKinnon R, Schoen FJ, Feldman MD, Grossman W, Morgan JP (1987): Abnormal intracellular calcium handling in myocardium from patients with end-stage heart failure. Circ Res $\underline{61}, 70-76$

Gwathmey JK, Hajjar RJ, Solaro RJ (1991): Contractile deactivation and uncoupling of crossbridges. Effects of 2,3-butanedione monoxime on mammalian myocardium. Circ Res $\underline{69}$, $1280-1292$

Hannon JD, Lee NK, Yandong C, Blinks JR (1992): Inositol trisphosphate (InsP3) causes contraction in skeletal muscle only under artificial conditions: evidence that $\mathrm{Ca} 2+$ release can result from depolarization of T-tubules. J Muscle Res Cell Motil 13, 447-456

Harding SE, Jones SM, O'Gara P, del Monte F, Vescovo G, Poole-Wilson PA (1992): Isolated ventricular myocytes from failing and non-failing human heart; the relation of age and clinical status of patients to isoproterenol response. J Mol Cell Cardiol 24, 549-564

Harrison SM, Bers DM (1989): Influence of temperature on the calcium sensitivity of the myofilaments of skinned ventricular muscle from the rabbit. J Gen Physiol $\underline{93}, 411-428$ 
Harrison SM, Frampton JE, McCall E, Boyett MR, Orchard CH (1992): Contraction and intracellular $\mathrm{Ca} 2+, \mathrm{Na}+$, and $\mathrm{H}+$ during acidosis in rat ventricular myocytes. Am $\mathrm{J}$ Physiol $\underline{262}, 348-357$

Hasenfuss G, Holubarsch C, Hermann HP, Astheimer K, Pieske B, Just H (1994 a): Influence of the force-frequency relationship on haemodynamics and left ventricular function in patients with non-failing hearts and in patients with dilated cardiomyopathy. Eur Heart J $\underline{15}, 164-170$

Hasenfuss G, Reinecke H, Studer R, Meyer M, Pieske B, Holtz J, Holubarsch C, Posival H, Just H, Drexler H (1994 b): Relation between myocardial function and expression of sarcoplasmic reticulum $\mathrm{Ca}(2+)$-ATPase in failing and nonfailing human myocardium. Circ Res $\underline{75}, 434-442$

Hasenfuss G, Maier LS, Hermann HP, Lüers C, Hünlich M, Zeitz O, Janssen PM, Pieske B (2002): Influence of pyruvate on contractile performance and $\mathrm{Ca}(2+)$ cycling in isolated failing human myocardium. Circulation $\underline{105}$, 194-199

Hastings JW, Mitchell G, Mattingly PH, Blinks JR, Van Leeuwen M (1969): Response of aequorin bioluminescence to rapid changes in calcium concentration. Nature $\underline{222}, 1047-1050$

Henderson IC, Frei E 3rd (1980): Adriamycin cardiotoxicity. Am Heart J 99, 671-674

Herland J, Julian FJ, Stephenson DG (1996): Rapid cooling contractures in rat skinned myocardium: effects of isoflurane and halothane. Am J Physiol 270, 1662-1671

Hermann HP, Pieske B, Schwarzmüller E, Keul J, Just H, Hasenfuss G (1999): Haemodynamic effects of intracoronary pyruvate in patients with congestive heart failure: an open study. Lancet $\underline{353}, 1321-1323$

Herrmann-Lingen C, Binder L, Klinge M, Sander J, Schenker W, Beyermann B, von Lewinski D, Pieske B (2003): High plasma levels of N-terminal pro-atrial natriuretic Peptide associated with low anxiety in severe heart failure. Psychosom Med $\underline{65}, 517-522$ 
Hieda HS, Gomez-Sanchez CE (1990): Hypoxia increases endothelin release in bovine endothelial cells in culture, but epinephrine, norepinephrine, serotonin, histamine and angiotensin II do not. Life Sci $\underline{47}, 247-251$

Hittinger L, Mirsky I, Shen YT, Patrick TA, Bishop SP, Vatner SF (1995): Hemodynamic mechanisms responsible for reduced subendocardial coronary reserve in dogs with severe left ventricular hypertrophy. Circulation 92, 978-986

Howell NJ, Ashrafian H, Drury NE, Ranasinghe AM, Contractor H, Isackson H, Calvert M, Williams LK, Freemantle N, Quinn DW et al. (2011): Glucose-insulin-potassium reduces the incidence of low cardiac output episodes after aortic valve replacement for aortic stenosis in patients with left ventricular hypertrophy: results from the Hypertrophy, Insulin, Glucose, and Electrolytes (HINGE) trial. Circulation $\underline{123}$, 170-177

Hsueh WA, Quiñones MJ (2003): Role of endothelial dysfunction in insulin resistance. Am J Cardiol. $\underline{92}, 10-17$

Hu J, Discher DJ, Bishopric NH, Webster KA (1998): Hypoxia regulates expression of the endothelin-1 gene through a proximal hypoxia-inducible factor-1 binding site on the antisense strand. Biochem Biophys Res Commun 245, 894-899

Hulsmann M, Stanek B, Frey B, Sturm B, Putz D, Kos T, Berger R, Woloszczuk W, Maurer G, Pacher R (1998): Value of cardiopulmonary exercise testing and big endothelin plasma levels to predict short-term prognosis of patients with chronic heart failure. J Am Coll Cardiol $\underline{32}, 1695-1700$

Huxley AF (1974): Muscular contraction. J Physiol 243, 1-43

Huxley H, Hanson J (1954): Changes in the cross-striations of muscle during contraction and stretch and their structural interpretation. Nature $\underline{173}, 973-976$

Hryshko LV, Stiffel V, Bers DM (1989): Rapid cooling contractures as an index of sarcoplasmic reticulum calcium content in rabbit ventricular myocytes. Am J Physiol 257, $1369-1377$ 
Ichiki T, Labosky PA, Shiota C, Okuyama S, Imagawa Y, Fogo A, Niimura F, Ichikawa I, Hogan BL, Inagami T (1995): Effects on blood pressure and exploratory behaviour of mice lacking angiotensin II type-2 receptor. Nature $\underline{377}, 748-750$

Ito H, Hirata Y, Hiroe M, Tsujino M, Adachi S, Takamoto T, Nitta M, Taniguchi K, Marumo F (1991): Endothelin-1 induces hypertrophy with enhanced expression of muscle-specific genes in cultured neonatal rat cardiomyocytes. Circ Res $\underline{69}, 209-215$

Jagasia D, Whiting JM, Concato J, Pfau S, McNulty PH (2001): Effect of non-insulindependent diabetes mellitus on myocardial insulin responsiveness in patients with ischemic heart disease. Circulation 103, 1734-1739

Jensen KT, Carstens J, Pedersen EB (1998): Effect of BNP on renal hemodynamics, tubular function and vasoactive hormones in humans. Am J Physiol 274, 63-72

Kanaide H, Ichiki T, Nishimura J, Hirano K (2003): Cellular mechanism of vasoconstriction induced by angiotensin II: it remains to be determined. Circ Res $\underline{93}$, 1015-1017

Kayki-Mutlu G, Arioglu-Inan E, Ozakca I, Ozcelikay AT, Altan VM (2014): ß3Adrenoceptor-mediated responses in diabetic rat heart. Gen Physiol Biophys $\underline{33}$, 99-109

Kentish JC, McCloskey DT, Layland J, Palmer S, Leiden JM, Martin AF, Solaro RJ (2001): Phosphorylation of troponin I by protein kinase A accelerates relaxation and crossbridge cycle kinetics in mouse ventricular muscle. Circ Res $\underline{88}$, 1059-1065

Kihara Y, Morgan JP (1989): A comparative study of three methods for intracellular loading of the calcium indicator aequorin in ferret papillary muscles. Biochem Biophys Res Commun $\underline{162}, 402-407$

Kirichok Y, Krapivinsky G, Clapham DE (2004): The mitochondrial calcium uniporter is a highly selective ion channel. Nature $\underline{427}, 360-364$

Knorr M, Münzel T, Wenzel P (2014): Interplay of NK cells and monocytes in vascular inflammation and myocardial infarction. Front Physiol 5, 295 
Koch-Weser J (1963): Effect of rate changes on strenght and time course of contraction of papillary muscle. Am J Physiol 204, 451-457

Kohomoto O, Levi AJ, Bridge JH (1994): Relation between reverse sodium-calcium exchange and sarcoplasmic reticulum calcium release in guinea pig ventricular cells. Circ Res $\underline{74}, 550-554$

Kolter T, Uphues I, Eckel J (1997): Molecular analysis of insulin resistance in isolated ventricular cardiomyocytes of obese Zucker rats. Am J Physiol 273, 59-67

Koranyi L, James DE, Kraegen EW, Permutt MA (1992): Feedback inhibition of insulin gene expression by insulin. J Clin Invest $\underline{89}, 432-436$

Krook A, Whitehead JP, Dobson SP, Griffiths MR, Ouwens M, Baker C, Hayward AC, Sen SK, Maassen JA, Siddle K et al. (1997): Two naturally occurring insulin receptor tyrosine kinase domain mutants provide evidence that phosphoinositide 3-kinase activation alone is not sufficient for the mediation of insulin's metabolic and mitogenic effects. J Biol Chem 272 , $30208-30214$

Kung G, Konstantinidis K, Kitsis RN (2011): Programmed necrosis, not apoptosis, in the heart. Circ Res $\underline{108}, 1017-1036$

Kurihara S, Sakai T (1985): Effects of rapid cooling on mechanical and electrical responses in ventricular muscle of guinea-pig. J Physiol $\underline{361}$, 361-378

Laughlin MR , Heineman FW (1994): The relationship between phosphorylation potential and redox state in the isolated working rabbit heart. J Mol Cell Cardiol 26, $1525-1536$

Lee KS (1987): Potentiation of the calcium-channel currents of internally perfused mammalian heart cells by repetitive depolarization. Proc Natl Acad Sci USA $\underline{84}$, 3941-3945

Lehnart SE, Wehrens XH, Reiken S, Warrier S, Belevych AE, Harvey RD, Richter W, Jin SL, Conti M, Marks AR (2005): Phosphodiesterase 4D deficiency in the ryanodine-receptor complex promotes heart failure and arrhythmias. Cell $\underline{123}, 25-35$ 
Levenbrown Y, Penfil S, Rodriguez E, Zhu Y, Hossain J, Bhat AM, Hesek A, O'Neil KB, Tobin K, Shaffer TH (2013): Use of insulin to decrease septic shock-induced myocardial depression in a porcine model. Inflammation $\underline{36}, 1494-1502$

Levy D, Garrison RJ, Savage DD, Kannel WB, Castelli WP (1990): Prognostic implications of echocardiographically determined left ventricular mass in the Framingham Heart Study. N Engl J Med 322, 1561-1566

Libby P (2002): Inflammation in atherosclerosis. Nature $\underline{420}$, 868-74

Limas CJ, Limas C, Kubo SH, Olivari MT (1990): Anti-beta-receptor antibodies in human dilated cardiomyopathy and correlation with HLA-DR antigens. Am J Cardiol $\underline{65}$, 483-487

Linck B, Boknik P, Eschenhagen T, Muller FU, Neumann J, Nose M, Jones LR, Schmitz W, Scholz H (1996): Messenger RNA expression and immunological quantification of phospholamban and SR-Ca(2+)-ATPase in failing and nonfailing human hearts. Cardiovasc $\operatorname{Res} \underline{31}, 625-632$

Lindner M, Erdmann E, Beuckelmann DJ (1998): Calcium content of the sarcoplasmic reticulum in isolated ventricular myocytes from patients with terminal heart failure. $\mathrm{J}$ Mol Cell Cardiol 30, 743-749

Lohse MJ, Engelhardt S, Eschenhagen T (2003): What is the role of beta-adrenergic signaling in heart failure? Circ Res $\underline{93}$, 896-906

Loschen G, Chance B (1971): Rapid kinetic studies of the light emitting protein aequorin. Nat New Biol 233, 273-274

Luef G, Abraham I, Hoppichler F, Trinka E, Unterberger I, Bauer G, Lechleitner M (2002): Increase in postprandial serum insulin levels in epileptic patients with valproic acid therapy. Metabolism 51, 1274-1278

Maier LS, Bers DM (2002): Calcium, calmodulin, and calcium-calmodulin kinase II: heartbeat to heartbeat and beyond. J Mol Cell Cardiol 34, 919-939 
Maier LS, Zhang T, Chen L, DeSantiago J, Brown JH, Bers DM (2003): Transgenic CaMKIIdeltaC overexpression uniquely alters cardiac myocyte $\mathrm{Ca} 2+$ handling: reduced $\mathrm{SR}$ Ca2+ load and activated SR Ca2+ release. Circ Res $\underline{92}$, 904-911

Mair J, Hammerer-Lercher A, Puschendorf B (2001): The impact of cardiac natriuretic peptide determination on the diagnosis and management of heart failure. Clin Chem Lab Med $\underline{39}, 571-588$

Maisch B, Deeg P, Liebau G, Kochsiek K (1983): Diagnostic relevance of humoral and cytotoxic immune reactions in primary and secondary dilated cardiomyopathy. Am J Cardiol $\underline{52}, 1072-1078$

Mallet RT (2000): Pyruvate: metabolic protector of cardiac performance. Proc Soc Exp Biol Med $\underline{223}, 136-148$

Mallet RT, Bünger R (1994): Energetic modulation of cardiac inotropism and sarcoplasmic reticular Ca2+ uptake. Biochim Biophys Acta 1224, 22-32

Mallet RT, Sun J (1999): Mitochondrial metabolism of pyruvate is required for its enhancement of cardiac function and energetics. Cardiovasc Res $\underline{42}, 149-161$

Mallet RT, Hartman DA, Bünger R (1990): Glucose requirement for postischemic recovery of perfused working heart. Eur J Biochem $\underline{188}$, 481-493

Mandel F, Kranias EG, Grassi de Gende A, Sumida M, Schwartz A (1982): The effect of pH on the transient-state kinetics of $\mathrm{Ca} 2+-\mathrm{Mg} 2+-\mathrm{ATPase}$ of cardiac sarcoplasmic reticulum. A comparison with skeletal sarcoplasmic reticulum. Circ Res $\underline{50}$, 310-317

Markovitz LJ, Hasin Y, Freund HR (1985): The effect of insulin and glucagon on systolic properties of the normal and septic isolated rat heart. Basic Res Cardiol 무, 377-383

Marrero MB, Paxton WG, Duff JL, Berk BC, Bernstein KE (1994): Angiotensin II stimulates tyrosine phosphorylation of phospholipase C-gamma 1 in vascular smooth muscle cells. J Biol Chem 269, 10935-10939 
Marx SO, Reiken S, Hisamatsu Y, Jayaraman T, Burkhoff D, Rosemblit N, Marks AR (2000): PKA phosphorylation dissociates FKBP12.6 from the calcium release channel (ryanodine receptor): defective regulation in failing hearts. Cell 101, 365-376

Marx SO, Gaburjakova J, Gaburjakova M, Henrikson C, Ondrias K, Marks AR (2001): Coupled gating between cardiac calcium release channels (ryanodine receptors). Circ Res $\underline{88}$, $1151-1158$

McMurray JJ, Ray SG, Abdullah I, Dargie HJ, Morton JJ (1992): Plasma endothelin in chronic heart failure. Circulation $\underline{85}$, 1374-1379

Mentzer RM Jr, Van Wylen DG, Sodhi J, Weiss RJ, Lasley RD, Willis J, Bünger R, Habil, Flint LM (1989): Effect of pyruvate on regional ventricular function in normal and stunned myocardium. Ann Surg 209, 629-633

Meyer M, Schillinger W, Pieske B, Holubarsch C, Heilmann C, Posival H, Kuwajima G, Mikoshiba K, Just H, Hasenfuss G (1995): Alterations of sarcoplasmic reticulum proteins in failing human dilated cardiomyopathy. Circulation $\underline{92}$, 778-784

Molkentin JD, Dorn GW (2001): Cytoplasmic signaling pathways that regulate cardiac hypertrophy. Annu Rev Physiol 63, 391-426

Molkentin JD, Lu JR, Antos CL, Markham B, Richardson J, Robbins J, Grant SR, Olson EN (1998): A calcineurin-dependent transcriptional pathway for cardiac hypertrophy. Cell $\underline{93}$, $215-228$

Morgan JP, Chesebro JH, Pluth JR, Puga FJ, Schaff HV (1984): Intracellular calcium transients in human working myocardium as detected with aequorin. J Am Coll Cardiol $\underline{3}$, $410-418$

Movsesian MA, Karimi M, Green K, Jones LR (1994): Ca(2+)-transporting ATPase, phospholamban, and calsequestrin levels in nonfailing and failing human myocardium. Circulation $\underline{90}, 653-657$ 
Mukoyama M, Nakajima M, Horiuchi M, Sasamura H, Pratt RE, Dzau VJ (1993): Expression cloning of type 2 angiotensin II receptor reveals a unique class of seven-transmembrane receptors. J Biol Chem $\underline{268}, 24539-24542$

Mulieri LA, Hasenfuss G, Ittleman F, Blanchard EM, Alpert NR (1989): Protection of human left ventricular myocardium from cutting injury with 2,3-butanedione monoxime. Circ Res $\underline{65}, 1441-1449$

Mulieri LA, Hasenfuss G, Leavitt B, Allen PD, Alpert NR (1992): Altered myocardial forcefrequency relation in human heart failure. Circulation $\underline{85}, 1743-1750$

Mullins LJ (1966): Ion and molecule fluxes in squid axons. Ann N Y Acad Sci 137, 830-836

Muniyappa R, Montagnani M, Koh KK, Quon MJ (2007): Cardiovascular actions of insulin. Endocr Rev 28, 463-491

Munziger W (1887): Tübinger Weinherz. Arch klin Med 19, 444-452

Murphy TJ, Alexander RW, Griendling KK, Runge MS, Bernstein KE (1991): Isolation of a cDNA encoding the vascular type-1 angiotensin II receptor. Nature $\underline{351}, 233-236$

Näbauer M, Callewaert G, Cleemann L, Morad M (1989): Regulation of calcium release is gated by calcium current, not gating charge, in cardiac myocytes. Science $\underline{244}, 800-803$

Nakae J, Kido Y, Accili D (2001): Distinct and overlapping functions of insulin and IGF-I receptors. Endocr Rev 22, 818-835

Nakagawa T, Shimizu S, Watanabe T, Yamaguchi O, Otsu K, Yamagata H, Inohara H, Kubo T, Tsujimoto Y (2005): Cyclophilin D-dependent mitochondrial permeability transition regulates some necrotic but not apoptotic cell death. Nature $\underline{434}, 652-658$

Nakipova OV, Chumaeva LA, Andreeva LA, Anufriev AI, Kukushkin NI (2012): Possible reasons for the variability of the inotropic insulin effect in papillary muscles of ground squirrel myocardium. Biofizika 57, 1020-1028 
Neering IR, Morgan KG (1980): Use of aequorin to study excitation-contraction coupling in mammalian smooth muscle. Nature $\underline{288}, 585-587$

Niggli E (1987): Mechanical parameters determined in dispersed ventricular heart cells. Experientia $\underline{43}, 1150-1153$

Niggli E, Lederer WJ (1990): Voltage-independent calcium release in heart muscle. Science $\underline{250}, 565-568$

Nilius B, Hess P, Lansman JB, Tsien RW (1985): A novel type of cardiac calcium channel in ventricular cells. Nature $\underline{316}, 443-446$

Noto H, Goto A, Tsujimoto T, Osame K, Noda M (2013): Latest insights into the risk of cancer in diabetes. J Diabetes Investig $\underline{4}, 225-232$

Ottensmeyer FP, Beniac DR, Luo RZ, Yip CC (2000): Mechanism of transmembrane signaling: insulin binding and the insulin receptor. Biochemistry $\underline{39}, 12103-12112$

Pandini G, Frasca F, Mineo R, Sciacca L, Vigneri R, Belfiore A (2002): Insulin/insulin-like growth factor I hybrid receptors have different biological characteristics depending on the insulin receptor isoform involved. J Biol Chem $\underline{277}$, 39684-39695

Paolisso G, De Riu S, Marrazzo G, Verza M, Varricchio M, D'Onofrio F (1991): Insulin resistance and hyperinsulinemia in patients with chronic congestive heart failure. Metabolism $\underline{40}, 972-977$

Paradise NF, Schmitter JL, Surmitis JM (1981): Criteria for adequate oxygenation of isometric kitten papillary muscle. Am J Physiol 241, 348-353

Patterson S, Starling EH (1914): On the mechanical factors which determine the output of the ventricels. J Physiol 4ㅇ, 357-379

Patti ME, Kahn CR (1998): The insulin receptor--a critical link in glucose homeostasis and insulin action. J Basic Clin Physiol Pharmacol 9, 89-109 
Peña JR, Wolska BM (2004): Troponin I phosphorylation plays an important role in the relaxant effect of beta-adrenergic stimulation in mouse hearts. Cardiovasc Res $\underline{61}, 756-763$

Perreault CL, Mulieri LA, Alpert NR, Ransil BJ, Allen PD, Morgan JP (1992): Cellular basis of negative inotropic effect of 2,3-butanedione monoxime in human myocardium. Am $\mathrm{J}$ Physiol 263, 503-510

Pessin JE, Saltiel AR (2000): Signaling pathways in insulin action: molecular targets of insulin resistance. J Clin Invest $\underline{106}, 165-169$

Philippe J (1991): Structure and pancreatic expression of the insulin and glucagon genes. Endocr Rev 12, 252-71.

Phillips RM, Altschuld RA (1996): 2,3-Butanedione 2-monoxime (BDM) induces calcium release from canine cardiac sarcoplasmic reticulum. Biochem Biophys Res Commun 229, $154-157$

Pieske B, Hasenfuss G, Holubarsch C, Schwinger R, Bohm M, Just H (1992): Alterations of the force-frequency relationship in the failing human heart depend on the underlying cardiac disease. Basic Res Cardiol 87, 213-221

Pieske B, Kretschmann B, Meyer M, Holubarsch C, Weirich J, Posival H, Minami K, Just H, Hasenfuss G (1995): Alterations in intracellular calcium handling associated with the inverse force-frequency relation in human dilated cardiomyopathy. Circulation $\underline{92}$, 1169-1178

Pieske B, Maier LS, Bers DM, Hasenfuss G (1999): Ca2+ handling and sarcoplasmic reticulum $\mathrm{Ca} 2+$ content in isolated failing and nonfailing human myocardium. Circ Res $\underline{85}$, $38-46$

Pieske B, Maier LS, Piacentino V 3rd, Weisser J, Hasenfuss G, Houser S (2002): Rate dependence of $[\mathrm{Na}+] \mathrm{i}$ and contractility in nonfailing and failing human myocardium. Circulation $\underline{106}, 447-453$ 
Piot C, Lemaire S, Albat B, Seguin J, Nargeot J, Richard S (1996): High frequency-induced upregulation of human cardiac calcium currents. Circulation $\underline{93}, 120-128$

Poole RC, Halestrap AP (1993): Transport of lactate and other monocarboxylates across mammalian plasma membranes. Am J Physiol 264, 761-782

Pousset F, Isnard R, Lechat P, Kalotka H, Carayon A, Maistre G, Escolano S, Thomas D, Komajda M (1997): Prognostic value of plasma endothelin-1 in patients with chronic heart failure. Eur Heart J $\underline{18}, 254-258$

Prestle J, Janssen PM, Janssen AP, Zeitz O, Lehnart SE, Bruce L, Smith GL, Hasenfuss G (2001): Overexpression of FK506-binding protein FKBP12.6 in cardiomyocytes reduces ryanodine receptor-mediated $\mathrm{Ca}(2+)$ leak from the sarcoplasmic reticulum and increases contractility. Circ Res $\underline{88}, 188-194$

Rabelink TJ, Kaasjager KA, Boer P, Stroes EG, Braam B, Koomans HA (1994): Effects of endothelin-1 on renal function in humans: implications for physiology and pathophysiology. Kidney Int $\underline{46}, 376-381$

Rayment I, Holden HM, Whittaker M, Yohn CB, Lorenz M, Holmes KC, Milligan RA (1993): Structure of the actin-myosin complex and its implications for muscle contraction. Science 261, 58-65

Regan TJ (1990): Alcohol and the cardiovascular system. Jama 264, 377-381

Reiken S, Gaburjakova M, Guatimosim S, Gomez AM, D'Armiento J, Burkhoff D, Wang J, Vassort G, Lederer WJ, Marks AR (2003): Protein kinase A phosphorylation of the cardiac calcium release channel (ryanodine receptor) in normal and failing hearts. Role of phosphatases and response to isoproterenol. J Biol Chem $\underline{278}$, 444-453

Ren J, Samson WK, Sowers JR (1999): Insulin-like growth factor I as a cardiac hormone: physiological and pathophysiological implications in heart disease. J Mol Cell Cardiol $\underline{31}$, 2049-2061 
Ren J, Sowers JR, Walsh MF, Brown RA (2000): Reduced contractile response to insulin and IGF-I in ventricular myocytes from genetically obese Zucker rats. Am J Physiol Heart Circ Physiol 279, 1708-1714

Rose CP, Burgess JH, Cousineau D (1985): Tracer norepinephrine kinetics in coronary circulation of patients with heart failure secondary to chronic pressure and volume overload. $\mathrm{J}$ Clin Invest $\underline{76}$, 1740-1747

Russell-Jones DL, Umpleby AM, Shojaee-Moradie F, Boroujerdi MA, Jones RH, Baxter RC, Sönksen PH (1997): The effect of an intravenous infusion of IGF-I and insulin on IGFBP-1, IGFBP-3, acid labile subunit, free and bound IGF-I, catecholamines and potassium in normal volunteers during an amino acid and glucose clamp. Clin Endocrinol (Oxf) $\underline{47}, 685-691$

Sadoshima J, Izumo S (1993): Molecular characterization of angiotensin II-induced hypertrophy of cardiac myocytes and hyperplasia of cardiac fibroblasts. Critical role of the AT1 receptor subtype. Circ Res $\underline{73}, 413-423$

Sakai, T (1965): The effects of temperature and caffeine on activation of the contractile mechanism in the striated muscle fibres. Jikeikai Med J $\underline{12}, 88$

Saltiel AR, Kahn CR (2001): Insulin signalling and the regulation of glucose and lipid metabolism. Nature $\underline{414}, 799-806$

Sasso FC, Carbonara O, Cozzolino D, Rambaldi P, Mansi L, Torella D, Gentile S, Turco S, Torella R, Salvatore T (2000): Effects of insulin-glucose infusion on left ventricular function at rest and during dynamic exercise in healthy subjects and noninsulin dependent diabetic patients: a radionuclide ventriculographic study. J Am Coll Cardiol 36, 219-226

Schmidt HD, Koch M (2002): Influence of perfusate calcium concentration on the inotropic insulin effect in isolated guinea pig and rat hearts. Basic Res Cardiol 97, 305-311

Schmidt U, Hajjar RJ, Helm PA, Kim CS, Doye AA, Gwathmey JK (1998): Contribution of abnormal sarcoplasmic reticulum ATPase activity to systolic and diastolic dysfunction in human heart failure. J Mol Cell Cardiol 30, 1929-1937 
Scholz TD, Laughlin MR, Balaban RS, Kupriyanov VV, Heineman FW (1995): Effect of substrate on mitochondrial NADH, cytosolic redox state, and phosphorylated compounds in isolated hearts. Am J Physiol 268, 82-91

Schulze K, Becker BF, Schultheiss HP (1989): Antibodies to the ADP/ATP carrier, an autoantigen in myocarditis and dilated cardiomyopathy, penetrate into myocardial cells and disturb energy metabolism in vivo. Circ Res $\underline{64}, 179-192$

Schwinger RH, Bohm M, Koch A, Uhlmann R, Uberfuhr P, Kreuzer E, Reichart B, Erdmann E (1993): Force-frequency-relation in human atrial and ventricular myocardium. Mol Cell Biochem 119, 73-78

Sebastião I, Candeias E, Santos MS, de Oliveira CR, Moreira PI, Duarte AI (2014): Insulin as a bridge between Type 2 Diabetes and Alzheimer Disease - How anti-diabetics could be a solution for dementia. Front Endocrinol 5, 110

Seidler T, Miller SL, Loughrey CM, Kania A, Burow A, Kettlewell S, Teucher N, Wagner S, Kögler H, Meyers MB, Hasenfuss G, Smith GL (2003): Effects of adenovirus-mediated sorcin overexpression on excitation-contraction coupling in isolated rabbit cardiomyocytes. Circ Res 93, 132-139

Sethi R, Rupp H, Naimark BJ, Barwinsky J, Beamish RE, Dhalla NS (1993): Characteristics and mechanisms of tachyphylaxis of cardiac contractile response to insulin. Int J Cardiol $\underline{38}$, $119-130$

Shigekawa M, Iwamoto $\mathrm{T}$ (2001): Cardiac $\mathrm{Na}^{+}-\mathrm{Ca}^{2+}$ exchange: molecular and pharmacological aspects. Circ Res $\underline{88}, 864-876$

Shimomura O, Johnson FH (1970): Calcium binding, quantum yield, and emitting molecule in aequorin bioluminescence. Nature $\underline{227}, 1356-1357$

Shimomura O, Johnson FH, Morise H (1974): Mechanism of the luminescent intramolecular reaction of aequorin. Biochemistry $\underline{13}, 3278-3286$ 
Siddle K, Ursø B, Niesler CA, Cope DL, Molina L, Surinya KH, Soos MA (2001): Specificity in ligand binding and intracellular signalling by insulin and insulin-like growth factor receptors. Biochem Soc Trans 29, 513-525

Simpson P (1983): Norepinephrine-stimulated hypertrophy of cultured rat myocardial cells is an alpha 1 adrenergic response. J Clin Invest $\underline{72}, 732-738$

Sitsapesan R, Montgomery RA, MacLeod KT, Williams AJ (1991): Sheep cardiac sarcoplasmic reticulum calcium-release channels: modification of conductance and gating by temperature. J Physiol $\underline{434}, 469-488$

Sodi-Pallares D, Testelli M, Fishleder F (1962): Effects of an intravenous infusion of a potassium-insulin-glucose solution on the electrocardiographic signs of myocardial infarction. Am J Cardiol 9, 166-181

Studer R, Reinecke H, Bilger J, Eschenhagen T, Bohm M, Hasenfuss G, Just H, Holtz J, Drexler H (1994): Gene expression of the cardiac $\mathrm{Na}(+)-\mathrm{Ca} 2+$ exchanger in end-stage human heart failure. Circ Res $\underline{75}$, 443-453

Swan JW, Anker SD, Walton C, Godsland IF, Clark AL, Leyva F, Stevenson JC, Coats AJ (1997): Insulin resistance in chronic heart failure: relation to severity and etiology of heart failure. J Am Coll Cardiol 30, 527-532

Tejero-Taldo MI, Caffrey JL, Sun J, Mallet RT (1999): Antioxidant properties of pyruvate mediate its potentiation of beta-adrenergic inotropism in stunned myocardium. J Mol Cell Cardiol 31, 1863-1872

Thirone AC, Huang C, Klip A (2006): Tissue-specific roles of IRS proteins in insulin signaling and glucose transport. Trends Endocrinol Metab 17, 72-78

Thomas JA, Marks BH (1978): Plasma norepinephrine in congestive heart failure. Am J Cardiol $\underline{41}, 233-243$ 
Tonnessen T, Naess PA, Kirkeboen KA, Ilebekk A, Christensen G (1993): Alterations in plasma endothelin during passage through the left heart chambers before and after brief myocardial ischaemia. Cardiovasc Res 27, 2160-2163

Tsutamoto T, Wada A, Maeda K, Hisanaga T, Maeda Y, Fukai D, Ohnishi M, Sugimoto Y, Kinoshita M (1997): Attenuation of compensation of endogenous cardiac natriuretic peptide system in chronic heart failure: prognostic role of plasma brain natriuretic peptide concentration in patients with chronic symptomatic left ventricular dysfunction. Circulation $\underline{96}, 509-516$

Urbano-Marquez A, Estruch R, Navarro-Lopez F, Grau JM, Mont L, Rubin E (1989): The effects of alcoholism on skeletal and cardiac muscle. N Engl J Med $\underline{320}, 409-415$

Urthaler F, Walker AA, Reeves RC, Hefner LL (1993): Beat-to-beat measurements of [Ca2+]i and force in ferret cardiac muscle after chemical loading of aequorin. Am J Physiol $\underline{265}, 1703-1710$

Valdivia CR, Chu WW, Pu J, Foell JD, Haworth RA, Wolff MR, Kamp TJ, Makielski JC (2005): Increased late sodium current in myocytes from a canine heart failure model and from failing human heart. J Mol Cell Cardiol $\underline{38}$, 475-483

Vetter U, Kupferschmid C, Lang D, Pentz S (1988): Insulin-like growth factors and insulin increase the contractility of neonatal rat cardiocytes in vitro. Basic Res Cardiol $\underline{83}, 647-654$

von Lewinski D, Voss K, Hulsmann S, Kogler H, Pieske B (2003): Insulin-like growth factor1 exerts $\mathrm{Ca} 2+-$ dependent positive inotropic effects in failing human myocardium. Circ Res $\underline{92}, 169-176$

Weber CR, Piacentino V 3rd, Houser SR, Bers DM (2003): Dynamic regulation of Sodium/Calcium exchange function in human heart failure. Circulation 108, 2224-2229 
Wehrens XH, Lehnart SE, Huang F, Vest JA, Reiken SR, Mohler PJ, Sun J, Guatimosim S, Song LS, Rosemblit N et al. (2003): FKBP12.6 deficiency and defective calcium release channel (ryanodine receptor) function linked to exercise-induced sudden cardiac death. Cell $\underline{113}, 829-840$

Wehrens XH, Lehnart SE, Reiken SR, Marks AR (2004): Ca2+/calmodulin-dependent protein kinase II phosphorylation regulates the cardiac ryanodine receptor. Circ Res 94, 61-70

Wessells RJ, Fitzgerald E, Cypser JR, Tatar M, Bodmer R (2004): Insulin regulation of heart function in aging fruit flies. Nat Genet $\underline{36}, 1275-81$

White MF (1998): The insulin and cytokine action. The IRS-signaling system: a network of docking proteins that mediate. Recent Prog Horm Res $\underline{53}$, 119-38.

Wibo M, Godfraind T (1991): Stoichiometrc ratio of calcium entry to calcium release channels in rat ventricel in relation to the mechanism of sarcoplasmic reticulum calcium release in cardiac tissue. Pflügers Archiv $\underline{419}$, R13

Wilkins MR, Redondo J, Brown LA (1997): The natriuretic-peptide family. Lancet $\underline{349}$, $1307-1310$

Winegrad S (1984): Regulation of cardiac contractile proteins. Correlations between physiology and biochemistry. Circ Res $\underline{55}, 565-574$

Yamazaki T, Komuro I, Kudoh S, Zou Y, Shiojima I, Mizuno T, Takano H, Hiroi Y, Ueki K, Tobe K ett al. (1995): Angiotensin II partly mediates mechanical stress-induced cardiac hypertrophy. Circ Res $\underline{77}, 258-265$

Yang Y, Yee D (2012): Targeting insulin and insulin-like growth factor signaling in breast cancer. J Mammary Gland Biol Neoplasia 17, 252-261 
Yano M, Ono K, Ohkusa T, Suetsugu M, Kohno M, Hisaoka T, Kobayashi S, Hisamatsu Y, Yamamoto T, Kohno M et al. (2000): Altered stoichiometry of FKBP12.6 versus ryanodine receptor as a cause of abnormal $\mathrm{Ca}(2+)$ leak through ryanodine receptor in heart failure. Circulation 102, 2131-2136

Yanos J, Patti MJ, Stanko RT (1994): Hemodynamic effects of intravenous pyruvate in the intact, anesthetized dog. Crit Care Med 22, 844-850

Zaha V, Francischetti I, Doenst T (2003): Insulin improves postischemic recovery of function through PI3K in isolated working rat heart. Mol Cell Biochem 247, 229 -232

Zhang CL, McKinsey TA, Chang S, Antos CL, Hill JA, Olson EN (2002): Class II histone deacetylases act as signal-responsive repressors of cardiac hypertrophy. Cell $\underline{110}, 479-488$

Zhang T, Maier LS, Dalton ND, Miyamoto S, Ross J Jr, Bers DM, Brown JH (2003): The deltaC isoform of CaMKII is activated in cardiac hypertrophy and induces dilated cardiomyopathy and heart failure. Circ Res $\underline{92}$, 912-919

Zhou Z, Lasley RD, Hegge JO, Bünger R, Mentzer RM Jr (1995): Myocardial stunning: a therapeutic conundrum. J Thorac Cardiovasc Surg $\underline{110}$, 1391-1400

Zima AV, Kockskämper J, Mejia-Alvarez R, Blatter LA (2003): Pyruvate modulates cardiac sarcoplasmic reticulum $\mathrm{Ca} 2+$ release in rats via mitochondria-dependent and -independent mechanisms. J Physiol 550, 765-783

Zweier JL, Jacobus WE (1987): Substrate-induced alterations of high energy phosphate metabolism and contractile function in the perfused heart. J Biol Chem $\underline{262}, 8015-8021$ 


\section{Danksagung}

Mein Dank gilt an erster Stelle Prof. Dr. med. Burkert Pieske für die Überlassung des Dissertationsthemas und die ständige Unterstützung, die zur Entstehung dieser Arbeit in erheblichem Maße beigetragen haben. Die Begeisterung für seinen Beruf, die Medizin, die Forschung und die medizinsiche Lehre hat mich sehr geprägt und beeindruckt. Durch seine Persönlichkeit hat er ein angenehmes und ideenreiches Arebitsumfeld geschaffen, in dem ich mich sehr wohlgefühlt habe.

Auch wenn ich in meiner weiteren medizinischen Laufbahn keinen direkten Kontakt zu ihm haben werde, wird mir sein Beispiel immer als Leitbild dienen.

Weiterer Dank gilt Prof. Dr. med. Dirk von Lewinski, der mich ständig motiviert und angeleitet hat. Besonders in schwierigen Zeiten hat er es geschafft, mich zu motivieren und hat mir geholfen, mit Rückschlägen umzugehen und neue Wege zu finden. Seine Ausdauer und die ständige Untertützung waren maßgeblich daran beteiligt, dass ich diese Arbeit fertig stellen konnte. Sein analytisches Denken und die Fähigkeit, nach der Lösung eines Problems sofort den nächsten Schritt zu erkennen und umzusetzen, haben mich sehr beeindruckt.

Auch sein Bild eines Mediziners, der seinen Beruf als Berufung sieht, wird mich in meinem weiteren Leben als Vorbild begleiten.

Ein besonderer Dank auch an Prof Dr. med. Rolf Wachter für die Übernahme der Doktorarbeit. Auch wenn ich nur kurz unter seiner Leitung gearbeitet habe, so bleibt er mir als hervorragender und gleichzeitig sehr besonnener Wissenschaftler in Erinnerung.

Auch wenn ich in meiner weiteren medizinischen Laufbahn keinen direkten Kontakt zur Forschung haben werde, so schöpfe ich doch weiter aus den vielen Fähigkeiten und Erkenntnissen, die mir die wissenschaftliche Arbeit im Labor vermittelt hat.

Deshalb möchte ich nochmals allen, Genannten und Ungenannten, für ihr Mitwirken am Gelingen dieses Projektes danken. 